CrossMark <click for updates

Cite this: Phys. Chem. Chem. Phys., 2015, 17, 2960

Received 22nd September 2014, Accepted 28th November 2014

DOI: $10.1039 / c 4 c p 04245 j$

www.rsc.org/pccp

\section{Review of one-dimensional and two-dimensional nanostructured materials for hydrogen generation}

\author{
Veluru Jagadeesh Babu, $\dagger^{\star^{a}}$ Sesha Vempati, $\dagger^{\star^{a}}$ Tamer Uyar*ab and \\ Seeram Ramakrishna*c
}

\begin{abstract}
Hydrogen is an attractive alternative to fossil fuels in terms of environmental and other advantages. Of the various production methods for $\mathrm{H}_{2}$, photocatalysis requires further development so that it can be applied economically on an industrial scale. One- and two-dimensional nanostructures in both pristine and modified forms have shown great potential as catalysts in the generation of $\mathrm{H}_{2}$. We review here recent developments in these nanostructure catalysts and their efficiency in the generation of $\mathrm{H}_{2}$ under UV/visible/simulated solar light. Despite much research effort, many photocatalysts do not yet meet the practical requirements for the generation of $\mathrm{H}_{2}$, such as visible light activity. $\mathrm{H}_{2}$ production is dependent on a variety of parameters and factors. To meet future energy demands, several challenges in $\mathrm{H}_{2}$ production still need to be solved. We address here the factors that influence the efficiency of $\mathrm{H}_{2}$ production and suggest alternatives. The nanostructures are classified based on their morphology and their efficiency is considered with respect to the influencing parameters. We suggest effective ways of engineering catalyst combinations to overcome the current performance barriers.
\end{abstract}

\section{Introduction}

Hydrogen $\left(\mathrm{H}_{2}\right)$ is considered to be an ideal fuel for future energy demands when it is sourced from clean and renewable energy resources. ${ }^{1} \mathrm{H}_{2}$ has attracted much interest as a result of its potentially unlimited generation from the Earth's abundant water resources. On combustion, $\mathrm{H}_{2}$ generates water rather than $\mathrm{CO}_{2}$, in contrast to conventional fossil fuels. Its gravimetric energy content (heat of combustion) is about five times higher than that of methanol and ethanol and about 2.5 times that of hydrocarbons. ${ }^{2}$ The greatest disadvantage of this fuel is its lack of natural availability. However, $\mathrm{H}_{2}$ can be produced from both renewable and conventional energy sources (solar, wind, hydro and geothermal power, fossil fuels, nuclear energy and biomass sources ${ }^{3}$ ) (Fig. 1). Renewable energy currently contributes almost $5 \%$ of the overall hydrogen production through the electrolysis of water, whereas the rest is mainly derived from fossil fuels. ${ }^{4}$ Producing $\mathrm{H}_{2}$ from fossil fuels is not economically feasible because it requires a high temperature

\footnotetext{
${ }^{a}$ UNAM-National Nanotechnology Research Center, Bilkent University, Ankara-06800,Turkey.E-mail: vjbabu2002@gmail.com,svempatio1@qub.ac.uk

${ }^{b}$ Institute of Materials Science \& Nanotechnology, Bilkent University, Ankara, 06800, Turkey.E-mail: uyar@unam.bilkent.edu.tr; Fax: +90 (312) 290 4365; Tel: +90 (312) 2903571

${ }^{c}$ NUS Center for Nanofibers and Nanotechnology (NUSCNN), NUS Nanoscience and Nanotechnology Initiative (NUSNNI), National University of Singapore,

Singapore-117576. E-mail: seeram@nus.edu.sg

$\dagger$ Authors contributed equally.
}

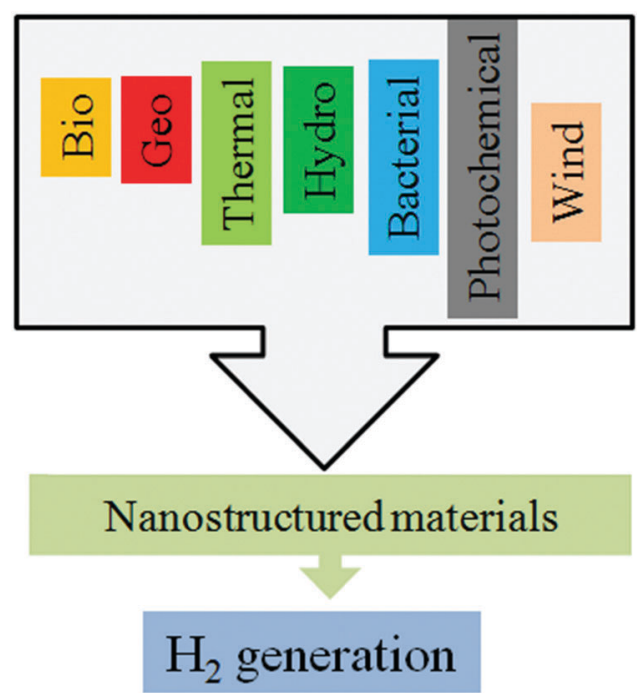

Fig. 1 Schematic diagram showing the various resources available for the production of $\mathrm{H}_{2}$.

input for synthesis and emits $\mathrm{CO}_{2}$; in addition, fossil fuels are non-renewable. ${ }^{3}$ Thus the generation of $\mathrm{H}_{2}$ from fossil fuels is not an environmentally friendly option. ${ }^{5}$

Among the renewable power sources, the photocatalytic splitting of water offers a promising method for the clean, low cost and environmentally friendly production of $\mathrm{H}_{2}$ by solar energy. Nanostructured catalysts have additional advantages in 
photocatalysis $^{6-11}$ and the photocatalytic production of $\mathrm{H}_{2}$ from water via solar energy is currently the best available method and is an attractive and competitive technology. As technology advances, the implementation and associated costs of this technique will be significantly reduced. In 1972, Fujishima and Honda $^{12}$ demonstrated a photoelectrochemical (PEC) method to split water into $\mathrm{H}_{2}$ and $\mathrm{O}_{2}$ in which a bias was applied across a $\mathrm{TiO}_{2}$ thin film and a Pt counter electrode. In 1979, Bard ${ }^{13-15}$ showed that water can be split into $\mathrm{H}_{2}$ and $\mathrm{O}_{2}$ by simply using a powdered $\mathrm{TiO}_{2}$ catalyst and exposing it to sunlight in the presence of a sacrificial reagent (SR) without applying any bias.

It is now understood that catalysis takes place on the surface of a semiconductor. When a photon of energy matches or exceeds the band gap energy $\left(E_{\mathrm{g}}\right)$ of a semiconductor, an electron is promoted to the conduction band (CB), leaving a hole in the valence band (VB). Essentially, the excited state $\mathrm{CB}$ electron and the VB hole can recombine or become trapped in a metastable surface state. They can also participate in reactions with electron donors and acceptors adsorbed on the surface of the semiconductor. Under suitable conditions, the $\mathrm{CB}$ electron can reduce $\mathrm{H}^{+}$ions to yield $\mathrm{H}_{2}$ gas and the VB hole can generate $\mathrm{O}_{2}$. Backreactions to form $\mathrm{H}_{2} \mathrm{O}$ instead of $\mathrm{H}_{2}$ gas are possible.

Efficient $\mathrm{e}-\mathrm{h}$ pair separation is crucial in catalysis. Selecting a semiconductor requires prior knowledge about the $\mathrm{CB}$ and $\mathrm{VB}$ levels with respect to the redox potential of $\mathrm{H}_{2} \mathrm{O}$, i.e. the $\mathrm{CB}$ should be lower than the $\mathrm{H}^{+} / \mathrm{H}_{2}$ potential and the VB should be higher than the $\mathrm{OH}^{-} / \mathrm{O}_{2}$ potential. The next immediate consideration is the $E_{\mathrm{g}}$ of the semiconductor, which determines the range of wavelengths for which it can absorb energy to create e-h pairs. Low $E_{\mathrm{g}}$ materials such as ferrous oxide $(1.9-2.1 \mathrm{eV}),{ }^{19}$ tungsten nitride $(2.2 \mathrm{eV})^{20}$ and other III-V and II-VI compound semiconductors ${ }^{21-23}$ may be active materials within the limits of the energetic locations of the $\mathrm{CB}$ and $\mathrm{VB}$ with respect to the $\mathrm{H}_{2} \mathrm{O}$ redox potential. For some semiconductors, although their $E_{\mathrm{g}}$ values cover the visible part of the solar spectrum, their CB and/or VB levels are not compatible with respect to the redox potential of $\mathrm{H}_{2} \mathrm{O}$. These materials, e.g. $\mathrm{MoS}_{2}, \mathrm{Fe}_{2} \mathrm{O}_{3}$ and $\mathrm{WO}_{3}$, may be photocorrosive if their $\mathrm{CB}$ minimum is lower than the thermodynamic requirement. ${ }^{24}$ Such photocorrosive catalysts have been explored after certain modifications, such as the incorporation of co-catalysts $\left(\mathrm{NiO}_{x}, \mathrm{RuO}_{2}{ }^{25,26}\right.$ or Rh-Cr), doping with metal ions or combination with other semiconductors. ${ }^{5,27-29}$ The same principle of thermodynamic requirement applies to the PEC method. ${ }^{29,30}$

Considerable use of small $E_{\mathrm{g}}$ semiconducting materials may cause serious environmental impacts as a result of their instability; wide $E_{\mathrm{g}}$ materials are preferable in $\mathrm{H}_{2}$ production. However, although suitable band positions and stability in the electrolyte favour large $E_{\mathrm{g}}$ materials $\left(\right.$ e.g. $\mathrm{TiO}_{2}$ or $\left.\mathrm{ZnO}\right),{ }^{30-32}$ their absorbance is limited to the UV region of the solar spectrum. A significant solar-to-hydrogen conversion efficiency $(\eta)$ of $16.25 \%$ has been obtained from $\mathrm{TiO}_{2}$ nanotubes (NTs) $(45 \mu \mathrm{m})$ under $100 \mathrm{~mW} \mathrm{~cm}{ }^{-2}$ irradiation with UV light $(320-400 \mathrm{~nm}) .{ }^{33}$ Only a small fraction (about 5\%) of the available energy in the solar spectrum is used in this example. Wide $E_{\mathrm{g}}$ materials can be subjected to modifications, such as doping ${ }^{34}$ and interfacing with other materials ${ }^{35,36}$ in the form of heterojunctions, to enable absorption in the visible region or to efficiently isolate the e-h pairs. This offers a clean, cost-effective and environmentally benign production method for $\mathrm{H}_{2}$. Izumi et al. ${ }^{34}$ studied the visible light response over $\mathrm{TiO}_{2} \mathrm{NTs}$ by anionic $(\mathrm{S}, \mathrm{N})$ doping. Zhan et al. $^{35}$ demonstrated that this heterostructure can cover about $22 \%$ of the entire solar spectrum. Sathre $e t ~ a l .{ }^{37}$ analysed the PEC method of hydrogen production based on fundamental principles. Hisatomi et al. ${ }^{38}$ addressed the fundamental aspects of the PEC method of water splitting. The Z-scheme and tandem systems based on multi-step photoexcitation liberate semiconducting materials from thermodynamic limitations and enable the application of a variety of materials to unassisted water splitting. ${ }^{38}$

Semiconducting nanostructures, especially one-dimensional (1D) and two-dimensional (2D) structures have superior photocatalytic activity as a result of improved e-h separation and a low recombination rate. Ford et al. ${ }^{16}$ reported that, by decreasing the diameters of InAs nanowires (NWs), the mobility of the electrons could be controlled. Martinson et al. ${ }^{17}$ compared the transport and recombination dynamics of sintered nanocrystalline particles versus nanorod (NR) arrays. Core-shell type nanostructures ${ }^{18}$ have been demonstrated to have enhanced PEC water splitting properties under solar light. Various architectures of 2D nanosheets (NSs) with thicknesses $<100 \mathrm{~nm}$ hold great promise for the efficient PEC splitting of water. 2D NSs also offer optimized charge migration, surface modification and light absorption. Zhou et al. ${ }^{39}$ addressed the performance of advanced PEC devices using 2D NSs as photoelectrodes. Chemically modified nanostructures offer a green and low cost method of generating $\mathrm{H}_{2}$ fuel via PEC water splitting. ${ }^{40}$ Liu et al. ${ }^{41}$ demonstrated that Pt-loaded titania hierarchical photonic crystals could double the evolution of $\mathrm{H}_{2}$ in photocatalytic water splitting. The enhancement in $\mathrm{H}_{2}$ evolution was a result of the hierarchical structure, which can cause multiple scattering among the photonic crystals and improve the absorbance of light. This provides a strong light-harvesting method.

The focus of research has recently intensified towards nanostructures and their potential applications. The high specific surface area (SA) of nanostructures provides a high density of active sites compared with their bulk counterparts. ${ }^{42,43}$ The effect of quantum confinement results in important optical and electronic properties. The properties of various types of $1 \mathrm{D}$ and 2D semiconducting nanostructures, such as NRs, NWs, NTs and nanofibres $(\mathrm{NFs})^{44,45}$ are considered in the next section, against the background of $\mathrm{H}_{2}$ generation.

\subsection{Why nanostructures for $\mathbf{H}_{2}$ generation?}

The growing interest in nanostructured metal oxides ${ }^{46-55}$ is due to their large SA, short lateral diffusion length and low reflectivity. However, most metal oxides have large band gap energies, leading to limited light absorption in the visible region. This imposes a fundamental limitation on the overall conversion efficiency of solar energy to hydrogen. Delaying the recombination of photogenerated e-h pairs creates the environment required for the exciton pair to diffuse to the surface and participate in catalysis. 1D nanostructures can trap photons more effectively 
under appropriate geometric configurations where the carrier diffusion lengths are comparable with their physical dimensions. ${ }^{46}$ As a result, the photocatalytic performance significantly increases $^{47-55}$ at smaller dimensions. The preparation of nanostructured photocatalysts is therefore indispensable in meeting future energy demands. The nano-dimensions facilitate the efficient collection of free carriers and increase $\eta \cdot{ }^{56-58}$

This concept of charge carrier generation and subsequent migration is similar to that in solar cells, where the intrinsic electrical field assists the separation. This concept of using an intrinsic electrical field is applied in $\mathrm{H}_{2}$ generation. ${ }^{59} \mathrm{n}-\mathrm{n}$ type heterojunctions yield similar results. ${ }^{35}$ In the case of photocatalytic $\mathrm{H}_{2}$ generation, the migration should take place by itself, although some assistance may be obtained from the depletion layer (if it exists) on the surface. Arrays of NRs have attracted considerable interest as a result of their enhanced absorption of incident light and their crystallinity. For example, ZnO NR arrays, ${ }^{60}$ single crystalline GaN NRs ${ }^{61}$ and GaP NRs ${ }^{62}$ can be used as effective anti-reflection coatings as a result of their regular textures and morphology. Strontium metaniobate $\left(\mathrm{SrNb}_{2} \mathrm{O}_{6}\right)$ NT morphologies are effective photocatalysts compared with their micron-sized powders. However, single crystalline $\mathrm{ZnO}$ shows enhanced electron collection efficiency compared with polycrystalline $\mathrm{ZnO}$ nanostructures, ${ }^{17}$ due to shorter collection times. Light reflection increases the ratio of non-diffusive absorption and diffusive scattering, which results in a reduction in photon harvesting. ${ }^{63}$ The periodic nature of nanostructures and their intrinsic property of low reflectivity can also be seen with NWs. NW arrays have a higher theoretical absorbance at lower wavelength regions than their thin-film counterparts. ${ }^{64}$ Single-crystal Si NWs have delayed recombination and high optical absorption. ${ }^{43,65,66}$

NW structures can absorb incident photons while the lowenergy photons are scattered inside the structure. Further increase in absorbance can be obtained by tailoring the fill factor of NWs. ${ }^{64}$ This phenomena of multiple reflections inside the nanostructure is similar to that seen in NT. ${ }^{67}$ These 1D structures (NWs and NTs) act as electron pathways in the axial directions. However, the scattered or transmitted light has a higher wavelength, which requires the use of sensitizers such as dyes (e.g. Eosin $\mathrm{Y}^{68}$ in combination with carbon NTs) to increase $\eta$. Arrays of $\mathrm{NWs}^{69}$ and dual-diameter germanium nanopillars ${ }^{70}$ have effective photon absorption at low (300-600 nm) and high (600-900 nm) wavelengths, respectively. Single crystalline $\mathrm{TiO}_{2}$ NWs showed faster electron mobility (about $1 \mathrm{~cm}^{2} \mathrm{~V}^{-1} \mathrm{~s}^{-1}$ ) than polycrystalline $\mathrm{NWs}^{71}$ likewise single crystalline ZnO NWs (1-5 $\left.\mathrm{cm}^{2} \mathrm{~V}^{-1} \mathrm{~s}^{-1}\right){ }^{72}$ Although the mobility of the charge carriers in $1 \mathrm{D}$ polycrystalline $\mathrm{TiO}_{2}$ is comparable with that of zero-dimensional (0D) $\mathrm{TiO}_{2},{ }^{67,73}$ the recombination time of $1 \mathrm{D}$ polycrystalline $\mathrm{TiO}_{2}$ is much longer than that of $0 \mathrm{D} \mathrm{TiO} 2$. This may be a result of the unevenly distributed recombination centres on the surface. Furthermore, the radial electrical field that may be present in 1D NWs delays the recombination process, which accounts for the enhanced electron collection efficiency in $1 \mathrm{D} \mathrm{TiO}_{2}{ }^{73-75} 1 \mathrm{D}$ materials with relatively small $E_{\mathrm{g}}$ values have been reported to have $\eta=0.6 \%$ (branched $\mathrm{CuO}$ NWs) and $\eta=0.71 \%$ (CuO-ZnO core-shell NR arrays). ${ }^{27}$ Hexagonal $\mathrm{Zn}_{2} \mathrm{GeO}_{4}$ NRs show the highest rate of $\mathrm{H}_{2}$ evolution of $0.6 \mathrm{mmol} \mathrm{h}^{-1} \cdot{ }^{76}$ A comparative study showed that $\mathrm{Zn}_{2} \mathrm{GeO}_{4} \mathrm{NRs}$ could produce a stable rate of $\mathrm{H}_{2}$ evolution of $6.24 \mathrm{mmol} \mathrm{g}^{-1} \mathrm{~h}^{-1}$ under irradiation with UV light. ${ }^{77}$

Haematite $\left(\alpha-\mathrm{Fe}_{2} \mathrm{O}_{3}\right)$ was considered for PEC solar water splitting ${ }^{78}$ with $3 \mathrm{D}$ nanophotonic structures, which resulted in a current density as high as $3.05 \mathrm{~mA} \mathrm{~cm} \mathrm{~cm}^{-2}$ at $1.23 \mathrm{~V}$ with respect to the reversible hydrogen electrode (RHE). Hwang et al. ${ }^{79}$ reported that layered perovskites loaded with $\mathrm{Ni}$ are important photocatalysts for water splitting, with a photon yield of $23 \%$. A quantum yield as high as $30 \%$ was obtained when $\mathrm{K}_{2} \mathrm{La}_{2} \mathrm{Ti}_{3} \mathrm{O}_{10}$ was prepared by a polymerized complex method. ${ }^{80}$ Zhang et al. ${ }^{81}$ reported an improved photochemical evolution of $\mathrm{H}_{2}$ from a $\mathrm{TiO}_{2}$ leaf structure. Nanostructures are therefore potential recyclable candidates for water splitting. ${ }^{82}$ Analysis from the ISI Web of Science has shown extensive growth in research on $\mathrm{H}_{2}$ production (Fig. 2). It is clear from Fig. 2 and 3 that PEC water splitting is a potentially important method of producing $\mathrm{H}_{2}$ with environmentally friendly features. Fig. 3 suggests that nanostructured materials are promising PEC catalysts.

This review focuses on the fundamental properties of nanostructured materials and their efficiency in the context of

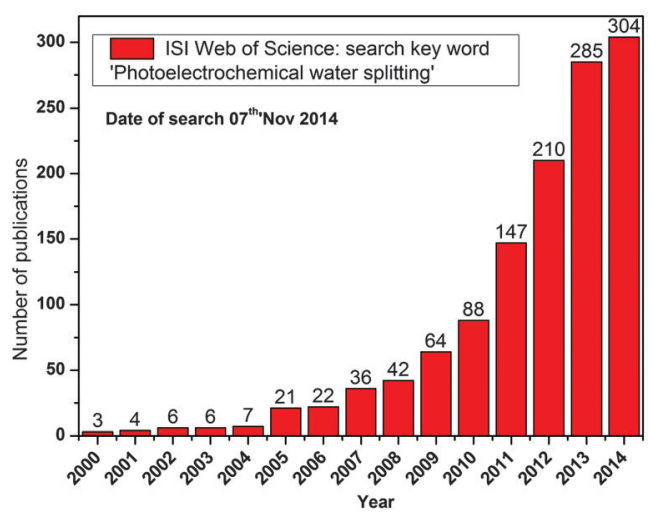

Fig. 2 Number of publications on PEC water splitting per year, 2000-2014.

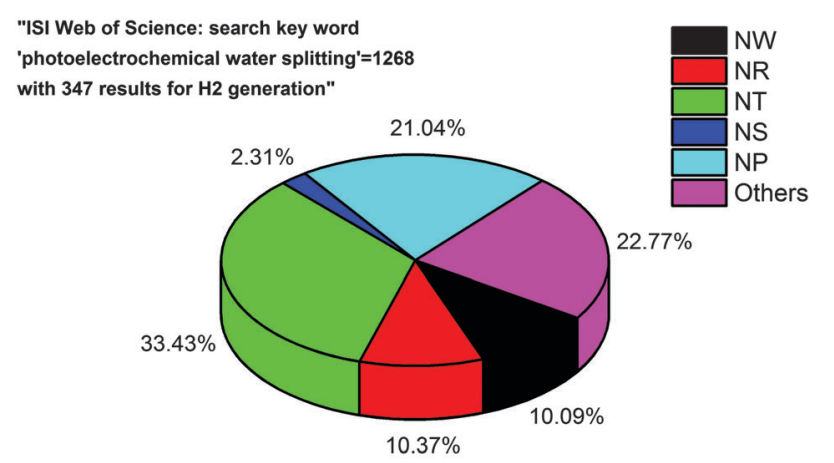

Date of search $07^{\text {th }}$ Nov 2014

Fig. $3 \mathrm{H}_{2}$ evolution from various nanostructures via PEC water splitting. $\mathrm{NW}=$ nanowires, NR = nanorods, NT = nanotubes, NS = nanosheets, NP = nanoparticles. 'Others' includes nanofibres, nanolayers, nanoribbons and nanospheres. 
processing parameters. The basic mechanism of $\mathrm{H}_{2}$ evolution is addressed, including the vital points that influence the catalytic activity. A wide range of photocatalysts has been developed for use under UV illumination and have been modified to extend their capability to use visible light. $\mathrm{H}_{2}$ evolution from various nanostructures are classified into two major sections: UV and visible illumination, along with various types of nanostructures such as NRs and NSs. The efficiencies and amount of $\mathrm{H}_{2}$ evolution from various materials in different morphologies are tabulated separately for both the UV and visible regions. Important results and the relevant configurations (e.g. heterojunctions) are discussed in detail. In the concluding remarks, we consider the crucial points that require further attention in the design of the next generation of catalysts.

\section{Basic mechanisms of hydrogen generation}

The basic PEC setup ${ }^{12}$ for water splitting is shown in Fig. 4a. When electrolysis takes place, the water molecules undergo redox reactions to generate $\mathrm{H}_{2}$ and $\mathrm{O}_{2}$ at the $\mathrm{Pt}$ and $\mathrm{TiO}_{2}$ electrodes, respectively. This PEC setup was later simplified by Bard, ${ }^{13-15}$ who used semiconducting particles and/or powders in the presence of aromatic compounds (Fig. 4b) as heterogeneous catalysts. The involvement of a semiconductor (catalyst), from which $\mathrm{e}-\mathrm{h}$ pairs are photogenerated to then take part in catalysis, is essential. The crucial factor in enhancing the productivity is to delay the recombination of the excited $\mathrm{e}-\mathrm{h}$ pairs and their subsequent migration (diffusion) to the surface. The output from the catalyst depends on how efficiently the e-h pairs are created and how well they diffuse to the surface.

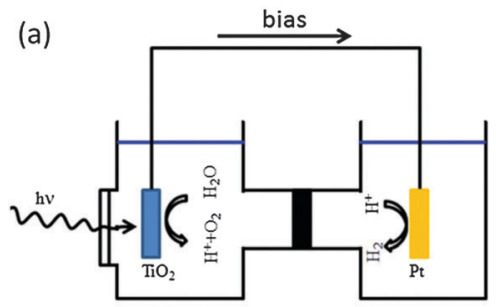

(b) -
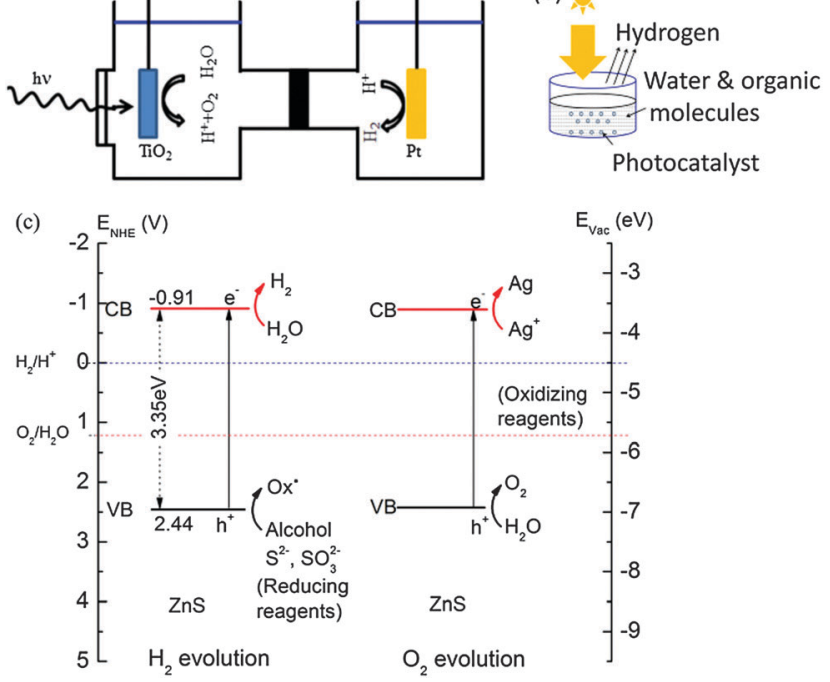

Fig. 4 Schematic diagrams of the setup for electrochemical water splitting: (a) after Fujishima and Honda; ${ }^{12}$ (b) using powdered photocatalysts (after Bard ${ }^{13-15}$ ); and (c) basic principle of water splitting with photocatalyst materials (figure redrawn based on Kudo and Misekia ${ }^{24}$ ).
These factors depend on the semiconductor used, ${ }^{16,17,60-62}$ the morphology, ${ }^{16,60}$ the crystal structure, ${ }^{17,25,61,62}$ intrinsic/surface defects, the intrinsic carrier lifetime and the collection time. ${ }^{17}$ These factors can be tuned in nano-scale catalysts.

The mechanism of water splitting is as follows. The water molecules are reduced to form $\mathrm{H}_{2}$ and oxidized to form $\mathrm{O}_{2}$. The reduction and oxidation are mediated by electrons and holes, respectively. The redox potential of water is $1.23 \mathrm{~V}$, i.e. $\mathrm{H}^{+} / \mathrm{H}_{2}$ is $0 \mathrm{~V}$ and $\mathrm{O}_{2} / \mathrm{H}_{2} \mathrm{O}$ is $1.23 \mathrm{~V}$ with respect to the normal hydrogen electrode (NHE) (Fig. 4c). Under suitable illumination, electrons and holes are created in the $\mathrm{CB}$ and $\mathrm{VB}$, respectively. Several factors are involved in photocatalytic water splitting that finally determine the value of $\eta$. These are: (1) the absorption of photons to form excited $\mathrm{e}-\mathrm{h}$ pairs; (2) the recombination, separation, migration, trapping and migration of excited charge carriers; and (3) surface chemical reactions (the construction of surface reaction active sites for the evolution of $\mathrm{H}_{2}$ and $\mathrm{O}_{2}$ ). When the conditions are favourable, these photoexcited electrons and holes migrate to the surface of the photocatalyst (Fig. 4). Fig. 4c describes the role of SRs in the catalysis process. As the quantity of SR decreases, the $\mathrm{H}_{2}$ production rate also decreases; however, the production rate can be regained if the reagent is replenished. ${ }^{83}$ It has been reported that SRs can effectively reduce $\mathrm{H}_{2} \mathrm{O}$ to $\mathrm{H}_{2}$ or oxide it to $\mathrm{O}_{2}$. Co-catalysts and/or the addition of SRs to $\mathrm{TiO}_{2}$ resulted in an improved performance. ${ }^{24}$ A sufficiently negative flat band potential, a good absorption cross-section over a wide spectral range, photostability and an appropriate band gap are also essential. In this context, metal oxides such as $\mathrm{TiO}_{2}, \mathrm{SrTiO}_{3}$ and $\mathrm{NaTiO}_{3}$ have been studied in detail as a result of their suitable band structures, low environmental impact and low toxicity, and high stability. However, these wide band gap oxides have only low conversion efficiencies as they are only active under UV light, which accounts for just $4 \%$ of the solar spectrum. Buhler et al. ${ }^{84}$ reported that CdS has promising absorption up to $520 \mathrm{~nm}$ and has a flat band potential of $-0.66 \mathrm{~V}(\mathrm{pH} 7)$. However, the $E_{\mathrm{g}}$ of $\mathrm{CdS}$ is still relatively large $(2.5 \mathrm{eV})$ and is not stable in aqueous solution under irradiation (anodic dissolution), although it can be stabilized in aqueous solutions by using reducing agents or SRs that provide electron donors to consume the photogenerated holes. SRs promote $\mathrm{H}_{2}$ evolution by contributing to half of the reaction. ${ }^{84}$ Where the SRs used two outputs can be expected: one is $\mathrm{H}_{2}$, although and the second is desulfurization processes of $\mathrm{S}^{2-}$ and $\mathrm{SO}_{3}{ }^{2-}$. In the case of dye sensitization, ${ }^{85}$ excitation and subsequent charge transfers occur on a sub-nanosecond or picosecond timescale. As electrons populate the $\mathrm{CB}$, their energy should be more negative than $\mathrm{H}^{+} / \mathrm{H}_{2}$ with reference to the NHE. Holes participate in catalysis from the $\mathrm{VB}$ and their energy should be more positive than $\mathrm{O}_{2} / \mathrm{H}_{2} \mathrm{O}(1.23 \mathrm{~V})$ with reference to the NHE. Therefore the $E_{\mathrm{g}}$ of the photocatalyst should be $>1.23 \mathrm{eV}$. The energetic levels of the VB and CB play a vital part in water splitting, where their edges correspond to the ionization potential and electron affinity, respectively. Fig. 5 shows the $\mathrm{CB}$ and $\mathrm{VB}$ edges for various semiconductors with reference to the NHE and a vacuum; these values are also given in Table 1 for easy reference.

The basic half-equations which form $\mathrm{H}_{2}$ and $\mathrm{O}_{2}$ gases are given in eqn (1)-(3). As a result of the uphill nature of the 


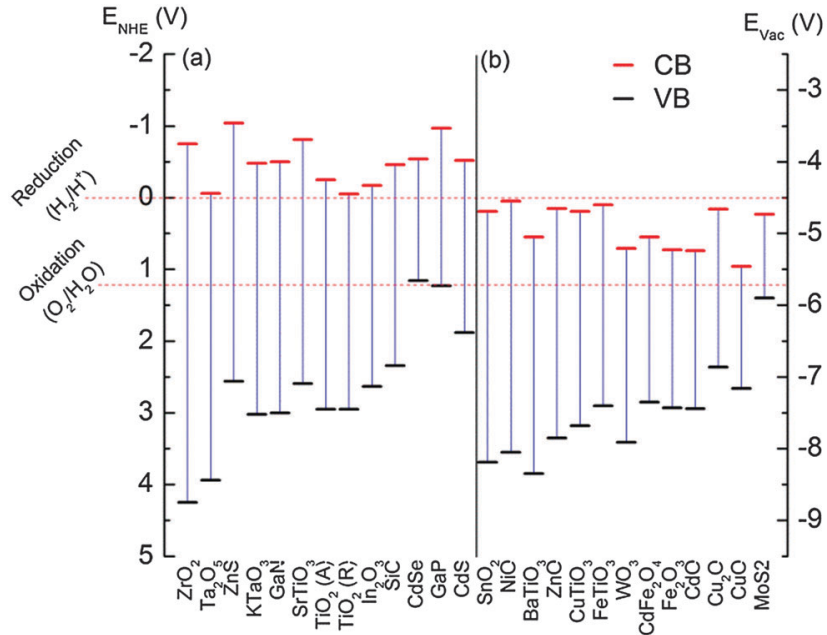

Fig. 5 Absolute $C B$ and $V B$ energy levels for some semiconducting photocatalysts with respect to the NHE and vacuum (Vac). Thermodynamically (a) suitable and (b) unsuitable materials. The band edge values for other perovskites are given in Castelli et al. ${ }^{86}$

Table 1 VB and CB levels of some semiconductors

Band levels with respect to NHE (eV)

\begin{tabular}{|c|c|c|c|c|}
\hline Semiconductor & CB & VB & $E_{\mathrm{g}}$ & Ref. \\
\hline $\mathrm{ZrO}_{2}$ & -0.75 & 4.25 & 5.0 & 87 \\
\hline $\mathrm{Ta}_{2} \mathrm{O} 5$ & -0.06 & 3.94 & 4.0 & 87 \\
\hline ZnS & -0.91 & 2.44 & 3.35 & 88 \\
\hline $\mathrm{KTaO}_{3}$ & -0.48 & 3.02 & 3.5 & 87 \\
\hline GaN & -0.5 & 3.0 & 3.5 & 89 \\
\hline $\mathrm{SrTiO}_{3}$ & -0.81 & 2.59 & 3.4 & 90 \\
\hline $\mathrm{TiO}_{2}(\mathrm{~A})$ & -0.25 & 2.95 & 3.2 & 90 \\
\hline $\mathrm{TiO}_{2}(\mathrm{R})$ & -0.05 & 2.95 & 3.0 & 90 \\
\hline $\mathrm{In}_{2} \mathrm{O}_{3}$ & -0.17 & 2.63 & 2.8 & 87 \\
\hline $\mathrm{SiC}$ & -0.46 & 2.34 & 2.8 & 91 \\
\hline CdSe & -0.54 & 1.16 & 1.7 & 24 \\
\hline $\mathrm{GaP}$ & -0.97 & 1.23 & 2.2 & 24 \\
\hline CdS & -0.52 & 1.88 & 2.4 & 87 \\
\hline $\mathrm{SnO}_{2}$ & 0.19 & 3.69 & 3.5 & 87 \\
\hline $\mathrm{NiO}$ & 0.05 & 3.55 & 3.5 & 87 \\
\hline $\mathrm{BaTiO}_{3}$ & 0.55 & 3.85 & 3.3 & 87 \\
\hline $\mathrm{ZnO}$ & 0.15 & 3.35 & 3.2 & 87 \\
\hline $\mathrm{CuTiO}_{3}$ & 0.19 & 3.18 & 3.0 & 87 \\
\hline $\mathrm{FeTiO}_{3}$ & 0.1 & 2.9 & 2.8 & 87 \\
\hline $\mathrm{WO}_{3}$ & 0.71 & 3.41 & 2.7 & 87 \\
\hline $\mathrm{CdFe}_{2} \mathrm{O}_{4}$ & 0.55 & 2.85 & 2.3 & 87 \\
\hline $\mathrm{Fe}_{2} \mathrm{O}_{3}$ & 0.73 & 2.93 & 2.2 & 87 \\
\hline CdO & 0.74 & 2.94 & 2.2 & 87 \\
\hline $\mathrm{Cu}_{2} \mathrm{O}$ & 0.16 & 2.36 & 2.2 & 87 \\
\hline $\mathrm{CuO}$ & 0.96 & 2.66 & 1.7 & 87 \\
\hline $\mathrm{MoS}_{2}$ & 0.23 & 1.4 & 1.2 & 87 \\
\hline
\end{tabular}

reaction (positive change of Gibbs free energy $\Delta G^{0}=237 \mathrm{~kJ} \mathrm{~mol}^{-1}$ at $25{ }^{\circ} \mathrm{C}$ ), back-reactions may take place between $\mathrm{H}_{2}$ and $\mathrm{O}_{2}$ to form water in addition to intermediate products. Hence the surface of the catalyst or co-catalyst (if any) should be less supportive of the back-reactions.

$$
\text { Reduction-Pt (Fig. 4c): } 2 \mathrm{H}^{+} \text {(aq) }+2 \mathrm{e}^{-} \rightarrow \mathrm{H}_{2} \text { (g) }
$$

Oxidation-catalyst (Fig. 4c): $2 \mathrm{H}_{2} \mathrm{O}(\mathrm{l})+4 \mathrm{~h}^{+} \rightarrow \mathrm{O}_{2}(\mathrm{~g})+4 \mathrm{H}^{+}$

$$
\text { Overall reaction: } 2 \mathrm{H}_{2} \mathrm{O}(\mathrm{l}) \rightarrow 2 \mathrm{H}_{2}(\mathrm{~g})+\mathrm{O}_{2}(\mathrm{~g})
$$

Fig. 5 gives information about semiconducting catalysts that are suitable and unsuitable materials for $\mathrm{H}_{2}$ production. Fig. 5a shows that, for most of the semiconductors, the VB edge is deeper than the $\mathrm{O}_{2} / \mathrm{H}_{2} \mathrm{O}$ oxidation potential. Hence there is no need for a co-catalyst, except in special cases. To increase the value of $\eta$, the visible light region of the solar spectrum should be used. Although there are some semiconductors whose band gap covers the visible light region of solar spectrum, they are not considered as active materials because of their unsuitable band energies with respect to the NHE. These semiconductors (e.g. $\mathrm{MoS}_{2}, \mathrm{Fe}_{2} \mathrm{O}_{3}$ and $\mathrm{WO}_{3}$ ) are known to be photocorrosive materials as their $\mathrm{CB}$ minimum is lower than the thermodynamic requirement (Fig. 5b). ${ }^{24}$ Wide band gap materials cannot harvest visible light, unless suitably modified. As an example, Fig. 6 shows a schematic band diagram of doped $\mathrm{TiO}_{2} \cdot{ }^{34}$ Under UV illumination $\left(h \nu_{1}\right)$, the evolution of both $\mathrm{H}_{2}$ and $\mathrm{O}_{2}$ is favourable. In the S-doped $\mathrm{TiO}_{2}$, the evolution of $\mathrm{O}_{2}$ is possible at $\mathrm{S}^{2-}$ sites under illumination with visible light $\left(h \nu_{2}\right)$, i.e. the $\mathrm{S}^{2-}$ state lies above the $\mathrm{O}_{2} / \mathrm{H}_{2} \mathrm{O}$ oxidation potential. In contrast, for V-doped $\mathrm{TiO}_{2}$, the evolution of $\mathrm{H}_{2}$ is not possible at the $\mathrm{V}^{4+/ 5+}$ site under illumination with visible light $\left(h \nu_{3}\right)$, i.e. the $\mathrm{V}^{4+5+}$ state is at a higher potential than the $\mathrm{H}_{2} / \mathrm{H}^{+}$reduction potential. It is important to note that the dopants form localized states. If they are accessible on the surface, then catalysis takes place from holes and electrons if the essential criteria for the redox potentials are met. Many photocatalysts have been reported to work under UV/visible light irradiation. ${ }^{2}$

Charge separation and migration of the photogenerated charge carriers are strongly affected by changes in crystal structure (polymorphs), ${ }^{77,92}$ crystallinity ${ }^{93}$ and particle size. Lattice defects act as traps or recombination centres and, consequently, the catalytic activity decreases. The density of defects can be lowered by increasing the crystallinity. By decreasing the size of the semiconductor, the photogenerated e-h pairs can migrate to the surface before they are trapped or recombined. If a catalytic site is

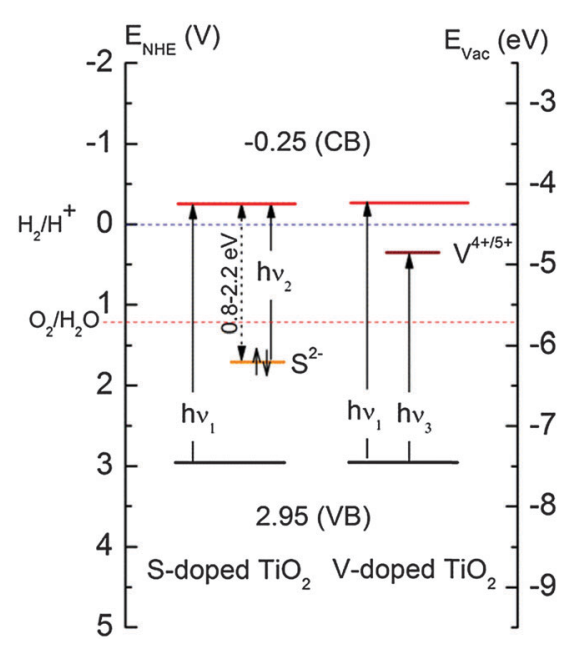

Fig. 6 Schematic band diagram for $\mathrm{S}$ - or $\mathrm{V}$-doped $\mathrm{TiO}_{2}$. Figure redrawn based on Izumi et al. ${ }^{34}$ 

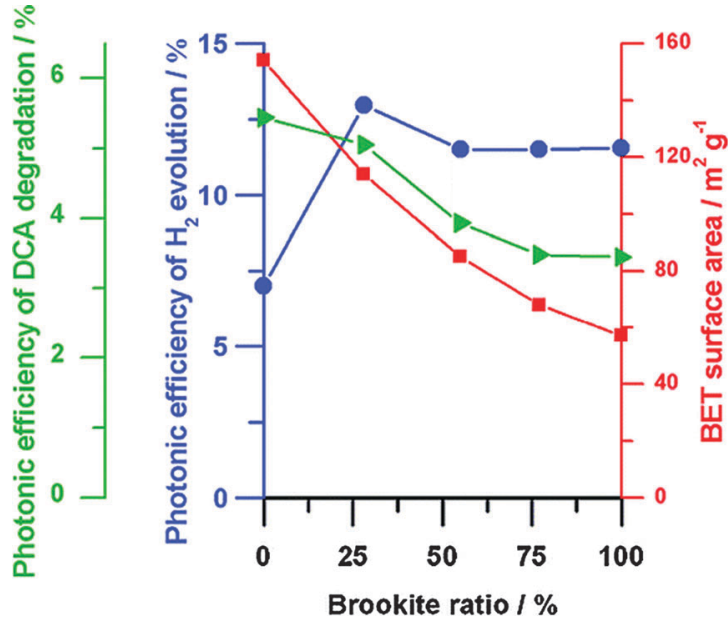

Fig. 7 Photonic efficiency and surface area versus the content of brookite. Green triangles = photonic efficiency of dichloroacetic acid (DCA) degradation; red squares = surface area; and blue circles = photonic efficiency of $\mathrm{H}_{2}$ evolution. Conditions: catalyst, $0.5 \mathrm{~g} \mathrm{~L}^{-1}$; aqueous $1 \mathrm{mM} \mathrm{L}^{-1} \mathrm{DCA}, 60 \mathrm{~mL}$; and $\mathrm{pH}$ 3. Reproduced with copyright permission from ref. 92

not available even after reaching the surface, then they will have to recombine irrespective of whether they have a high enough potential to split water molecules. The surface chemical reactions depend on the SA and the density of surface defects.

Doped $\mathrm{TiO}_{2}$ is visibly active where the dopants create intermediate bands within the band gap. However, the evolution of $\mathrm{H}_{2}$ varies within $\mathrm{TiO}_{2}$ polymorphs ${ }^{92}$ (Fig. 7), in which the flat band potential of rutile and anatase varies with reference to the $\mathrm{H}^{+}$ reduction potential. The flat band potential of rutile $\mathrm{TiO}_{2}$ is almost the same as that of the reduction potential of protons, whereas that of anatase $\mathrm{TiO}_{2}$ is shifted negatively by about $0.2 \mathrm{~V} .^{94}$ This implies that the photogenerated electrons in anatase are more energetic than those in rutile. When recombination sites are dominant, as in amorphous $\mathrm{TiO}_{2}$, negligible catalytic activity is expected. ${ }^{95}$ Another polymorph of $\mathrm{TiO}_{2}$ is brookite, which has a better catalytic activity than commercial $\mathrm{TiO}_{2}(\mathrm{P}-25) \cdot{ }^{96}$ Again, the difference in the flat band potential explains the higher efficiency: for brookite, the flat band potential is cathodically shifted by $0.14 \mathrm{~V}$ compared with anatase. Kandiel et al. ${ }^{92}$ studied three $\mathrm{TiO}_{2}$ polymorphs with respect to their production of $\mathrm{H}_{2}$ from $\mathrm{MeOH}-\mathrm{H}_{2} \mathrm{O}$ gas. Their results suggested that the anatase and brookite phases result in similar $\mathrm{H}_{2}$ production, whereas rutile has a lower performance. Cubic structured $\mathrm{KNbO}_{3}$ had a higher rate of $\mathrm{H}_{2}$ production than orthorhombic and commercial $\mathrm{KNbO}_{3} .{ }^{97}$

\section{Quantification of hydrogen generation}

Many types of illumination sources (Xe or Hg lamps) have been used with different amounts of catalysts. An agreed quantification method is needed so that efficiencies can be compared across different studies.

\subsection{Solar-to-hydrogen conversion efficiency $(\eta, \%)$}

The efficiency of $\mathrm{H}_{2}$ generation can be measured either by quantifying the amount of $\mathrm{H}_{2}$ gas evolved or the number of electrons transferred from the photocatalyst to the water within a certain time period under illumination. The overall conversion of solar energy is given by the following equation: ${ }^{33}$

$$
\begin{aligned}
(\%) & =\frac{\text { total power output }- \text { electrical power output }}{\text { energy of incident light }} \times 100 \\
& =j_{\mathrm{p}}\left[\left(E_{\mathrm{rev}}^{0}-\left|E_{\mathrm{app}}\right|\right) / I_{0}\right] \times 100
\end{aligned}
$$

where $j_{\mathrm{p}}$ is the photocurrent density $\left(\mathrm{mW} \mathrm{cm}^{-2}\right), j_{\mathrm{p}} E_{\mathrm{rev}}^{0}$ is the total power output, $j_{\mathrm{p}}\left|E_{\text {app }}\right|$ is the electrical power output and $I_{0}$ is the power density of the incident light $\left(\mathrm{mW} \mathrm{cm}^{-2}\right) \cdot E_{\text {rev }}^{0}$ is the standard reversible potential (1.23 V/NHE). $E_{\text {app }}$ is the applied potential, which can be derived from $E_{\text {app }}=E_{\text {meas }}-E_{\text {aoc }}$, where $E_{\text {meas }}$ is the electrode potential of the working electrode at which the photocurrent was measured under illumination and $E_{\text {aoc }}$ is the electrode potential of the same working electrode under open circuit conditions, under the same illumination when immersed in the same electrolyte. $E_{\text {aoc }}$ and $E_{\text {app }}$ are measured with respect to $\mathrm{Ag} / \mathrm{AgCl}$. The voltage at which the photocurrent becomes zero is taken as $E_{\text {aoc. }}$. The details of the light source can be included in the quantification process and the quantum yield (QY) can be calculated. The overall QY is defined in eqn (5) and (6) for $\mathrm{H}_{2}$ and $\mathrm{O}_{2}$, respectively: ${ }^{98}$

$$
\begin{aligned}
& \text { QY\% }=\frac{2 \times \text { number of evolved } \mathrm{H}_{2} \text { molecules }}{\text { number of absorbed photons }} \times 100 \\
& \text { QY\% }=\frac{4 \times \text { number of evolved } \mathrm{O}_{2} \text { molecules }}{\text { number of absorbed photons }} \times 100
\end{aligned}
$$

Some photocatalysts are active in visible light, whereas others are active in the UV region of the solar spectrum. Although the principle of $\mathrm{H}_{2}$ generation is the same for both $\mathrm{UV}$ and visible irradiation, given the large amount of visible light available it is appropriate to discuss these regions separately.

\section{UV-active nanostructured photocatalysts for hydrogen generation}

Wide band gap semiconductors can only use the UV region of the solar spectrum. Nevertheless, considerable amounts of $\mathrm{H}_{2}$ have been reported ${ }^{47-52}$ to be produced when these catalysts are in the form of nanostructures. ${ }^{5,99}$ The density of active surface sites increases with increasing SA, ${ }^{100-102}$ particularly with $1 \mathrm{D}$ nanostructures, which have fast charge transfer rates and efficient charge separation. ${ }^{103}$ For example, NWs, ${ }^{93,104,105}$ NTs, ${ }^{106-110}$ NRs/ nanoribbons ${ }^{111-116}$ and $\mathrm{NFs}^{44,117-121}$ have shown great potential for the production of $\mathrm{H}_{2}$. However, it is vital to understand which type of 1D structure is better for the generation of $\mathrm{H}_{2}$. We have carried out a comparative analysis of these 1D structures with respect to their efficiency under UV irradiation.

\subsection{Nanowires}

NWs have shown significance photocatalytic activity as a result of the improvement in electron-hole separation and lower recombination rates. Such remarkable features are highly desirable to 
enhance the efficiency of PEC water splitting. NWs have been studied extensively. ${ }^{93,122-124}$ Yang et al. ${ }^{122}$ reported that $\mathrm{N}$-doped ZnO NWs used as photoanodes in PEC yielded relatively higher efficiencies as a result of the improved charge transport over the $0 \mathrm{D}$ nanostructures. $\mathrm{TiO}_{2} \mathrm{NWs}$ were more effective for $\mathrm{H}_{2}$ generation than commercial $\mathrm{TiO}_{2}$ nanoparticles (NPs). The yield from these NWs was about $1.421 \mu \mathrm{mol} \mathrm{m} \mathrm{m}^{-2}$, which is significant $^{123}$ and was ascribed to the high SA and low recombination rate of the e-h pairs. Jitputti et al. ${ }^{93}$ studied $\mathrm{TiO}_{2} \mathrm{NWs}$ with methanol as a SR to show the effects of post-treatment and its consequences for the SA. The SRs removed the photogenerated holes in an irreversible fashion, thereby preventing mutual electron-hole recombination and the $\mathrm{H}_{2}$ and $\mathrm{O}_{2}$ back-reaction ${ }^{124}$ (eqn (2)). The overall process can be expressed by the following equations: ${ }^{125}$

$$
\begin{aligned}
& \mathrm{CH}_{3} \mathrm{OH} \stackrel{h v, \text { Cat. }}{\longrightarrow} \mathrm{HCHO}+\mathrm{H}_{2} \\
& \mathrm{HCHO}+\mathrm{H}_{2} \mathrm{O} \stackrel{h v, \text { Cat. }}{\longrightarrow} \mathrm{HCO}_{2} \mathrm{H}+\mathrm{H}_{2} \\
& \mathrm{HCO}_{2} \mathrm{H} \stackrel{h v, \text { Cat. }}{\longrightarrow} \mathrm{CO}_{2}+\mathrm{H}_{2} \\
& \mathrm{CO}_{2}+\mathrm{H}_{2} \mathrm{O} \stackrel{h v,\left(\mathrm{M}-\mathrm{TiO}_{2}\right)}{\longrightarrow}\left\{\begin{array}{c}
\mathrm{CH}_{4} \\
\mathrm{CH}_{2} \mathrm{O} \\
\mathrm{CH}_{3} \mathrm{COOH} \\
\text { (where } \mathrm{M}=\mathrm{Pt}, \mathrm{Pd}, \mathrm{Au}, \mathrm{Cu}, \mathrm{Ru})
\end{array}\right.
\end{aligned}
$$

Notably, methanol is oxidized to form $\mathrm{CO}_{2}$, which is an adverse effect. Despite this, the $\mathrm{H}_{2}$ yield was about $20.1 \mu \mathrm{mol} \mathrm{h}{ }^{-1}$ for the samples post-treated at $500{ }^{\circ} \mathrm{C}$ for $1 \mathrm{~h}$ (Fig. 8). This may be because the unique $1 \mathrm{D}$ NWs and high crystallinity promoted the evolution of $\mathrm{H}_{2}$ under UV irradiation. ${ }^{93}$ The amount of $\mathrm{H}_{2}$ evolved increases with increasing post-treatment temperatures up to $500{ }^{\circ} \mathrm{C}$, then decreases with further increases in temperature. The decrease may be a result of the lowered SA. A similar effect has been reported ${ }^{26}$ for lithium niobate $\left(\mathrm{LiNbO}_{3}\right) \mathrm{NWs}$, for which a higher SA yielded better results. However, when $\mathrm{RuO}_{2}$ is used as a co-catalyst under UV-visible illumination, the overall amount of water splitting is increased.

Si NWs (n type) are known for their competitive carrier recombination. Forming a $\mathrm{p}-\mathrm{n}$ heterojunction accelerates improves the separation of the photogenerated charge carriers. This was illustrated by Xiong et al. ${ }^{59}$ using $\mathrm{Cu}_{2} \mathrm{O}$ (p-type) as a core-shell structure with $\mathrm{Pt}$ as a co-catalyst. This composite structure showed a nearly $45 \%$ increase in the generation of $\mathrm{H}_{2}$ compared with pristine Si NWs. In addition to p-n type heterojunctions, ${ }^{59} \mathrm{n}$-n type heterojunctions have also been investigated in a similar core-shell structure with $\mathrm{ZnO} / \mathrm{Zn}_{x} \mathrm{Cd}_{1-x} \mathrm{Te}_{\mathrm{NWs}}{ }^{35}$ To put this in context, it is important to mention a study ${ }^{36}$ which showed the selective isolation of electron-hole pairs in an $n-n$ type heterojunction. Such structures help to isolate the hole, thereby inhibiting back-reactions. In $\mathrm{ZnO}-\mathrm{Zn}_{x} \mathrm{Cd}_{1-x} \mathrm{Te}$ NW heterojunctions, the shell material absorbs in the NIR
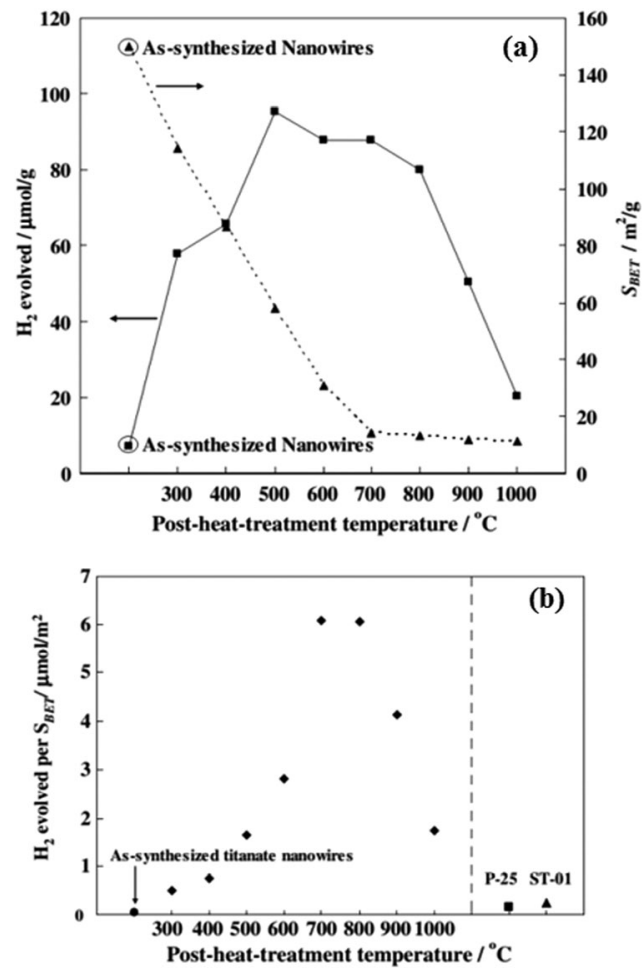

Fig. 8 Efficiency of $\mathrm{H}_{2}$ generation at different post-treatment temperatures with respect to (a) surface area $\left(\mathrm{S}_{\mathrm{BET}}\right)$ and (b) $\mathrm{TiO}_{2}$ powder (Degussa P-25) and commercial $\mathrm{TiO}_{2}$ (Ishihara ST-01). Reproduced with copyright permission from ref. 93.

region (855 $\mathrm{nm}$ ), in contrast with the core, which absorbs the UV region (380 $\mathrm{nm}$ ), covering about $22 \%$ of the solar spectrum. Under suitable illumination, type II band alignment allows the transfer of photogenerated electrons from the CB of $\mathrm{Zn}_{x} \mathrm{Cd}_{1-x} \mathrm{Te}$ ( $E_{\mathrm{g}}$ tunability 2.25-1.45 eV depending on the $\mathrm{Cd}: \mathrm{Zn}$ ratio) to the $\mathrm{CB}$ of ZnO (Fig. 9a). The recombination is delayed while the transfer takes place, yielding higher $\mathrm{H}_{2}$ production. The electrons collected at the ITO produce $\mathrm{H}_{2}$ molecules. The holes are transferred to the $\mathrm{VB}$ of the $\mathrm{Zn}_{x} \mathrm{Cd}_{1-x} \mathrm{Te}$ shell and are consumed by the $\mathrm{SR}\left(\mathrm{S}^{2-}\right.$ and $\left.\mathrm{SO}_{3}{ }^{2-}\right)$. If the $\mathrm{Zn}_{x} \mathrm{Cd}_{1-x}$ Te covers the whole substrate, including the ITO, then it is not useful for the generation of $\mathrm{H}_{2}$. As the ITO is an expensive substrate, alternative methods of fabrication should be considered. For example, if $\mathrm{ZnO}$ is taken as the shell and $\mathrm{Zn}_{x} \mathrm{Cd}_{1-x} \mathrm{Te}$ as the core, then the electrons can take part in the catalysis from a much higher SA (in the original configuration ${ }^{35}$ it is just the ITO). Even if the ZnO covers the whole substrate, good access to the electrons is preserved when the fabrication difficulties in this configuration are acknowledged.

These heterojunctions have been developed further by introducing Pt as a co-catalyst ${ }^{126}$ - for example, in CdSe-CdS coreshell NW heterojunctions. After charge generation the Pt acts as an electron collector and enhances the production of $\mathrm{H}_{2}$ at its best value of $434.29 \mu \mathrm{mol} \mathrm{h}{ }^{-1} \mathrm{~g}^{-1}$ under UV illumination. The CdS shell also helps to passivate the surface defects of the core, which helps to increase the carrier lifetime. Tongying et al. ${ }^{126}$ illustrated a band diagram without considering the energetic 


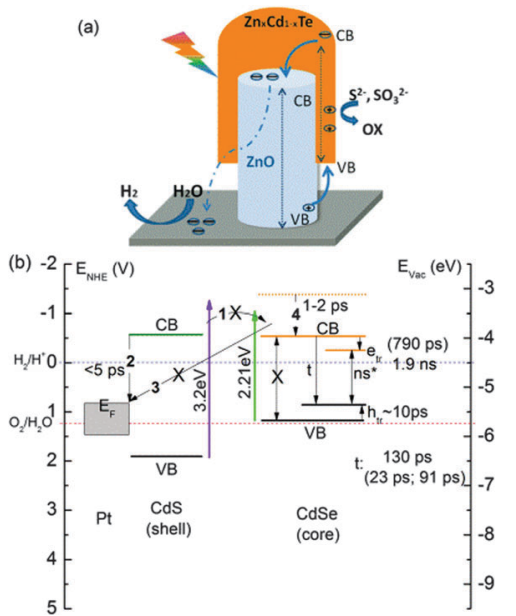

Fig. 9 (a) Schematic representation of the charge transfer and separation process in $\mathrm{ZnO} / \mathrm{Zn}_{x} \mathrm{Cd}_{1-x} \mathrm{Te}$ core-shell NW array. Reproduced with copyright permission from ref. 35. (b) CdSe-CdS core-shell NW heterojunctions with Pt as the co-catalyst. ${ }^{126} e_{t r}$ and $h_{t r}$ are electron and hole traps, respectively.

locations of the bands. However, we have redrawn this (Fig. 9b), taking the $\mathrm{CB}$ and $\mathrm{VB}$ edges for the two semiconductors from Table 1. In process 1 , Tongying et al. ${ }^{126}$ suggested that the electron from the CB of CdS does not reach the CB of CdSe. In process 2 , the electron from the $\mathrm{CB}$ of CdS takes $<5$ ps to reach the $E_{\mathrm{F}}$ of Pt. Process 3 is, of course, not possible given the physical inaccessibility. In process 4 , the electron takes nearly 1-2 ps to reach the bottom of the $\mathrm{CB}$ of CdSe. Electron and hole trap processes ( $e_{t r}$ and $h_{t r}$, respectively) take place in CdSe and the time-scales are shown in Fig. 9b. Within CdSe it was suggested ${ }^{126}$ that the electrons are not excited to the bottom of the $\mathrm{CB}$ and hence do not recombine directly, however mediated by $\mathrm{e}_{\mathrm{tr}}$ and $\mathrm{h}_{\mathrm{tr}}$. Wu et al. ${ }^{127}$ reported the evolution of $\mathrm{H}_{2}$ from $\mathrm{N}$-doped $\mathrm{TiO}_{2} \mathrm{NFs}$ (hydrothermal) decorated with Pt NPs of about $2 \mathrm{~nm}$ diameter under different wavelengths of illumination. The catalysts were effective in the production of $\mathrm{H}_{2}$ with conversion efficiencies of 3.6 and $12.3 \%$ for UV irradiation at 365 and $312 \mathrm{~nm}$, respectively.

\subsection{Nanotubes}

$\mathrm{TiO}_{2}$-based NTs have been shown to have considerable efficiency as catalysts for the generation of $\mathrm{H}_{2}$ under UV irradiation..$^{33,128-132}$ The physical dimensions of these NTs control the overall efficiency of water splitting. When the scattering of light within the structures increases, a higher rate of $\mathrm{H}_{2}$ generation can be expected. ${ }^{129}$ Paulose et al. ${ }^{33}$ fabricated self-aligned $\mathrm{TiO}_{2}$ NTs (134 $\mu \mathrm{m}$ length, $20-150 \mathrm{~nm}$ pore diameter) by anodization using a process in which the pore size and length could be tuned (Fig. 10a-c). After annealing the amorphous NTs at $550{ }^{\circ} \mathrm{C}$, a photoconversion efficiency of about $16.25 \%$ was achieved under UV illumination. Mor et al. ${ }^{128}$ demonstrated Ti-Fe-O NTs based on thin films with an $\mathrm{H}_{2}$ production rate of about $7.1 \mathrm{~mL} \mathrm{~W}^{-1} \mathrm{~h}^{-1}$. Eder et al. ${ }^{133}$ reported $\mathrm{Fe} / \mathrm{Pt}-\mathrm{TiO}_{2}$ NTs with superior electron lifetimes and efficient charge separation under UV light. ${ }^{131,134}$ Bulk recombination is reduced by the NT architecture (porosity), while the photogenerated minority

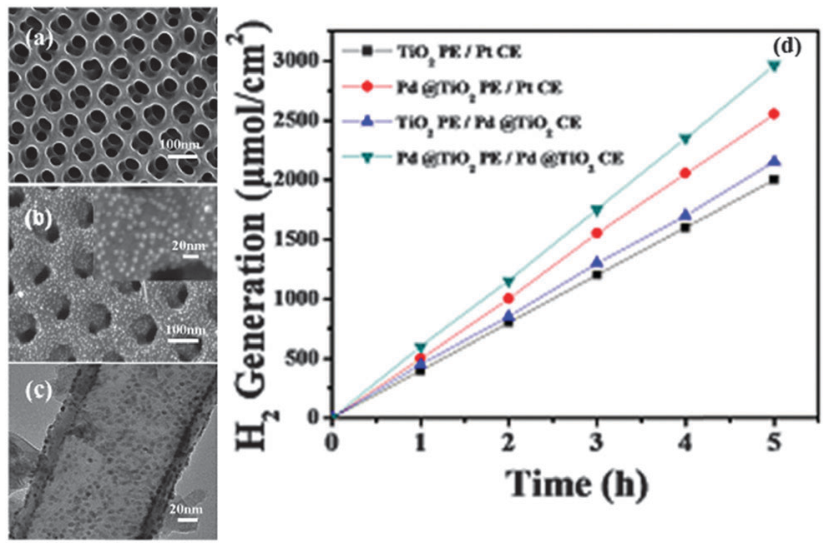

Fig. 10 SEM micrographs of (a) $\mathrm{TiO}_{2} \mathrm{NTS}$ and (b) $\mathrm{TiO}_{2} \mathrm{NT}$ coated with Pd QDs (inset shows higher magnification) (c) TEM image of $\mathrm{TiO}_{2}$ NTs with $\mathrm{Pd}$ QDs. (d) $\mathrm{H}_{2}$ generation from various catalysts plotted against time. Reproduced with the copyright permission from ref. 140.

carriers (holes) can be trapped by surface states based on a model proposed by Lubberhuizen et al. ${ }^{135}$ For example, the typical time needed for holes to reach the surface is about $10^{-10} \mathrm{~s}$ in nanoporous GaP.

It is known that the noble metals (e.g. $\mathrm{Au},{ }^{136,137} \mathrm{Pt}^{46,133,138}$ $\mathrm{Ag}^{139}$ and $\mathrm{Pd}^{140}$ ) and many co-catalysts $\left(\right.$ e.g. $\mathrm{NiO}_{x}^{46}$ ) act as electron reservoirs (acceptors) ${ }^{138}$ and collect photogenerated electrons from the $\mathrm{CB}$ of semiconductors in close contact. As a result, recombination is delayed, i.e. there is Fermi level $\left(E_{\mathrm{F}}\right)$ equilibration of the metal and the semiconductor. Delayed recombination helps to enhance the activity of the catalyst. Pt is special because it has a favourable $\mathrm{H}^{+}$chemisorption energy and a high activity for proton reduction reactions and it also has a low electrochemical impedance to discharge the absorbents. ${ }^{138}$ This is discussed in detail in Tongying et al. ${ }^{126}$ Pt forms a Schottky junction with $\mathrm{TiO}_{2}$, which is crucial for the generation of $\mathrm{H}_{2}$. However, the formation of the Schottky barrier is prevented when $\mathrm{Pt}$ is calcined at $873 \mathrm{~K} \cdot{ }^{141} \mathrm{As}$ an additional advantage, these noble metals are not photocorrosive. However, an optimum loading of Pt should be maintained because excessive loadings decrease the production of $\mathrm{H}_{2}$ as a result of the decreased SA for chemisorption. ${ }^{142,143}$ The performance of $\mathrm{Au}$ depends on the shape and structure of the NTs. ${ }^{137}$

$\mathrm{TiO}_{2}$ NTs with Au NPs have shown enhanced $\mathrm{H}_{2}$ production. ${ }^{136} \mathrm{Pd}$ quantum dots (QDs) have been used in conjunction with $\mathrm{TiO}_{2}$ NTs in a solution containing $\mathrm{Na}_{2} \mathrm{CO}_{3}$ and ethylene glycol (EG) with significant results. ${ }^{140}$ Fig. 10a-c shows SEM images of $\mathrm{TiO}_{2} \mathrm{NT}$ arrays with Pd QDs; the evolution of $\mathrm{H}_{2}$ is shown in Fig. 10d. ${ }^{140}$ The measurements were performed at $-0.3 \mathrm{~V}$ versus a standard calomel electrode containing $2 \mathrm{M}$ $\mathrm{Na}_{2} \mathrm{CO}_{3}+0.5 \mathrm{M}$ EG solution under $320 \mathrm{~mW} \mathrm{~cm} \mathrm{~cm}^{-2}$ irradiation for a Pd weight percentage of 2.15. Pt NPs have been used extensively in conjunction with $\mathrm{TiO}_{2} \mathrm{NTs},{ }^{144}$ with a reported QY of about $16 \%$ under UV irradiation.

The recombination rate of e-h pairs in $\mathrm{TiO}_{2}$ NTs is reduced in the presence of $\mathrm{Ag}$ NPs (Fig. 11a-c). The yield of $\mathrm{H}_{2}$ (about $10.69 \mu \mathrm{mol} \mathrm{h}^{-1}$ ) is dependent on the anodization voltage 

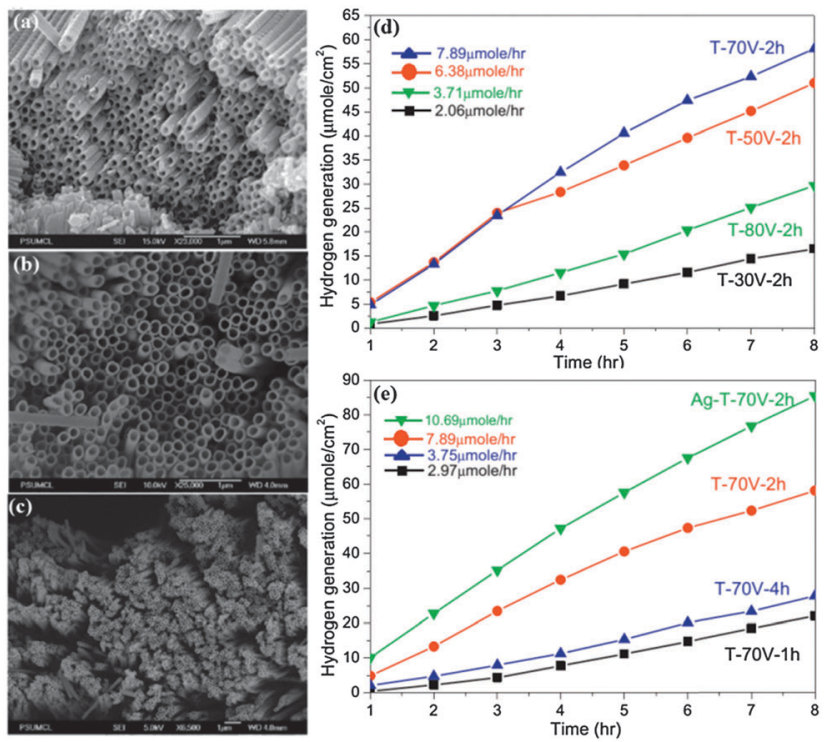

Fig. 11 FE-SEM images of NT arrays produced by anodization at (a) $60 \mathrm{~V}$, 0.25 wt\% $\mathrm{NH}_{4} \mathrm{~F}$ in $\mathrm{EG}$, (b) $40 \mathrm{~V}$ in dimethyl sulfoxide with $2 \% \mathrm{HF}$, (c) $60 \mathrm{~V}$ in DMSO containing $2 \% \mathrm{HF} . \mathrm{H}_{2}$ generation measured from (d) $\mathrm{TiO}_{2}$ NTs produced at different anodization voltages and (e) Ag-modified $\mathrm{TiO}_{2} \mathrm{NTs}$ and unmodified NTs with respect to anodization time. Reproduced with copyright permission from ref. 33 and 139.

and time (the texture of $\left.\mathrm{TiO}_{2} \mathrm{NTs}\right)^{139}$ (Fig. 11d and e). A smooth texture provides a better channel for the transport of electrons with minimal scattering. Similar results have been reported by $\mathrm{Li}$ et al. ${ }^{145}$ who showed that the morphology, anodization potential and time were interlinked with the efficiency of $\mathrm{H}_{2}$ production.

An annealing temperature of about $350{ }^{\circ} \mathrm{C}$ has been found to be optimum for $\mathrm{TiO}_{2} \mathrm{NTs}^{146}$ At higher annealing temperatures, the barrier thickness of the NT arrays and Ti substrate becomes thicker, which inhibits the transfer of charge to the Ti substrate. Fig. 12 shows the generation of $\mathrm{H}_{2}$ with respect to temperature and cycle times. W-doped $\left(\mathrm{W}^{6+}\right.$ state) $\mathrm{TiO}_{2} \mathrm{NTs}$ were investigated under a glycerol/fluoride electrolyte and the production of $\mathrm{H}_{2}$ was about $24.97 \mu \mathrm{mol} \mathrm{h}^{-1}$, depending on the $\mathrm{W}$ loading and annealing temperature. ${ }^{147}$ The effect of the processing parameters was extended to $\mathrm{Ta}_{2} \mathrm{O}_{5}$ NTs by Gonçalves et al. ${ }^{148}$ who suggested that the anodization potential, electrolyte temperature (diameter, length of NTs) and annealing temperature influence the generation of $\mathrm{H}_{2}$ with ethanol as an SR. Fig. 13 shows the current densities at different electrolyte temperatures, from which the variation in length and diameter of the tubes can be seen. Gonçalves et al. ${ }^{148}$ observed that $\mathrm{CO}, \mathrm{CO}_{2}, \mathrm{CH}_{4}, \mathrm{C}_{2} \mathrm{H}_{4}$ and $\mathrm{C}_{2} \mathrm{H}_{6}$ gases were produced during ethanol photo-reformation. The amount of gas generated increased with increasing annealing temperature. ${ }^{148}$ Single crystalline NT arrays of $\mathrm{SrNb}_{2} \mathrm{O}_{6}$ with rhombic cross-sections showed superior $\mathrm{H}_{2}$ evolution compared with their bulk counterparts as a result of the smaller diffusion length of the charge carriers, in addition to the high SA. ${ }^{46}$ This was further enhanced (to $102 \mu \mathrm{mol} \mathrm{g}^{-1}$ ) by introducing $\mathrm{NiO}_{x}$ and Pt by impregnation and photodeposition methods, respectively.

$\mathrm{H}_{2}$ production efficiencies can be enhanced by carbon-rich catalysts such as graphene, multiwalled carbon NTs (MWCNTs),
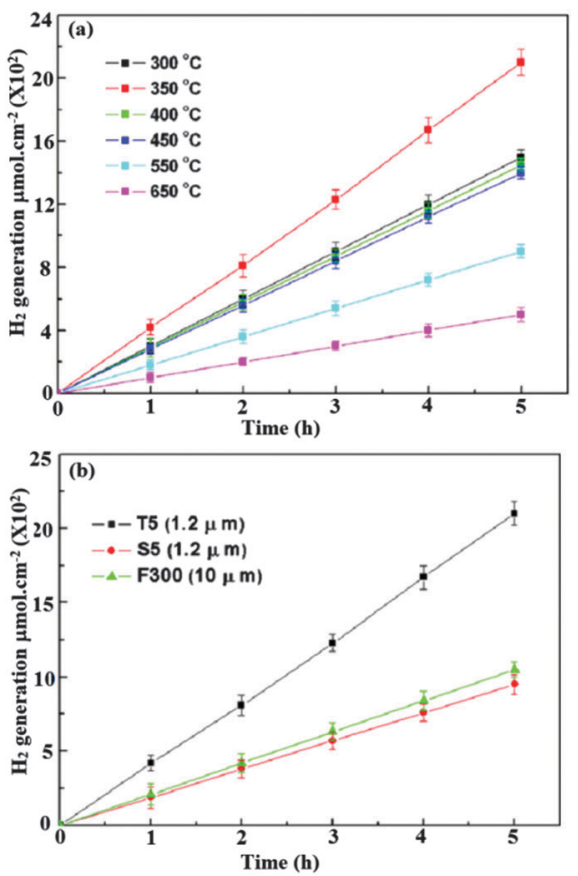

Fig. 12 Amount of $\mathrm{H}_{2}$ generated from catalysts produced (a) at different annealing temperatures and (b) by highly ordered $\mathrm{TiO}_{2} \mathrm{NTs}$ in the first (F300), second (S5) and third (T5) anodization. Reproduced with the copyright permission from ref. 146
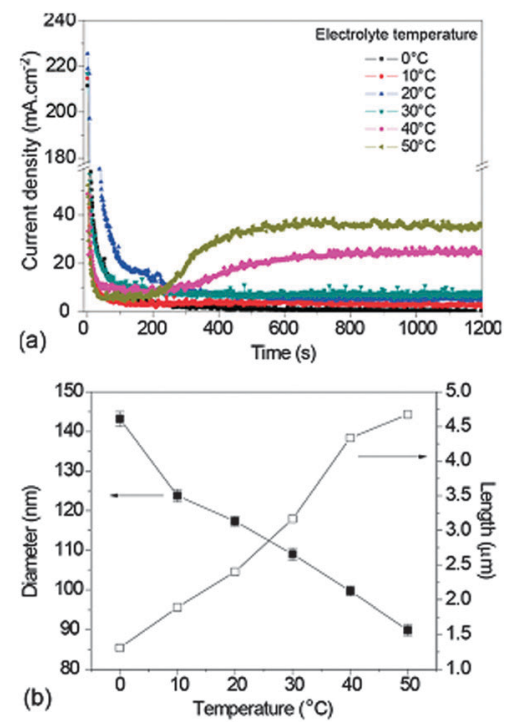

Fig. 13 (a) Current density curves for anodization of Ta discs at $50 \mathrm{~V}$ at different electrolyte temperatures and (b) effect of electrolyte temperature on the outer diameter and length of the NTs. Figure is reproduced with copyright permission from ref. 148.

carbon fibres and activated carbon. Cargnello et al. ${ }^{149}$ enhanced the generation of $\mathrm{H}_{2}$ from MWCNTs@M/TiO ${ }_{2}$ to about $10 \mathrm{mmol} \mathrm{h}^{-1} \mathrm{~g}^{-1}$ in the presence of methanol as a SR, where $\mathrm{M}=\mathrm{Pt}$ or Pd. It was also suggested that the nanocomposite with Pt was slightly more active than that with Pd. This is a result of the various positive effects from the MWCNTs, Pt and the metal 


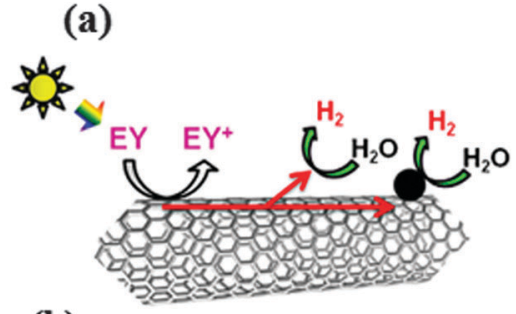

(b)

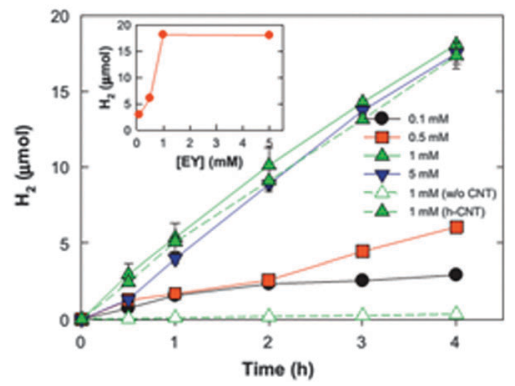

Fig. 14 (a) Schematic illustration of an Eosin Y (EY) sensitized CNT catalyst. (b) $\mathrm{H}_{2}$ production as a function of $\mathrm{EY}$ concentration. This figure is reproduced with copyright permission from ref. 68 .

oxide. Primarily, MWCNTs delocalize the photogenerated electrons, thus enhancing the lifetime of the charge carriers, which eventually increases the evolution of $\mathrm{H}_{2} \cdot{ }^{150}$

In a typical investigation, ${ }^{68}$ Eosin $\mathrm{Y}(\mathrm{EY})$ and triethanolamine (TEOA) were used as a sensitizer and electron donor, respectively, and the MWCNTs showed a nearly nine-fold enhancement in performance compared with other carbon-rich catalysts under simulated sunlight. Fig. 14a is a schematic representation of an EY-loaded MWCNT on which noble metal NPs can also be used. Fig. 14b shows the evolution of $\mathrm{H}_{2}$ against EY concentration.

\subsection{Nanorods}

Arrays of NRs have similar effects to NWs, such as a high $\mathrm{SA}^{111,114}$ promoting surface reactions rather than recombination $^{151}$ and short collection lengths for excited carriers in a direction normal to light absorption. Rutile $\mathrm{TiO}_{2}$ NRs have shown efficient $\mathrm{H}_{2}$ generation in aqueous solutions containing methanol-water SRs in the presence of $\mathrm{Cu}^{2+}$ under UV light irradiation. ${ }^{152}$ In addition, the design of a radial $\mathrm{p}-\mathrm{n}$ junction NR device could provide large improvements in efficiency relative to a conventional planar geometry. ${ }^{153}$

$\mathrm{SrSnO}_{3} \mathrm{NR}$ structures were synthesized via a hydrothermal method and showed a better $\mathrm{H}_{2}$ production rate than dumbbell like structures (Fig. 15a). Fig. 15b shows the UV-visible diffuse reflectance spectra of these NRs and dumb-bells together with a band level diagram for $\mathrm{SrSnO}_{3}{ }^{154}$

Sun et al. ${ }^{155}$ used Sb-doped $\mathrm{SnO}_{2}$ NRs as a transparent electrode in the presence of $\mathrm{H}_{2} \mathrm{O}_{2} \mathrm{SR}$, which improved the conductivity of the scaffold. The improvement in PEC performance is a result of enhanced charge separation efficiency and charge injection efficiency. Controlled incorporation of Sn-doped $\mathrm{TiO}_{2}$ NRs achieved a good PEC performance. ${ }^{156}$ Wang et al. ${ }^{143}$ reported that the well dispersed CdZnS single crystalline
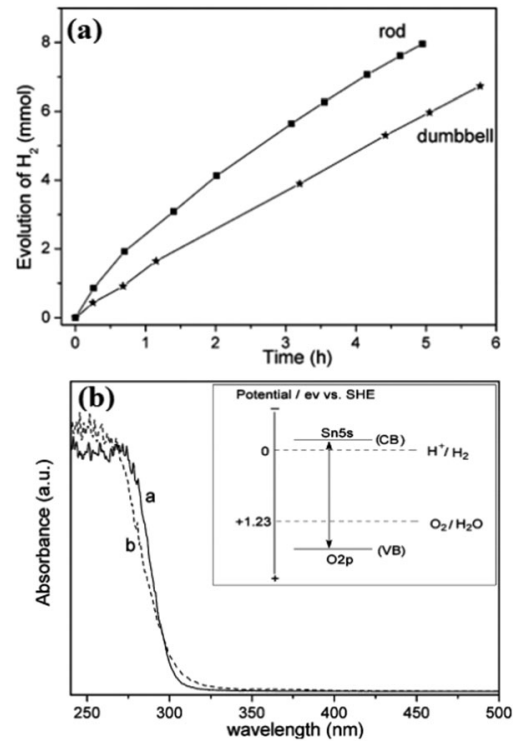

Fig. 15 (a) Evolution of $\mathrm{H}_{2}$ from $\mathrm{SrSnO}_{3} \mathrm{NRs}$ and nano dumb-bells. (b) UV-visible diffuse reflectance spectra of $\mathrm{SrSnO}_{3}$ from NRs (dotted line) and dumb-bell like (solid line) morphologies. Inset shows the band diagram of $\mathrm{SrSnO}_{3}$. Reproduced with copyright permission from ref. 154.

NRs showed higher $\mathrm{H}_{2}$ generation than CdS when the aqueous solution contained two different $\mathrm{SRs}\left(\mathrm{SO}_{3}{ }^{2-}\right.$ and $\left.\mathrm{S}^{2-}\right)$ with and without Pt under simulated solar light. This enhancement is attributed to the abundant hydrogen reactive sites on CdZnS. However, the incorporation of SRs, co-catalysts, sensitizers, electrolytes and reducing agents yielded a better performance. ${ }^{144}$ The parameters affecting the catalytic activity of SRs are not yet well understood. A higher activity is associated with the protonexchange capability of the materials. Sometimes the native material performs better in the absence of co-catalysts.

Nanostructures of $\mathrm{Zn}_{2} \mathrm{GeO}_{4}$ have been reported by a number of researchers. ${ }^{25,76,77,157,158}$ Liang et al. ${ }^{76}$ reported on hexagonal $\mathrm{Zn}_{2} \mathrm{GeO}_{4}$ NFs and NRs (Fig. 16a and b) and compared the evolution of $\mathrm{H}_{2}$ with its bulk counterpart (Fig. 16c). The results suggest that $\mathrm{Zn}_{2} \mathrm{GeO}_{4}$ NRs show better $\mathrm{H}_{2}$ evolution than the NFs and bulk particles where the NRs have predominant

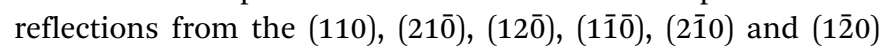
planes. Another study on $\mathrm{Zn}_{2} \mathrm{GeO}_{4}$ suggested that a rhombohedral phase crystal orientation yields better $\mathrm{H}_{2}$ evolution. ${ }^{77}$ Similar to the $\mathrm{TiO}_{2}$ nanostructures (section 4.2), the process parameters of $\mathrm{Zn}_{2} \mathrm{GeO}_{4}$ play a crucial part in determining the efficiency of catalytic $\mathrm{H}_{2}$ generation. Lin et al. ${ }^{157}$ studied the evolution of $\mathrm{H}_{2}$ in relation to the calcination temperature of $\mathrm{Zn}_{2} \mathrm{GeO}_{4}$ NRs. The results (Fig. 17) suggested that a higher calcination temperature $\left(1000{ }^{\circ} \mathrm{C}\right)$ gives a performance as high as $430 \mu \mathrm{mol} \mathrm{h}{ }^{-1} \mathrm{~g}^{-1}$, which is nearly seven times higher than that of a sample calcined at $400{ }^{\circ} \mathrm{C} .{ }^{157}$ However, the SA dropped to onefifth of that of the sample calcined at $400{ }^{\circ} \mathrm{C}$. Although the SA influences $\mathrm{H}_{2}$ production, a more crucial parameter is the quality of the crystal and its facets. ${ }^{25,77}$ Yan et al. ${ }^{25}$ reported that $\mathrm{Zn}_{2} \mathrm{GeO}_{4}$ NRs have the best performance with $3 \mathrm{wt} \%$ of $\mathrm{RuO}_{2}$. The overall water splitting performance depends on the synthesis temperature; NRs obtained at lower temperatures $\left(40{ }^{\circ} \mathrm{C}\right)$ had a dominant 

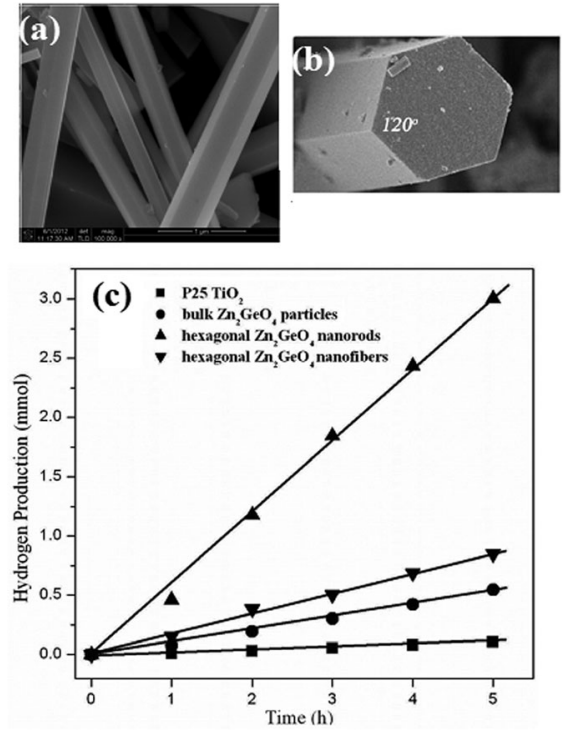

Fig. 16 FE-SEM images of (a) $\mathrm{Zn}_{2} \mathrm{GeO}_{4} \mathrm{NFs}$ and NRs samples obtained at $200{ }^{\circ} \mathrm{C}$ with $1.6 \mathrm{~g}$ of $\mathrm{NaOH}$, (b) cross-sectional view of an NF and (c) rate of evolution of $\mathrm{H}_{2}$ from an aqueous $\mathrm{MeOH}$ solution compared with various photocatalysts under UV light. Amount of catalyst, $0.1 \mathrm{~g}$; volumes of $\mathrm{H}_{2} \mathrm{O}$ and $\mathrm{CH}_{3} \mathrm{OH}, 55$ and $5 \mathrm{~mL}$, respectively. Figures are reproduced with copyright permission from ref. 76 .
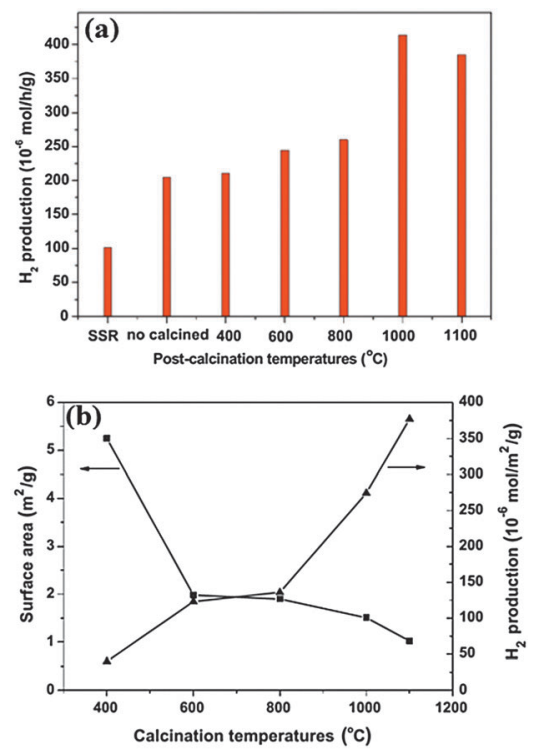

Fig. 17 (a) Evolution of $\mathrm{H}_{2}$ from $\mathrm{Zn}_{2} \mathrm{GeO}_{4}$ samples calcined at various temperatures. Conditions: photocatalyst, $0.1 \mathrm{~g}$; Pt co-catalyst, $0.1 \mathrm{wt} \%$; and aqueous $\mathrm{MeOH}$ solution (100 mL of 20 vol\%). (b) Surface area plotted against calcination temperature showing evolution of $\mathrm{H}_{2}$. Reproduced with copyright permission from ref. 157

(110) crystal face. This face may induce strong $\mathrm{CO}_{2}$ gas adsorption and hence higher $\mathrm{H}_{2}$ production. Liang et al. ${ }^{158}$ reported a method for crystal orientation and the self-assembly of $\mathrm{Zn}_{2} \mathrm{GeO}_{4} \mathrm{NRs}$.

Similar to other core-shell heterojunction catalysts, Yang et al. ${ }^{159}$ reported the fabrication of $\mathrm{In}_{2} \mathrm{O}_{3}-\mathrm{In}_{2} \mathrm{~S}_{3}$ core-shell NRs that showed a better performance than their individual NR counterparts. Fig. 18 shows the band diagram of the interface of the $\operatorname{In}_{2} \mathrm{O}_{3}$ and

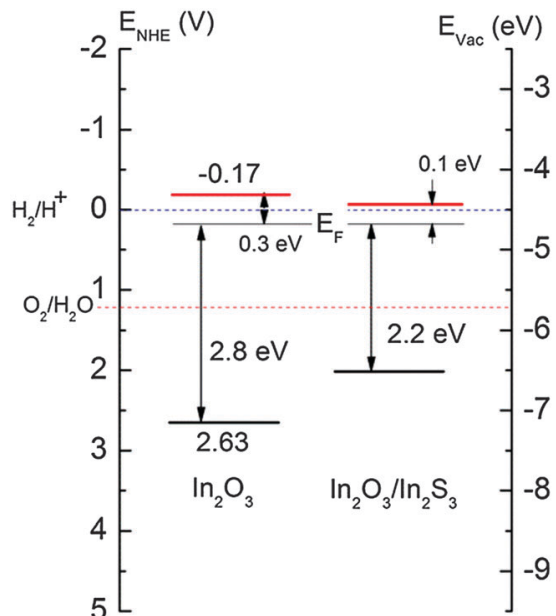

Fig. 18 Band level diagram for $\ln _{2} \mathrm{O}_{3}$ and $\ln _{2} \mathrm{~S}_{3}$ core-shell interfaces. Figure redrawn from ref. 159

$\mathrm{In}_{2} \mathrm{~S}_{3}$ shell, where the energetic alignment of the bands favours the transfer of both electrons and holes to the shell layer (type I band alignment). It is notable that, if the electrons and holes are transferred to the shell region, then the recombination is delayed, yielding $\mathrm{O}_{2}$ and $\mathrm{H}_{2}$, which may cause a back-reaction.

\subsection{Electrospun nanofibres}

Electrospinning is a versatile and convenient technology to produce 1D nanostructures, ${ }^{160-163}$ although there are other physical and chemical methods to synthesize fibres. ${ }^{164-169}$ 1D NFs are important in electronics, optoelectronics, magnetic sensors, ${ }^{170}$ photo-dye degradation, ${ }^{36,171-173}$ photocatalysis ${ }^{174}$ and in energyharvesting technologies. ${ }^{175-178}$ Functional electrospun NFs have important optical ${ }^{179-185}$ and/or electronic properties. ${ }^{186-197}$ In the context of $\mathrm{H}_{2}$ production, $\mathrm{TiO}_{2}$ electrospun NFs (Fig. 19) perform better than nanostructures produced by hydrothermal synthesis,

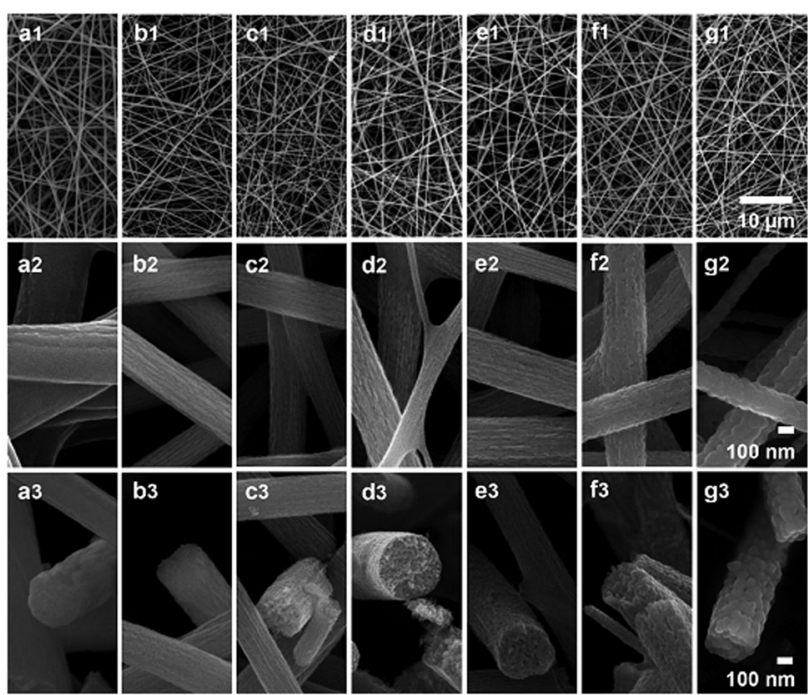

Fig. 19 SEM images of (a) as-spun $\mathrm{TiO}_{2}$ precursor NFs and NFs after calcination for $3 \mathrm{~h}$ at (b) $300{ }^{\circ} \mathrm{C}$, (c) $400{ }^{\circ} \mathrm{C}$, (d) $450{ }^{\circ} \mathrm{C}$, (e) $500{ }^{\circ} \mathrm{C}$, (f) $600{ }^{\circ} \mathrm{C}$ and (g) $700{ }^{\circ} \mathrm{C}$. Reproduced with copyright permission from ref. 117. 

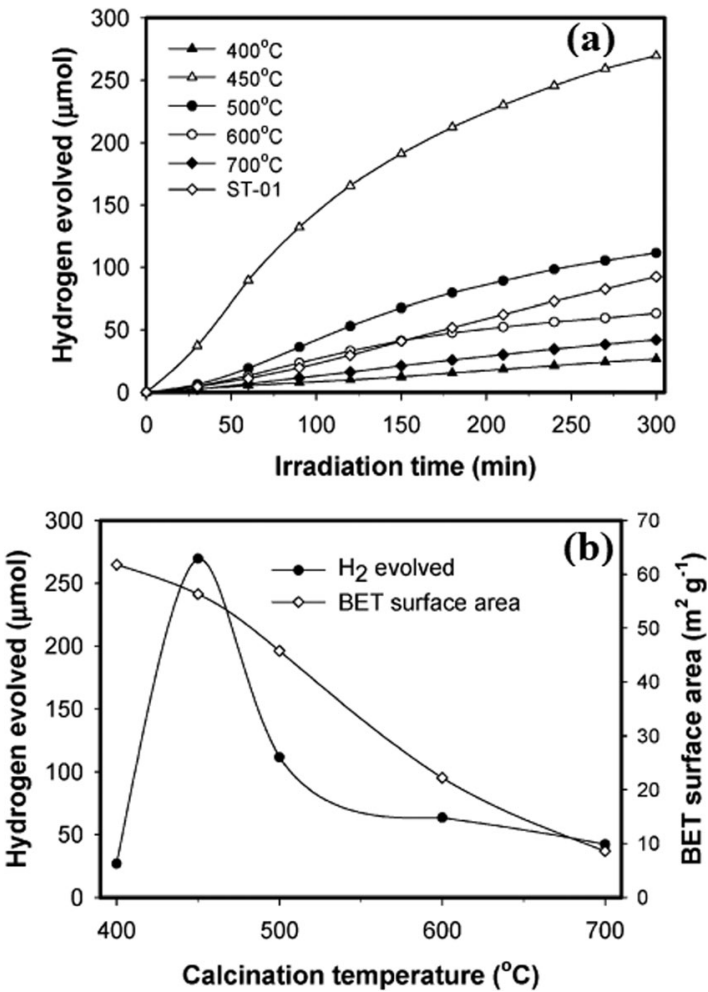

Fig. 20 (a) $\mathrm{H}_{2}$ production with $\mathrm{TiO}_{2}$ fibres calcined at various temperatures. (b) Dependence of the calcination temperature on the BET surface area. This figure is reproduced with copyright permission from ref. 117.

where process parameters such as the calcination temperature, crystallinity and SA are determining factors (Fig. 20). ${ }^{117}$

The results suggest that a calcination temperature of $450{ }^{\circ} \mathrm{C}$ is the optimum to give the highest yield. However, although calcination at $400{ }^{\circ} \mathrm{C}$ gave the highest $\mathrm{SA}$, the $\mathrm{H}_{2}$ evolution is not significant, as a result of the lowered crystallinity (Fig. 20b). Similar to NRs and NWs, noble metal NPs are used in conjunction with NFs and act as an electron skin, enhancing $\mathrm{H}_{2}$ production. Zhang et al. ${ }^{118}$ used Au and Pt NPs simultaneously in the presence of SRs ( $0.1 \mathrm{M}$ L-ascorbic acid at $\mathrm{pH} 4.0$ ). Their results suggested that the best combination is $\mathrm{Au}_{0.25} / \mathrm{Pt}_{0.25} / \mathrm{TiO}_{2} \cdot{ }^{118} \mathrm{Zhang}$ et al. ${ }^{118}$ reported that no $\mathrm{H}_{2}$ is evolved for Au NPs under surface plasmon resonance illumination (about $550 \mathrm{~nm}$ or visible light). The process of electrospinning can also be applied to mixed oxides such as $\mathrm{TiO}_{2}-\mathrm{SnO}_{2}{ }^{119}$ and the calcination temperature plays a key part in the efficiency of $\mathrm{H}_{2}$ generation (methanol is used as an SR). Another catalyst combination is $\mathrm{SrTiO}_{3}-\mathrm{TiO}_{2} \mathrm{NFs}$, for which the efficiency is better than the individual counterparts when a watermethanol mixture is used as a SR under UV irradiation. ${ }^{198}$ Similar to the earlier examples, the $\mathrm{H}_{2}$ yield is dependent on the calcination temperature and the SA. ${ }^{120}$ These composite fibres contrast with core-shell structures where the combination of materials can be selected so that electrons are transferred to the shell region and holes are transferred to the core region. However, in composite structures, the recombination of photogenerated electrons and holes is delayed during the transfer while both stay within the structure. The long NF structure and larger specific SA are advantageous for catalytic activity. ${ }^{121}$ Our group has reported the development of $\mathrm{MWCNT}-\mathrm{TiO}_{2} \mathrm{NFs}$ and their $\mathrm{H}_{2}$ generation capability. ${ }^{44}$

\subsection{Two-dimensional nanostructures}

2D nanostructures such as nanobelts (NBs), ${ }^{199-201}$ NSs, ${ }^{202-204}$ nanoplates ${ }^{, 05-207}$ nanolayers, ${ }^{208,209}$ nanoribbons,${ }^{115,210}$ and nanoleaves ${ }^{211}$ are also efficient for the production of $\mathrm{H}_{2}$. The transfer of charge carriers to the surface takes place in a similar manner to 1D structures and helps to enhance performance. ${ }^{201,212-216}$

Pure $\mathrm{TiO}_{2} \mathrm{NS}$ surfaces are catalytically inactive as a result of the presence of a large over-potential and fast backward reaction (generation of $\mathrm{H}_{2} \mathrm{O}$ ), whereas surface-fluorinated $\mathrm{Pt}^{-\mathrm{TiO}_{2}} \mathrm{NSs}$ have significant catalytic activity. ${ }^{217}$ However, in sharp contrast, ultrathin $\mathrm{TiO}_{2}$ NSs showed a high catalytic activity as a result of a shorter migration time, which suppressed recombination. ${ }^{218}$ Fig. 21a shows the process of producing photogenerated electrons and holes at the $\mathrm{TiO}_{2}$ surface, where Pt acts as an electron skin (Fig. 21b). However, an optimum amount of Pt should be determined because further increases in the Pt content decrease the production of $\mathrm{H}_{2}$ (Fig. 21c). $\mathrm{TiO}_{2}$ NSs showed a better performance than commercial $\mathrm{TiO}_{2}$ anatase powder, ${ }^{219}$ whereas $\mathrm{TiO}_{x}$ NSs fabricated by photodepositing the metal and metal oxide showed enhanced activity ${ }^{203}$ with slower e-h recombination in the $\mathrm{TiO}_{x}$ NSs than in the single crystalline counterparts. In single crystalline NSs, the photogenerated electrons react at the edge of the NSs while, in contrast, the holes react over all of the surface.

ZnO NB arrays have shown better activity than thin films or the rod/comb-like ZnO nanostructures under similar conditions. ${ }^{199}$ Micro- and nanocomponents of $\mathrm{ZnO}$ were combined by $\mathrm{Lu}$
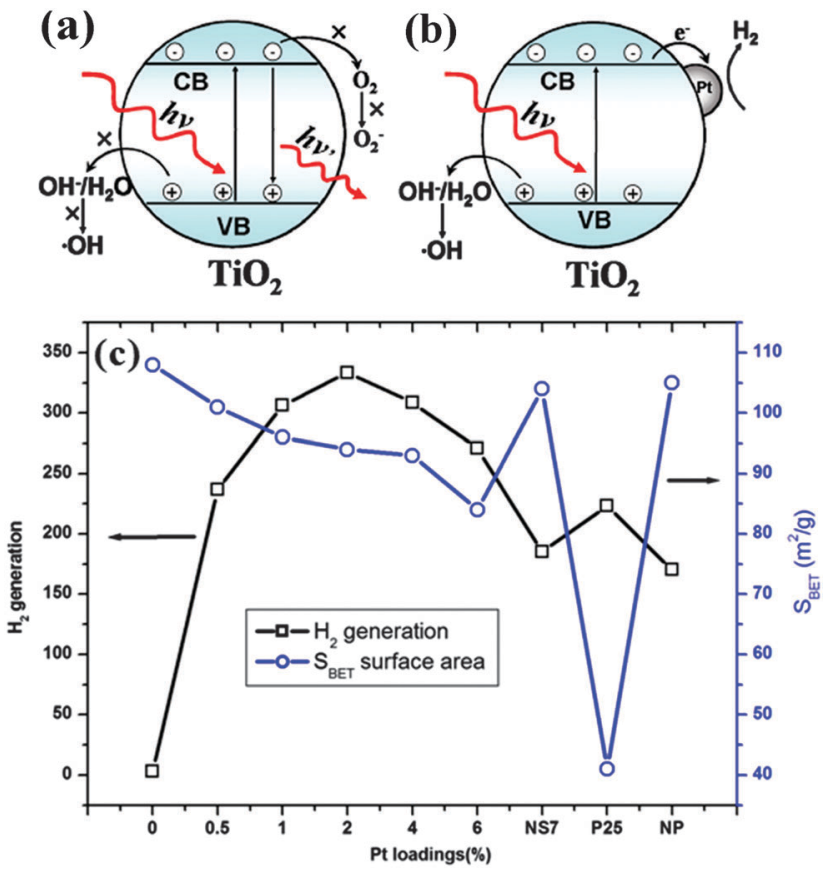

Fig. 21 Probable dynamics of photogenerated electrons and holes on the surface of $\mathrm{TiO}_{2}$ in (a) a clean anaerobic environment and (b) in the presence of $\mathrm{Pt}^{217}$ (c) $\mathrm{H}_{2}$ generation with respect to the surface area and Pt loadings in $\mathrm{TiO}_{2}$ (fluorinated). NS7 = without fluorination, P25 = Degussa and NP = NPs of $\mathrm{TiO}_{2}$. Figure is reproduced with copyright permission from ref. 217. 
et al., ${ }^{7}$ in which NS networks on hexagonal pyramid-like microcrystals were studied to determine their catalytic performance. In this complex structure, electrons were transferred from the NSs of high electrical potential to the core micro-pyramids of low electrical potential; this reduces the probability of photogenerated e-h recombination. NiO hollow microspheres showed greater catalytic activity than rods ${ }^{6}$ because the microspheres facilitated a higher density of active sites and a better surface charge carrier transfer rate.

Semiconducting niobate NSs were integrated ${ }^{220,221}$ into twocomponent nanostructure systems with separate sites for water reduction and oxidation. Although $\mathrm{WO}_{3}$ is inactive for $\mathrm{H}_{2}$ evolution, its derivative $\mathrm{Na}_{2} \mathrm{~W}_{4} \mathrm{O}_{13}$ is active for overall water splitting from aqueous solutions containing SRs where the later have a layered structure (see ref. 247 cited in Chen et al. ${ }^{222}$ ). $\mathrm{Bi}_{2} \mathrm{WO}_{6}$ nanoplates were reported by Zhang and Zhu. ${ }^{206}$ Kale et al. ${ }^{8}$ reported that $\mathrm{CdIn}_{2} \mathrm{~S}_{4}$ nanostructures with a marigold-like morphology composed of numerous nanosized petals displayed significant $\mathrm{H}_{2}$ production from $\mathrm{H}_{2} \mathrm{~S}$ in $\mathrm{KOH}$ aqueous solution.

A special class of 2D NSs self-assembled into a 3D architecture is another important research area in photocatalysis. ${ }^{6-11}$ Layered titanates have been introduced for $\mathrm{H}_{2}$ production as a result of their proton-exchange capability in the absence of co-catalysts. ${ }^{223,224}$ Sodium trititanate $\left(\mathrm{Na}_{2} \mathrm{Ti}_{3-x} \mathrm{M}_{x} \mathrm{O}_{7}\right)$, potassium tetratitanate $\left(\mathrm{K}_{2} \mathrm{Ti}_{4-x} \mathrm{M}_{x} \mathrm{O}_{9}\right)$ (where $\mathrm{M}=\mathrm{Mn}, \mathrm{Fe}, \mathrm{Co}, \mathrm{Ni}, \mathrm{Cu}$ and $x$ varies from 0.15 to 0.30 ) and their substituted samples with $\mathrm{SiO}_{2}$-pillared structures at the interlayer showed high activities. ${ }^{223}$ Fig. 22 shows the effect of the BET SA of the unsubstituted triand tetratitanates with respect to $\mathrm{H}_{2}$ generation. Layered double hydroxides have the general formula $\left[\mathrm{M}^{\mathrm{II}}{ }_{(1-x)}-\mathrm{M}^{\mathrm{III}}{ }_{x}(\mathrm{OH})_{2}\right] \mathrm{A}_{x / n}^{n-} \cdot m \mathrm{H}_{2} \mathrm{O}$, where $\mathrm{M}^{\mathrm{II}}$ is a divalent metal cation (e.g. $\mathrm{Mg}^{2+}, \mathrm{Co}^{2+}, \mathrm{Ni}^{2+}{\mathrm{Or} \mathrm{Zn}^{2+}}^{2+}$, $\mathrm{M}^{\mathrm{III}}$ is a trivalent metal cation $\left(\right.$ e.g. $\mathrm{Al}^{3+}, \mathrm{Cr}^{3+}, \mathrm{Ga}^{3+}$ or $\mathrm{Fe}^{3+}$ ) and $\mathrm{A}^{-}$can be an organic and/or inorganic anion (see references cited in Parida et al. ${ }^{209}$ ). These layered hydroxides can be doped with a cation at the octahedral sites, which yields properties similar to doped semiconductors. $\mathrm{Mg} / \mathrm{Al}$ layered double hydroxides with incorporated $\mathrm{Fe}^{3+}$ showed significant $\mathrm{H}_{2}$ production. ${ }^{209}$ Compton et al. ${ }^{220,221}$ reported calcium niobate $\left(\mathrm{HCa}_{2} \mathrm{Nb}_{3} \mathrm{O}_{10}\right)$ NSs with Pt for photochemical generation of $\mathrm{H}_{2}$. Ferroelectric materials, such as the stibiotantalites, $\mathrm{SbMO}_{4}(\mathrm{M}=\mathrm{Nb}$, Ta) were investigated for $\mathrm{H}_{2}$ production in the form of NPs. ${ }^{208}$ The evolution rate of $\mathrm{H}_{2}$ from $\mathrm{SbTaO}_{4}(3.72 \mathrm{eV})$ was approximately twice as high as that of $\mathrm{SbNbO}_{4}(3.12 \mathrm{eV})$ and was further enhanced after the incorporation of a $\mathrm{RuO}_{2}$ co-catalyst. The differences in activity are attributed to the higher $\mathrm{CB}$ edge of $\mathrm{SbTaO}_{4}$ (Ta 5d orbitals in $\mathrm{TaO}_{6}$ octahedral configuration) and the high dielectric constant, which enhances the photogenerated charge separation.

Polyoxometalates, such as $\mathrm{Bi}_{2} \mathrm{~W}_{2} \mathrm{O}_{9}, \mathrm{BaBi}_{4} \mathrm{Ti}_{4} \mathrm{O}_{15}$ and $\mathrm{Bi}_{3} \mathrm{TiNbO}_{9}$ layered structures, are highlighted for $\mathrm{H}_{2}$ evolution in the presence of SRs in a review article by Yamase. ${ }^{225}$ Scheelite-structured $\mathrm{PbMoO}_{4}$ shows activities for $\mathrm{H}_{2}$ and $\mathrm{O}_{2}$ evolution in the presence of SRs under UV irradiation. The substituted compounds $\mathrm{Na}_{0.5} \mathrm{Bi}_{0.5} \mathrm{MoO}_{4}, \mathrm{Ag}_{0.5} \mathrm{Bi}_{0.5} \mathrm{MoO}_{4}, \mathrm{Na}_{0.5} \mathrm{Bi}_{0.5} \mathrm{WO}_{4}$ and $\mathrm{Ag}_{0.5} \mathrm{Bi}_{0.5} \mathrm{WO}_{4}$ are also active for $\mathrm{O}_{2}$ evolution; ${ }^{222}$ however, molybdates and tungstates only respond to $\mathrm{UV}$. $\mathrm{Pb}, \mathrm{Bi}$ and $\mathrm{Ag}$ play important
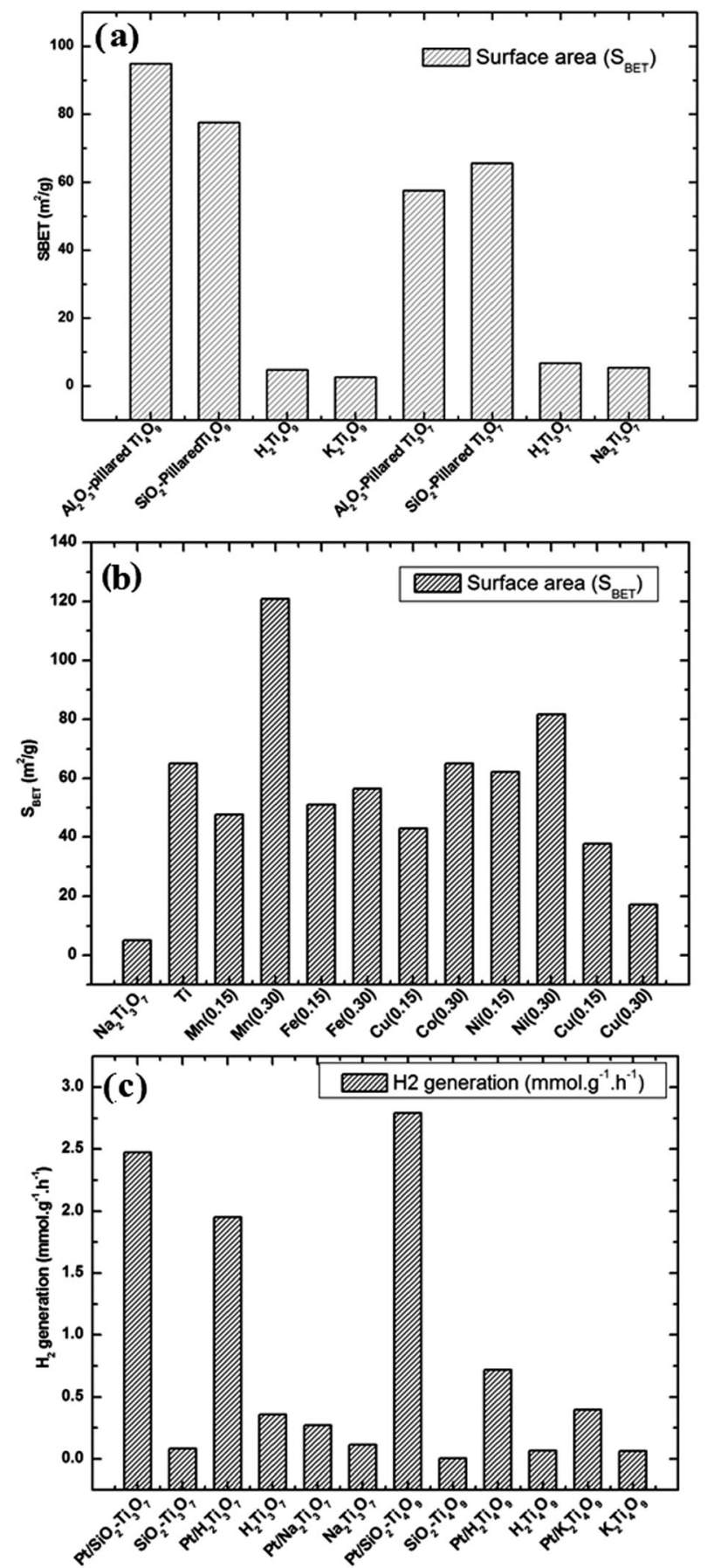

Fig. 22 Properties of different semiconductors: (a, b) BET surface area and (c) $\mathrm{H}_{2}$ production. The figure is redrawn based on the results from ref. 223.

parts in the structure of the VB. Solid solutions of $b-\mathrm{Ga}_{2} \mathrm{O}_{3}$ and $\mathrm{In}_{2} \mathrm{O}_{3}$ consisting of $\mathrm{d}^{10}$ cations have been systematically studied for $\mathrm{H}_{2}$ or $\mathrm{O}_{2}$ evolution from aqueous solutions in the presence of SRs. In these catalysts, the band gap and luminescent energy decrease as the ratio of indium increases. ${ }^{22}$

Sabio et al. $^{226}$ reported that hydroxide-supported calcium niobium $\left(\mathrm{HCa}_{2} \mathrm{Nb}_{3} \mathrm{O}_{10}\right) \mathrm{NSs}$ had a superior $\mathrm{H}_{2}$ production rate under UV irradiation in the presence of SR or co-catalysts. NSs produced $\mathrm{H}_{2}$ at a high rate compared with their bulk 
Table 2 UV-active nanocatalysts for water splitting

\begin{tabular}{|c|c|c|c|c|c|c|}
\hline Catalyst & $\begin{array}{l}\text { SA } \\
\left(\mathrm{m}^{2} \mathrm{~g}^{-1}\right)\end{array}$ & $E_{\mathrm{g}}(\mathrm{eV})$ & Co-catalyst/SR & $\begin{array}{l}\text { Light source } \\
\text { (UV-visible) }\end{array}$ & $\begin{array}{l}\text { Catalytic activity } \\
\mathrm{H}_{2}\left(\mu \mathrm{mol} \mathrm{h}^{-1}\right)\end{array}$ & Ref. \\
\hline \multicolumn{7}{|l|}{ Nanowires } \\
\hline $\mathrm{LiNbO}_{3}$ & 28 & & $\mathrm{RuO}_{2}$ & $300 \mathrm{~W}$ Xe & 275 & 26 \\
\hline $\mathrm{LiNbO}_{3}$ & 28 & & $\mathrm{RuO}_{2}$ & $400 \mathrm{~W} \mathrm{Hg}$ & 47 & 26 \\
\hline $\mathrm{Si} / \mathrm{Cu}_{2} \mathrm{O}$ & & & $\mathrm{Pt} / \mathrm{Na}_{2} \mathrm{SO}_{3}-\mathrm{Na}_{2} \mathrm{~S}$ & $300 \mathrm{~W}$ Xe & 95 & 59 \\
\hline $\mathrm{ZnO} / \mathrm{Zn}_{x} \mathrm{Cd}_{1-x} \mathrm{Te}$ & & 1.48 & $\mathrm{Na}_{2} \mathrm{SO}_{3}-\mathrm{Na}_{2} \mathrm{~S}$ & $300 \mathrm{~W}$ Xe & 265 & 35 \\
\hline CdSe/CdS N-doped $\mathrm{TiO}_{2}$ & & & Pt & $520 \mathrm{~nm}$ LED & 434.29 & 126 \\
\hline \multirow[t]{2}{*}{$\mathrm{N}$-doped $\mathrm{TiO}_{2}$} & & & $\mathrm{Pt} / \mathrm{EtOH}-\mathrm{H}_{2} \mathrm{O}$ & 3.15 W UVA & 700 & 127 \\
\hline & & & & $3.0 \mathrm{~W}$ UVB & 2250 & 127 \\
\hline \multicolumn{7}{|l|}{ Nanotubes } \\
\hline $\mathrm{TiO}_{2}$ & & & $\mathrm{Pt} / \mathrm{Ag}$ & $365 \mathrm{~nm}, 50 \mathrm{~mW} \mathrm{~cm}{ }^{-2}$ & 10.69 & 139 \\
\hline $\mathrm{TiO}_{2}$ & & & $\mathrm{Pt} / \mathrm{EG}\left(\mathrm{NH}_{4} \mathrm{~F}-\mathrm{H}_{2} \mathrm{O}\right)$ & $300 \mathrm{~W}$ Xe & 420 & 146 \\
\hline $\mathrm{Ti}-\mathrm{Fe}-\mathrm{O}$ & & & $\mathrm{Pt} / \mathrm{KOH}$ & $300 \mathrm{~W}$ Xe & $7.1 \mathrm{~mL} \mathrm{~W}^{-1} \mathrm{~h}^{-1}$ & 128 \\
\hline Titania & & & $\mathrm{Pt}$ & $50 \mathrm{~W}$ metal hydride & $960 \mu \mathrm{mol} \mathrm{h}{ }^{-1} \mathrm{~W}^{-1}$ & 129 \\
\hline $\mathrm{NiO}_{x} \mathrm{SrNb}_{2} \mathrm{O}_{6}$ & 8.1 & & Pt & $450 \mathrm{~W} \mathrm{Hg}$ & 102 & 46 \\
\hline $\mathrm{TiO}_{2}$ & & & $\mathrm{Pt} / \mathrm{EtOH}-\mathrm{H}_{2} \mathrm{O}$ & $150 \mathrm{~W} \mathrm{Xe-Hg}$ & 0.98 & 144 \\
\hline $\mathrm{TiO}_{2}$ & & & Pt/glycol and $\mathrm{NH}_{4} \mathrm{~F}$ & $300 \mathrm{~W}$ Xe & $0.57 \mathrm{~mL} \mathrm{~h}^{-1} \mathrm{~cm}^{2}$ & 145 \\
\hline $\mathrm{W}-\mathrm{TiO}_{2}$ & & & $\mathrm{Na}_{2} \mathrm{~S}+\mathrm{Na}_{2} \mathrm{SO}_{3}$ & $300 \mathrm{~W}$ Xe & 24.97 & 147 \\
\hline $\mathrm{Ta}_{2} \mathrm{O}_{5}$ & 16.2 & & EtOH- $\mathrm{H}_{2} \mathrm{O}$ & $240 \mathrm{~W} \mathrm{Hg}-\mathrm{Xe}$ & 2600 & 148 \\
\hline $\mathrm{TiO}_{2}$ & & & $\mathrm{NH}_{4} \mathrm{~F} / \mathrm{EG}(\mathrm{ETG}) / \mathrm{Au}$ & $150 \mathrm{~W} \mathrm{Hg}-\mathrm{Xe}$ & $0.65 \mu \mathrm{mol} \mathrm{cm}^{-2} \mathrm{~h}^{-1}$ & 136 \\
\hline CNT & 194 & & Eosin Y (EY)-TEOA & $\begin{array}{l}\text { Solar simulator } \\
\left(100 \mathrm{~mW} \mathrm{~cm}^{-2}\right)\end{array}$ & 18 & 68 \\
\hline $\mathrm{Pd} / \mathrm{TiO}_{2}$ & & & $\mathrm{Na}_{2} \mathrm{CO}_{3}$ and $\mathrm{EG}$ & $300 \mathrm{~W}$ Xe & $592 \mu \mathrm{mol} \mathrm{h}{ }^{-1} \mathrm{~cm}^{-2}$ & 140 \\
\hline \multicolumn{7}{|l|}{ Nanorods } \\
\hline $\mathrm{SrSnO}_{3}$ & 0.5 & 4.1 & $\mathrm{Pt} / \mathrm{AgNO}_{3}$ & $200 \mathrm{~W} \mathrm{Hg}-\mathrm{Xe}$ & 8200 & 154 \\
\hline \multirow{2}{*}{$\left(\mathrm{Cd}_{0.8} \mathrm{Zn}_{0.2}\right) \mathrm{S}$} & 72 & 2.4 & $\mathrm{SO}_{3}^{2-}\left(\mathrm{Na}_{2} \mathrm{SO}_{3}\right)$ & $300 \mathrm{~W}$ Xe & 1710 & 143 \\
\hline & & & $\mathrm{S}^{2-}\left(\mathrm{Ns}_{2} \mathrm{~S}\right)$ & $300 \mathrm{~W} \mathrm{Xe}$ & 3020 & 143 \\
\hline \multirow[t]{5}{*}{$\mathrm{Zn}_{2} \mathrm{GeO}_{4}$} & & & $\mathrm{MeOH}$ & $125 \mathrm{~W} \mathrm{Hg}$ & 6240 & 77 \\
\hline & 33.2 & 4.67 & $\mathrm{Na}_{2} \mathrm{SO}_{4}$ & $125 \mathrm{~W} \mathrm{Hg}$ & 6000 & 76 \\
\hline & & & $\mathrm{MeOH}$ & $150 \mathrm{~W} \mathrm{Hg}$ & 430 & 157 \\
\hline & 36 & 4.67 & $\mathrm{MeOH}-\mathrm{H}_{2} \mathrm{O}$ & $300 \mathrm{~W}$ Xe & 4900 & 158 \\
\hline & 33.1 & & $\mathrm{RuO}_{2}$ & 300W Xe & 17.4 & 25 \\
\hline $\operatorname{In}_{2} \mathrm{O}_{3}-\operatorname{In}_{2} \mathrm{~S}_{3}$ & & & $\mathrm{MeOH}-\mathrm{H}_{2} \mathrm{O}$ & $300 \mathrm{~W}$ Xe & 61.4 & 159 \\
\hline $\mathrm{TiO}_{2}$ & 64.19 & & $\mathrm{MeOH}-\mathrm{H}_{2} \mathrm{O} / \mathrm{Cu}^{2+}$ & $400 \mathrm{~W} \mathrm{Hg}$ & 3000 & 152 \\
\hline \multicolumn{7}{|l|}{ Nanofibres } \\
\hline $\mathrm{TiO}_{2}$ & 56.3 & & $\mathrm{MeOH}$ & $450 \mathrm{~W} \mathrm{Hg}$ & 54 & 117 \\
\hline $\mathrm{SrTiO}_{3}$ & 31.3 & & $\mathrm{MeOH}$ & $450 \mathrm{~W} \mathrm{Hg}$ & 167 & 120 \\
\hline $\mathrm{SrTiO}_{3} / \mathrm{TiO}_{2}$ & 98.26 & & $\mathrm{MeOH}-\mathrm{H}_{2} \mathrm{O}$ & $400 \mathrm{~W} \mathrm{Hg}$ & About 1100 & 198 \\
\hline $\mathrm{Au} / \mathrm{Pt} / \mathrm{TiO}_{2}$ & & 3.2 & L-Ascorbic acid & $300 \mathrm{~W}$ Xe & 11.66 & 118 \\
\hline $\mathrm{TiO}_{2} / \mathrm{SrTiO}_{3}$ & 98.26 & & $\mathrm{MeOH}-\mathrm{H}_{2} \mathrm{O}$ & $400 \mathrm{~W} \mathrm{Hg}$ & 1100 & 121 \\
\hline $\mathrm{TiO}_{2}$ & 47.45 & & & $400 \mathrm{~W} \mathrm{Hg}$ (UV) & 90 & 121 \\
\hline $\mathrm{TiO}_{2}\left(500{ }^{\circ} \mathrm{C}\right)$ & 96.3 & & & Visible & 206 & 85 \\
\hline $\mathrm{TiO}_{2}\left(500{ }^{\circ} \mathrm{C}\right)$ & 58.2 & & & $450 \mathrm{~W} \mathrm{Hg}$ & 19.1 & 93 \\
\hline $\mathrm{TiO}_{2} / \mathrm{Pt}\left(500{ }^{\circ} \mathrm{C}\right)$ & 96.3 & & & $>420 \mathrm{~nm}$ (visible) & 7110 & 85 \\
\hline $\mathrm{TiO}_{2} / \mathrm{CuO}\left(450{ }^{\circ} \mathrm{C}\right)$ & 108.1 & & & $400 \mathrm{~W} \mathrm{Hg}(\mathrm{UV})$ & 62.7 & 228 \\
\hline $\mathrm{TiO}_{2} / \mathrm{SnO}_{2}\left(450{ }^{\circ} \mathrm{C}\right)$ & 73.1 & & $\mathrm{MeOH}-\mathrm{H}_{2} \mathrm{O}$ & $400 \mathrm{~W} \mathrm{Hg}$ (UV) & 200 & 119 \\
\hline $\mathrm{TiO}_{2} / \mathrm{MWCNT}$ & 600 & & $\mathrm{Pt} /$ parylene & $150 \mathrm{~W}$ Xe & 691 & 44 \\
\hline \multicolumn{7}{|l|}{ Nanolayers } \\
\hline $\mathrm{SbNbO}_{4}$ & 1.66 & 4.1 & $\mathrm{RuO}_{2}$ & $450 \mathrm{~W} \mathrm{Hg}$ & 24 & 208 \\
\hline $\mathrm{SbTaO}_{4}$ & 1.53 & 3.9 & $\mathrm{RuO}_{2}$ & $450 \mathrm{~W} \mathrm{Hg}$ & 58 & 208 \\
\hline $\mathrm{Fe}^{3+}-\mathrm{Mg} / \mathrm{Al}$ & 62 & & $\mathrm{MeOH}$ & $125 \mathrm{~W} \mathrm{Hg}$ & 301 & 209 \\
\hline \multicolumn{7}{|l|}{ Nanoribbons } \\
\hline CdSe & & & $\mathrm{Na}_{2} \mathrm{SO}_{3}-\mathrm{Na}_{2} \mathrm{~S}$ & $175 \mathrm{~W} \mathrm{Hg}$ & 106.79 & 115 \\
\hline \multicolumn{7}{|l|}{ Nanoleaves } \\
\hline $\mathrm{Na}_{2} \mathrm{Ti}_{4} \mathrm{O}_{9}$ & & 4.11 & $\mathrm{MeOH}-\mathrm{H}_{2} \mathrm{O}$ & $350 \mathrm{~W} \mathrm{Hg}$ & 5.72 & 211 \\
\hline \multicolumn{7}{|l|}{ Nanosheets } \\
\hline $\mathrm{Pt} / \mathrm{TiO}_{2}$ & 94 & & EtOH & $350 \mathrm{~W}$ Xe & 333.5 & 217 \\
\hline \multicolumn{7}{|l|}{ Nanosheets } \\
\hline $\mathrm{HCa}_{2} \mathrm{Nb}_{3} \mathrm{O}_{10}$ & & 3.53 & $\mathrm{Pt}$ & $175 \mathrm{~W} \mathrm{Hg}$ & $78.37 \mu \mathrm{mol}$ & 220 \\
\hline $\mathrm{HCa}_{2} \mathrm{Nb}_{3} \mathrm{O}_{10}$ & & 3.53 & $\mathrm{Pt}$ & $175 \mathrm{~W} \mathrm{Hg}$ & 49.15 & 221 \\
\hline Tetrabutyl ammonium- & & & $\mathrm{Pt} / \mathrm{MeOH}-\mathrm{AgNO}_{3}$ & $350 \mathrm{~W}$ Xe & 3231.40 & 226 \\
\hline
\end{tabular}


Table 2 (continued)

\begin{tabular}{|c|c|c|c|c|c|c|}
\hline Catalyst & $\begin{array}{l}\text { SA } \\
\left(\mathrm{m}^{2} \mathrm{~g}^{-1}\right)\end{array}$ & $E_{\mathrm{g}}(\mathrm{eV})$ & Co-catalyst/SR & $\begin{array}{l}\text { Light source } \\
\text { (UV-visible) }\end{array}$ & $\begin{array}{l}\text { Catalytic activity } \\
\mathrm{H}_{2}\left(\mu \mathrm{mol} \mathrm{h}^{-1}\right)\end{array}$ & Ref. \\
\hline $\mathrm{TiO}_{2}$ & & & $\mathrm{MeOH}-\mathrm{H}_{2} \mathrm{O}$ & $150 \mathrm{~W} \mathrm{Xe}$ & 6000 & 227 \\
\hline Flower $\mathrm{TiO}_{2}\left(500{ }^{\circ} \mathrm{C}\right)$ anatase & 31.7 & & $\mathrm{MeOH}-\mathrm{H}_{2} \mathrm{O}$ & $450 \mathrm{~W} \mathrm{Hg}$ & 117.6 & 219 \\
\hline Flower $\mathrm{TiO}_{2}\left(500{ }^{\circ} \mathrm{C}\right)$ & 31.7 & & & $450 \mathrm{~W} \mathrm{Hg}$ & 588 & \\
\hline \multicolumn{7}{|l|}{ Photonic crystals } \\
\hline $\mathrm{TiO}_{2}$ & 75.5 & & $\mathrm{CH}_{3} \mathrm{OH}$ & $500 \mathrm{~W}$ Xe lamp & $247 \mu \mathrm{mol} \mathrm{h}^{-1}$ & 41 \\
\hline $\mathrm{N}-\mathrm{TiO}_{2}$ leaf & 103.31 & & $\mathrm{Pt} /$ methanol & $400 \mathrm{~mW} \mathrm{~cm}^{-2}$ Xe lamp & $1401.70 \mu \mathrm{mol} \mathrm{h}^{-1}$ & 81 \\
\hline
\end{tabular}

counterparts. The structural conversion of $\mathrm{TiO}_{2}$ NPs to NSs showed their high catalytic activity for $\mathrm{H}_{2}$ generation and the removal of environmental pollution. ${ }^{227}$ Pt-loaded $\mathrm{TiO}_{2}$ hierarchical photonic crystals ${ }^{41}$ have shown a doubling of efficiency. The rate of hydrogen production was $247 \mu \mathrm{mol} \mathrm{h}{ }^{-1}$ and the QY was about $11.9 \%$. The experimental results showed that the stop band reflectivity was suppressed, enhancing the evolution of $\mathrm{H}_{2}$. Zhou et $a{ }^{81}$ fabricated a leaf-like structure by copying the complex architecture of leaves and replacing the natural photosynthetic pigments with catalysts to realize an efficient catalyst. The use of $20 \%$ aqueous methanol as an SR might have improved the rate of evolution of $\mathrm{H}_{2}$ (Table 2).

\section{Modified visible light active photocatalysts for hydrogen generation}

Photogenerated electrons easily recombine with holes in semiconductors. This recombination leads to the low quantum efficiency (QE) of photocatalysis. SRs can effectively restrain this recombination process and improve the QE. Several common approaches have been adopted to activate wide band gap materials to visible light for water splitting: (1) doping with metal and/or non-metal ions; (2) controlling the band structure by developing solid solutions; (3) dye sensitization; (4) band gap engineering; and (5) combining wide band gap materials with visible light active semiconductors. The visible light activity of nanostructured materials has been important in enhancing the efficiency of electron injection to the CB in photocatalysts.

\subsection{Nanowires}

The fabrication and doping of a variety of nanostructures has improved the activity of PEC water splitting. The confined dimensionality of $1 \mathrm{D}$ and $2 \mathrm{D}$ structures offers enhanced light absorption as a result of the large active SA and ultrafast charge transport behaviour. In the introduction, we outlined the thermodynamic requirement ${ }^{24}$ that must be met to avoid catalyst corrosion. However, $\mathrm{CdS}\left(E_{\mathrm{g}}=2.4 \mathrm{eV}\right)$ is very effective in splitting water under visible light irradiation ${ }^{229}$ in the presence of SRs such as $\mathrm{S}^{2-}$ and $\mathrm{SO}_{3}{ }^{2-}$. Fig. 23 shows the effect of SA and generation of $\mathrm{H}_{2}$ with respect to synthesis temperature. As the synthesis temperature increases, the evolution of $\mathrm{H}_{2}$ also increases, despite the decrease in the SA (Fig. 23a). The rate of $\mathrm{H}_{2}$ production was improved by incorporating graphitic $\left(\mathrm{g}-\mathrm{C}_{3} \mathrm{~N}_{4}\right)$ structures with $\mathrm{CdS}$ under visible light irradiation (see Table 3 ). ${ }^{230}$ In the presence of Pt and SRs, CdS showed further improvement in $\mathrm{H}_{2}$ production. ${ }^{104}$ Titanic acid NWs/EY in the presence of Pt NPs and TEOA have been shown to yield significant $\mathrm{H}_{2} \cdot{ }^{231}$ The performance of NWs was significantly improved by introducing $\mathrm{Au}$ $\mathrm{NPs} ;{ }^{137}$ it was noted that the $\mathrm{H}_{2}$ yield depends on the shape and structure of Au. Kibria et al. ${ }^{232}$ reported GaN NW photocatalysts for spontaneous water splitting to produce $\mathrm{H}_{2}$ under visible and IR light irradiation.

With respect to heterostructures, $\mathrm{CdS}-\mathrm{TiO}_{2}$ NTs were investigated for $\mathrm{H}_{2}$ production ${ }^{233}$ and the results suggested a QE of about $43.4 \%$ under visible light irradiation $(\geq 420 \mathrm{~nm})$. The high activity is a result of the quantum size effect and the potential gradient at the interface. ${ }^{234}$ Liu et al. ${ }^{234}$ combined Si (cathode) and $\mathrm{TiO}_{2}$ (anode) NWs; both the difference in the band gap of
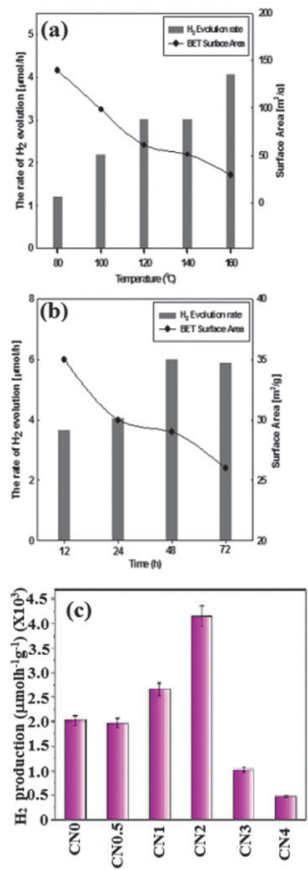

Fig. 23 (a) Rate of $\mathrm{H}_{2}$ evolution and surface area of $\mathrm{CdS}$ samples synthesized by a solvothermal reaction at different temperatures. (b) Synthesis at $160{ }^{\circ} \mathrm{C}$ for $12 \mathrm{~h}, 24 \mathrm{~h}, 48 \mathrm{~h}$ and $72 \mathrm{~h}$. Catalysis: $0.1 \mathrm{~g}$ CdS with 1 wt\% Pt; $0.1 \mathrm{M} \mathrm{Na}_{2} \mathrm{~S}+0.02 \mathrm{M} \mathrm{Na}_{2} \mathrm{SO}_{3} ; 500 \mathrm{~W} \mathrm{Hg}$ lamp with a cutoff filter $(\lambda \geq 420 \mathrm{~nm})$. Reproduced with copyright permission from ref. 229 . (c) $\mathrm{H}_{2}$ production from $\mathrm{CdS} N W s(\mathrm{CNO})$ and g- $\mathrm{C}_{3} \mathrm{~N}_{4}$-coated CdS NWs (CNO.5, $\mathrm{CN1}, \mathrm{CN} 2, \mathrm{CN} 3$ and $\mathrm{CN} 4)$ from $0.35 \mathrm{M} \mathrm{Na}_{2} \mathrm{~S}+0.25 \mathrm{M} \mathrm{Na}_{2} \mathrm{SO}_{3}$ aqueous solution. Reproduced with copyright permission from ref. 230 . 
Table 3 Visible light active and/or modified nanocatalysts for water splitting

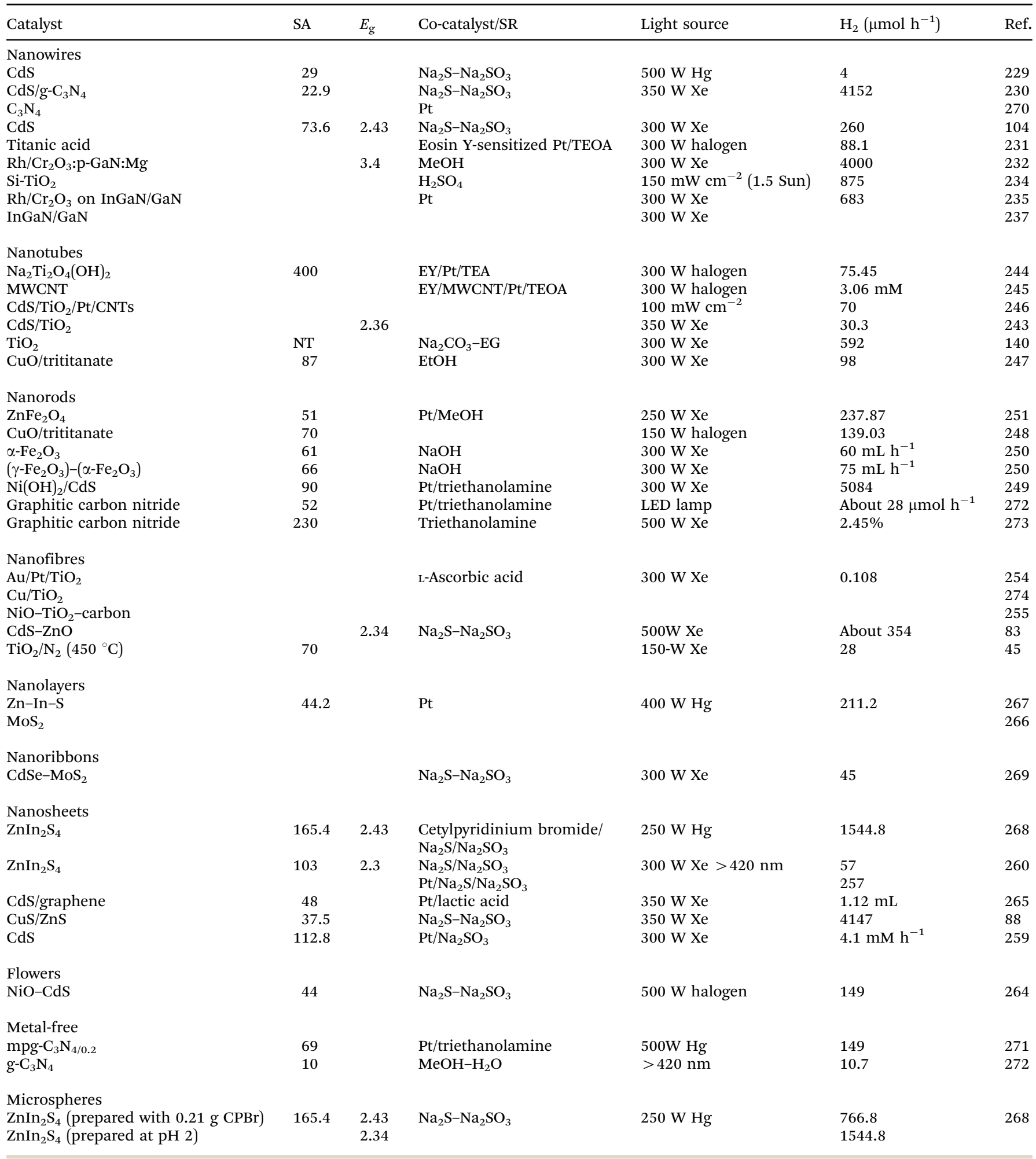

these materials and the band alignment are notable (Fig. 24). In this instance e-h pairs are generated in $\mathrm{Si}$ and $\mathrm{TiO}_{2}$ under illumination during the absorption of different wavelength regions of the solar spectrum. The band bending shown in Fig. 24d favours the transfer of electrons from $\mathrm{TiO}_{2}$ to recombine with holes in $\mathrm{Si}$. The electrons from $\mathrm{Si}$ and holes from $\mathrm{TiO}_{2}$ take part in $\mathrm{H}_{2}$ and $\mathrm{O}_{2}$ generation, respectively.

1D NWs of the multi-band gap metal nitride (InGaN-GaN) heterostructure facilitated efficient matching and use of the incident solar irradiation. ${ }^{235}$ InGaN-GaN NWs with various doping levels of In facilitated a broad range of absorption wavelengths with 


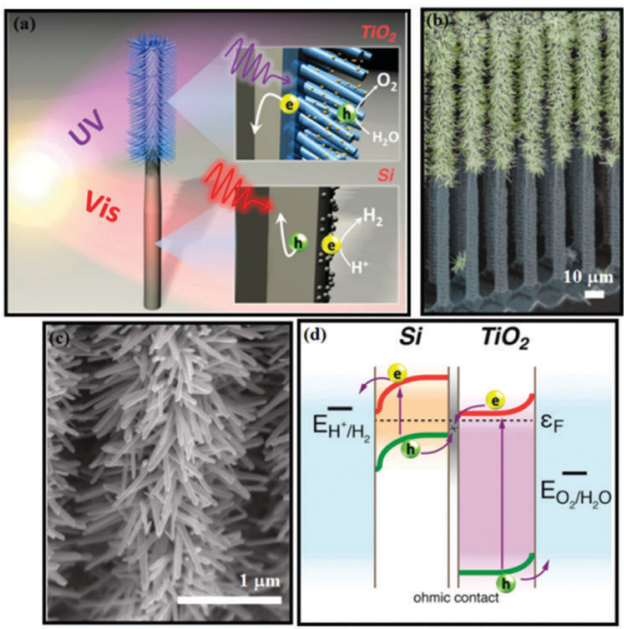

Fig. 24 (a) Schematic diagram of $\mathrm{Si} / \mathrm{TiO}_{2}$ tree-like heterostructures. (b) False-colour SEM image of an $\mathrm{Si} / \mathrm{TiO}_{2}$ nanotree. (c) Magnified SEM image and (d) band gap diagram of the two components. This figure is reproduced with copyright permission from ref. 234

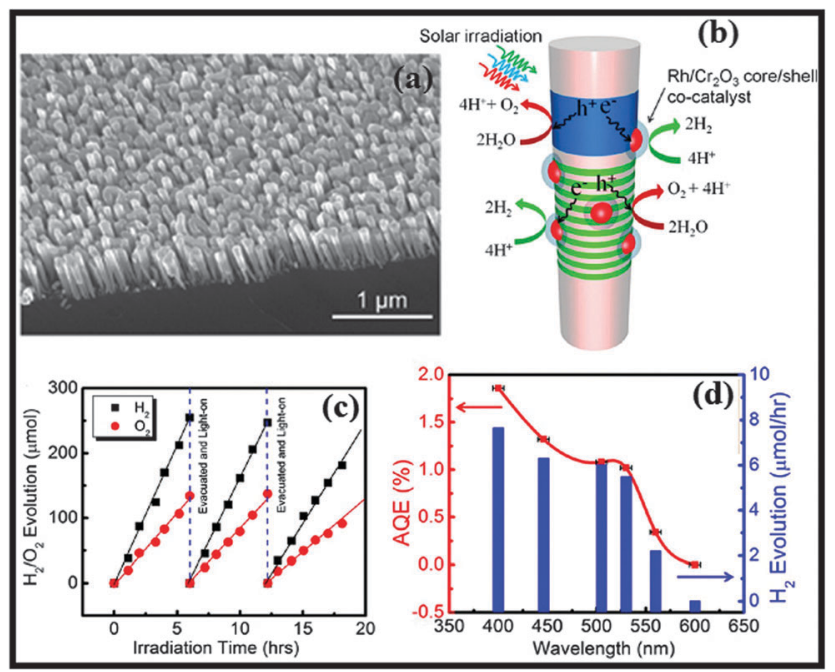

Fig. 25 (a) SEM image of GaN/InGaN NW grown on an Si substrate. (b) Water splitting mechanism on $\mathrm{Rh} / \mathrm{Cr}_{2} \mathrm{O}_{3} / \mathrm{InGaN} / \mathrm{GaN}$ catalyst. (c) Irradiation time versus $\mathrm{H}_{2} / \mathrm{O}_{2}$ evolution. (d) Apparent quantum efficiency (AQE) and $\mathrm{H}_{2}$ evolution rate against incident wavelength (the FWHM of the optical filters is given as error bars). The $\mathrm{H}_{2}$ evolution rate was derived from about $2 \mathrm{~h}$ of overall water splitting under each optical filter. Reproduced with copyright permission from ref. 235.

co-catalyst $\mathrm{Rh}-\mathrm{Cr}_{2} \mathrm{O}_{3}$ core-shell NPs. ${ }^{236}$ Fig. $25 \mathrm{a}$ shows the SEM image of GaN-InGaN NWs grown on GaN nanowire templates on an $\mathrm{Si}(111)$ substrate; Fig. 25b suggests the reaction mechanism on the co-catalyst and InGaN-GaN NWs. Water splitting takes place on both GaN and InGaN NWs (Fig. 25c) under suitable illumination. With increasing wavelength, the apparent $\mathrm{QE}$ decreases (Fig. 25d). Similar work with GaN and InGaN heterostructures have been reported by the same research group. ${ }^{237}$

\subsection{Nanotubes}

In general, surface defects such as oxygen vacancies on the semiconductors play a crucial part in catalysis. ${ }^{36,172,173,238-241}$
The oxygen vacancies serve as adsorption sites depending on their physical location within the catalyst, as well as help to delay recombination. ${ }^{36,72,173}$ For $\mathrm{TiO}_{2}$ NTs, Kang et al. ${ }^{242}$ suggested that $\mathrm{NaBH}_{4}$ treatment could control the defects on the surface. The treated surface had better electron transfer properties at the semiconductor/electrolyte interface than the parent surface. However, predominant oxygen vacancies will not help to enhance the $\mathrm{H}_{2}$ production. Similar results were obtained on surface-fluorinated $\mathrm{TiO}_{2}$ nanoporous films. $\mathrm{TiO}_{2}$ NTs with Pd QDs as a co-catalyst facilitated a relatively higher efficiency of photocatalytic $\mathrm{H}_{2}$ generation ${ }^{140}$ (Fig. 26).

1D nanostructured titanate NTs are known for their cationexchange capacities, which allow high loading of the active catalysts. $\mathrm{Li}$ and $\mathrm{Lu}^{244}$ investigated $\mathrm{Na}_{2} \mathrm{Ti}_{2} \mathrm{O}_{4}(\mathrm{OH})_{2}$ NTs in the presence of triethanolamine (TEA) and Pt. Titanates have been investigated for their photocatalytic degradation of dye molecules, ${ }^{171}$ but they should also be considered for $\mathrm{H}_{2}$ production because of their predominant surface defect densities, which enhance catalysis.

Li et $a l .{ }^{245}$ reported that EY-MWCNTs in the presence of TEOA (electron donor) showed significant $\mathrm{H}_{2}$ generation under visible light illumination $(\lambda \geq 420 \mathrm{~nm})$. The role of MWCNTs is similar to that of the noble metals in the context of delaying recombination by trapping electrons and they may be a good substitute for Pt. Type I and type II band alignments consist of two semiconductors such as $\mathrm{CdS}-\mathrm{TiO}_{2},{ }^{243}$ whereas ternary $\left(\mathrm{CdS}-\mathrm{TiO}_{2}-\right.$ $\mathrm{Pt}$ and $\left.\mathrm{CdS}-\mathrm{TiO}_{2}-\mathrm{CNTs}\right)$ and quaternary (CdS-TiO $\left.2-\mathrm{Pt}-\mathrm{CNTs}\right)$ composites have also demonstrated significant $\mathrm{H}_{2}$ generation. In all these instances, cascaded charge transfer takes place between the $\mathrm{TiO}_{2}$ and CdS, while the Pt and/or CNTs act as electron collectors. ${ }^{246} \mathrm{TiO}_{2}$ in the form of NTs modified by CdS nanostructures have been investigated ${ }^{243}$ (Fig. 27a). p-type Cu-Ti-O
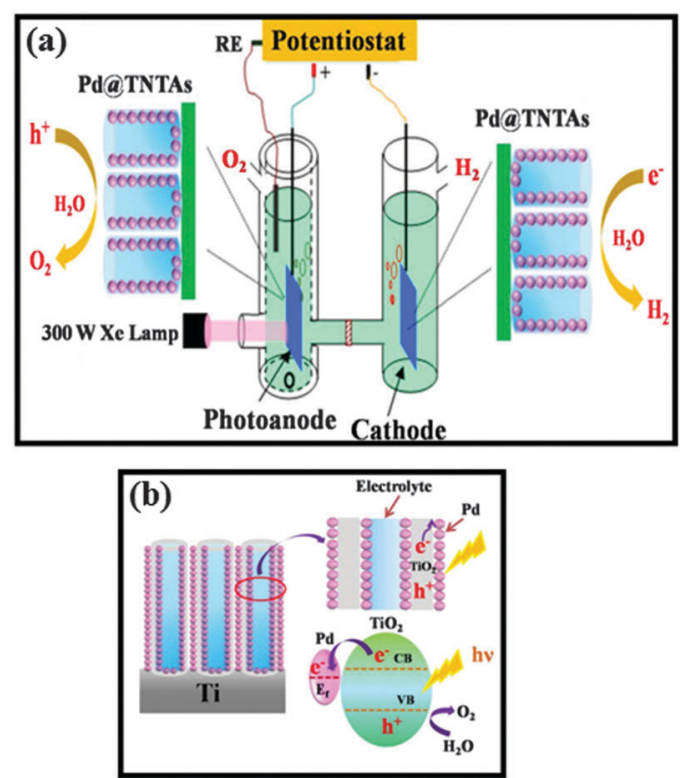

Fig. 26 (a) Schematic diagram of a PEC cell with $\mathrm{Pd}-\mathrm{TiO}_{2} \mathrm{NTs}$ and $\mathrm{Pt}-\mathrm{TiO}_{2}$ NTs. Close-up shows both the photoanode and cathode. (b) Schematic diagram of $\mathrm{Pd} Q \mathrm{QDs}-\mathrm{TiO}_{2} \mathrm{NTs}$ and the charge transfer process from $\mathrm{TiO}_{2}$ to $\mathrm{Pd}$ (lower right panel). This figure is reproduced with copyright permission from ref. 140. 
(a) $\mathrm{Ti}$

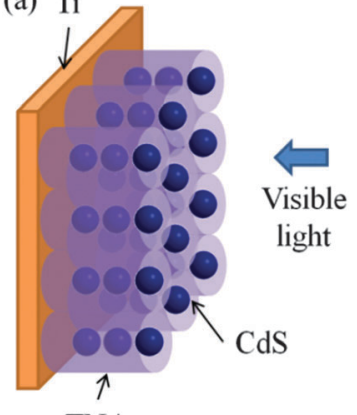

TNA

(b)

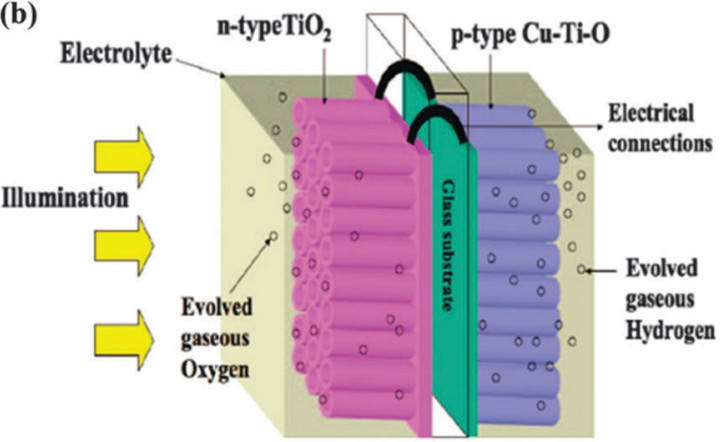

Fig. 27 (a) Schematic diagram of $\mathrm{CdS}-\mathrm{TiO}_{2}$ NTs (left) and the charge transfer process (right). This figures is redrawn based on the results from ref. 243. (b) PEC diode consisting of $\mathrm{TiO}_{2}$ and $\mathrm{Cu}-\mathrm{Ti}-\mathrm{O}$ NT arrays. The oxygen-evolving $\mathrm{TiO}_{2}$ side absorbs UV irradiation and the $\mathrm{Cu}-\mathrm{Ti}-\mathrm{O}$ side absorbs the visible part of the spectrum, evolving $\mathrm{H}_{2}$. Figure is reproduced with copyright permission from ref. 132.

NTs with n type $\mathrm{TiO}_{2}$ NTs have shown significant photocurrent generation, although they are self-biased as a result of suitable band alignment (Fig. 27b). ${ }^{132} \mathrm{CdS}$-trititanate NTs have been investigated for their $\mathrm{H}_{2}$ generation capability. Effective charge separation is evidenced in this composite, which favours the catalytic activity. ${ }^{247}$

\subsection{Nanorods}

The incorporation of a small amount (about 1\%) of copper ions into $\mathrm{TiO}_{2}$ NRs gave an improved performance over their pure counterparts under solar light. ${ }^{248}$ Doping caused the band gap to shrink from 3.10 to $2.84 \mathrm{eV}$. However, a further decrease in $E_{\mathrm{g}}(2.40 \mathrm{eV}$ at about $3 \% \mathrm{Cu}$ doping) decreased the production of $\mathrm{H}_{2}$ by about five times in pure water. In the presence of $\mathrm{MeOH}$ aqueous solution, the production of $\mathrm{H}_{2}$ from 1 and $3 \%$ Cu-doped $\mathrm{TiO}_{2}$ is comparable. It was suggested that a lower band gap may not enhance photon harvest in all instances. Severe doping may cause lattice defects or the formation of a secondary phase that might act as an electron trap, thereby decreasing the production of $\mathrm{H}_{2}$. However, if the density of the hole traps can be increased, then the $\mathrm{H}_{2}$ productivity can be increased, or, at least, the back-reactions can be minimized. The morphology and crystal quality help to enhance the generation of $\mathrm{H}_{2}$, as seen with CdS NRs and nanograins, where NRs gave better results. ${ }^{113} \mathrm{CdS}$ NRs modified with $\mathrm{Ni}(\mathrm{OH})_{2}$ (23 mol\%) showed the highest reported generation of $\mathrm{H}_{2}$ under visible light
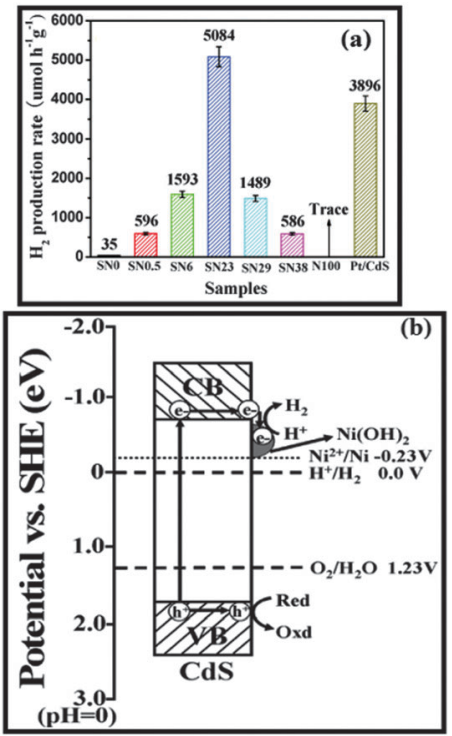

Fig. 28 (a) Comparison of $\mathrm{H}_{2}$ production for various ratios of $\mathrm{CdS}$ to $\mathrm{Ni}(\mathrm{OH})_{2}(\mathrm{SN})$. The ratios (in parentheses) for various samples were SNO (0), SN (0.5), SN (6), SN (23), SN (29), SN(38), N (100) with 1 wt\% Pt-CdS under visible light in a TEA aqueous solution. (b) Proposed mechanism for $\mathrm{H}_{2}$ production. This figure is reproduced with copyright permission from ref. 249.

irradiation $^{249}$ (Fig. 28a). Fig. 28b shows that the potential of $\mathrm{Ni}^{2+} / \mathrm{Ni}$ is lower than the $\mathrm{CB}$ of $\mathrm{CdS}$ and more negative than the $\mathrm{H}^{+} / \mathrm{H}_{2}$ potential. This alignment favours the transfer of electron from the CB of CdS to $\mathrm{Ni}(\mathrm{OH})_{2}$ and the reduction of $\mathrm{H}^{+}$to $\mathrm{H}_{2}$. Based on the band gap of iron oxide (corresponding to absorption in the visible range), maghemite $\left(\gamma-\mathrm{Fe}_{2} \mathrm{O}_{3}\right)$-haematite $\left(\alpha-\mathrm{Fe}_{2} \mathrm{O}_{3}\right)$ core-shell NRs were produced and showed a higher evolution of $\mathrm{H}_{2}$ from $\mathrm{H}_{2} \mathrm{~S}$ than their individual NRs. ${ }^{250}$ Porous $\mathrm{ZnFe}_{2} \mathrm{O}_{4}$ NRs showed effective evolution of $\mathrm{H}_{2}$ from an aqueous methanol solution under visible light; the shapes and intraparticle porous structure were beneficial for the rapid transfer of photogenerated carriers onto the surface. ${ }^{252}$ The evolution of $\mathrm{O}_{2}$ was not detected, as a result of the mismatched energy levels of the VB (of $\mathrm{ZnFe}_{2} \mathrm{O}_{4}$ ) and the oxidation potential of water. Surprisingly, without using any SRs, an Au NRs/TiO ${ }_{2}$ cap/Pt NP configuration $^{252}$ produced about $2.8 \mathrm{mmol} \mathrm{h}^{-1} \mathrm{~g}$ of $\mathrm{H}_{2}$. The improved evolution of $\mathrm{H}_{2}$ was a result of the promotion of trapbound electrons in the $\mathrm{TiO}_{2}$ to the CB. These electrons were then captured by $\mathrm{Pt}$ to participate in the $\mathrm{H}_{2}$ evolution. ${ }^{150}$

\subsection{Electrospun nanofibres}

Metal oxide composite NFs ${ }^{228,253}$ have also proved to be efficient in $\mathrm{H}_{2}$ generation. Zhang et al. ${ }^{254}$ reported plasmon enhancement of photocatalytic $\mathrm{H}_{2}$ generation over $\mathrm{Au}-\mathrm{Pt}-\mathrm{TiO}_{2}$ electrospun NFs. Yousef et al. ${ }^{255}$ suggested that the incorporation of transition metal NPs strongly modifies the physiochemical characteristics of the metal oxide nanostructures. Lee et al. ${ }^{254}$ have shown that $\mathrm{TiO}_{2}-\mathrm{CuO}$ composite NFs are promising for $\mathrm{H}_{2}$ production. Fig. 29a-c shows typical SEM images of the electrospun fibres and $\mathrm{H}_{2}$ production over time. Charge generation and subsequent catalysis are shown in Fig. 29d. Similar work by the 

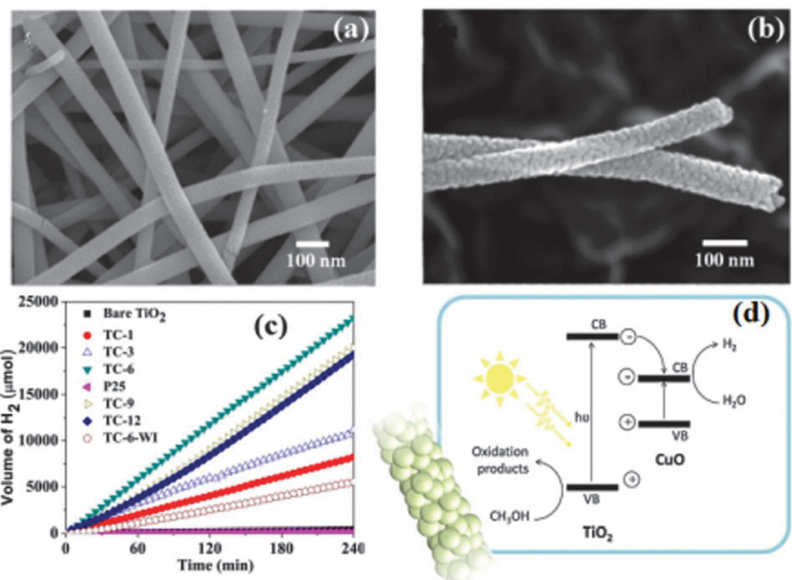

Fig. 29 (a) FE-SEM images of $\mathrm{TiO}_{2}-\mathrm{CuO}$ at 6 mol\% in $\mathrm{Cu}$ NFs. (b) High magnification FE-SEM image. (c) $\mathrm{H}_{2}$ evolution with time. (d) Schematic band gap diagram of $\mathrm{TiO}_{2} / \mathrm{CuO}$ heterojunction. Reproduced with copyright permission from ref. 253.

same research group has also been published elsewhere. ${ }^{228}$ It has been reported that the combination of $\mathrm{Fe}_{2} \mathrm{O}_{3} \mathrm{NPs}$ and $\mathrm{TiO}_{2}$ NFs has advantages over the individual materials and enhances light absorption. ${ }^{256}$ An effective strategy to overcome photocorrosion and toxicity problems from CdS-based materials is their incorporation in polymeric NFs. CdS and CdS-PdS NPs were mixed in poly(vinyl acetate) electrospun NFs and the composite produced more $\mathrm{H}_{2}$ than bare CdS NPs. ${ }^{257}$ The efficiency of $\mathrm{H}_{2}$ generation also depends on the morphology of the NFs. ${ }^{83}$ Yang et al. ${ }^{83}$ reported that electrospun core-shell CdS-ZnO NFs showed excellent $\mathrm{H}_{2}$ generation under visible light. The activity was mainly attributed to high visible light absorption and low charge carrier recombination. $\mathrm{N}$-doped $\mathrm{TiO}_{2}$ electrospun $\mathrm{NFs}$ were also explored for efficient $\mathrm{H}_{2}$ generation and the efficiency was found to be dependent on the concentration of the $\mathrm{N}$ precursor. ${ }^{45}$ Caterpillarlike $\mathrm{ZnO}$ nanostructures on $\mathrm{ZnO}$ force-spun NFs showed about $0.165 \%$ photon-to-hydrogen conversion efficiency; ${ }^{258}$ the increase is accounted for by enhanced light-harvesting ability and the effective electron-hole separation.

\subsection{Two-dimensional nanostructures}

5.5.1. Nanosheets. CdS NSs produced by a two-step synthesis were able to produce $\mathrm{H}_{2}$ at about $4.1 \mathrm{mM} \mathrm{h}^{-1}$ under visible light $^{259}$ (Fig. 30a). From earlier results, it is clear that Pt is an excellent co-catalyst. However, it is vital to quantify its loading percentage. As expected, excessive loadings may not increase the yield and the optimum loading is shown in Fig. 30b. This study also optimized the concentration of SRs and $\mathrm{H}_{2}$ evolution from various cycles (Fig. $30 \mathrm{c}$ and d). $\mathrm{ZnS}\left(E_{\mathrm{g}}=3.4 \mathrm{eV}\right)$ is not active in the visible region, in contrast with $\mathrm{ZnIn}_{2} \mathrm{~S}_{4},{ }^{260}$ which has an almost five times higher activity in the presence of $\mathrm{Pt}$ in the visible region than its pristine counterpart. ZnS NSs have been studied in combination with $\mathrm{CuS}-\mathrm{Cu}_{2} \mathrm{~S}$ in the presence of $\mathrm{Na}_{2} \mathrm{~S}$ and $\mathrm{Na}_{2} \mathrm{SO}_{3}{ }^{88}$ Fig. 31a shows $\mathrm{H}_{2}$ production rates from different catalyst combinations. Pristine ZnS (CZ0) has a negligible production of $\mathrm{H}_{2}$ as its band gap is too large to absorb visible light.
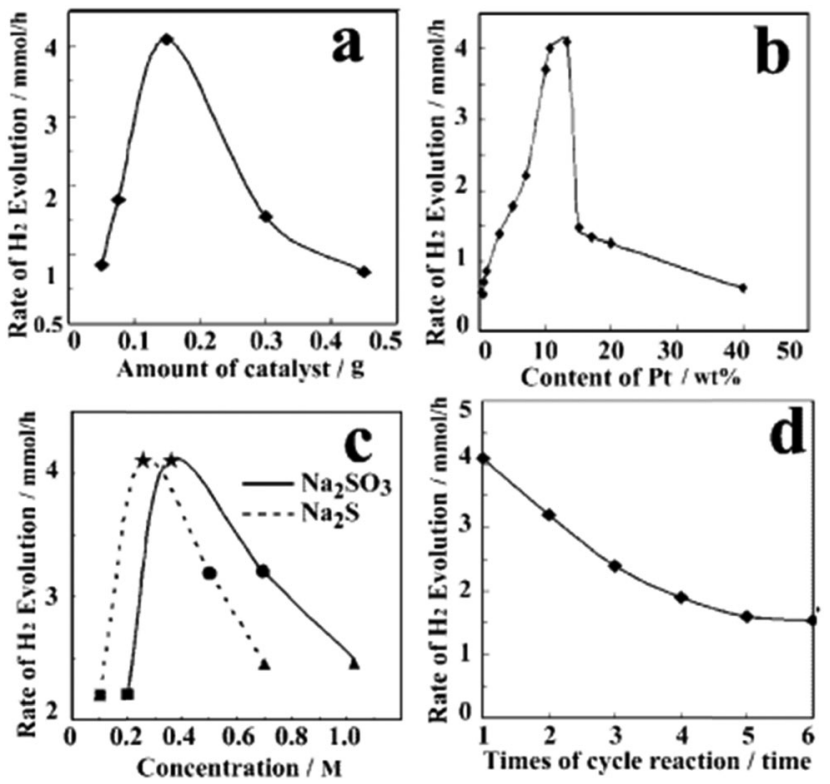

Fig. 30 Evolution of $\mathrm{H}_{2}$ with (a) amount of $\mathrm{CdS}$ catalyst with $10 \mathrm{wt} \% \mathrm{Pt}$ and (b) Pt loading $(0.15 \mathrm{~g} \mathrm{CdS})$. (c) Concentration of SRs against $\mathrm{H}_{2}$ evolution rate from $0.15 \mathrm{~g}$ of $\mathrm{Pt}-\mathrm{CdS}$ and (d) $0.15 \mathrm{~g}$ of $10 \mathrm{wt} \% \mathrm{Pt}-\mathrm{CdS}$. (a), (b) and (d) used a $0.25 \mathrm{M} \mathrm{Na}_{2} \mathrm{SO}_{3}+0.35 \mathrm{M} \mathrm{Na}_{2} \mathrm{~S}$ electrolyte. All reactions were performed under visible light. Reproduced with the copyright permission from ref. 259.
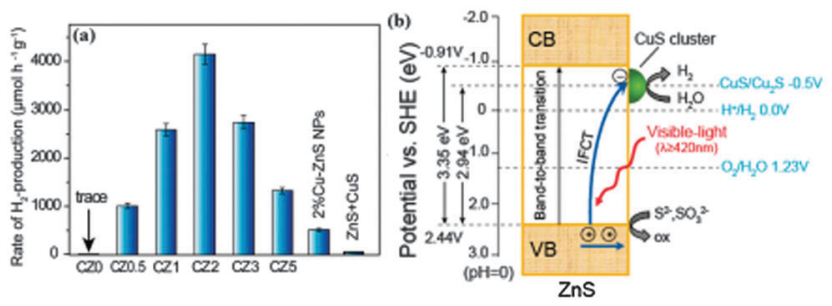

(c)
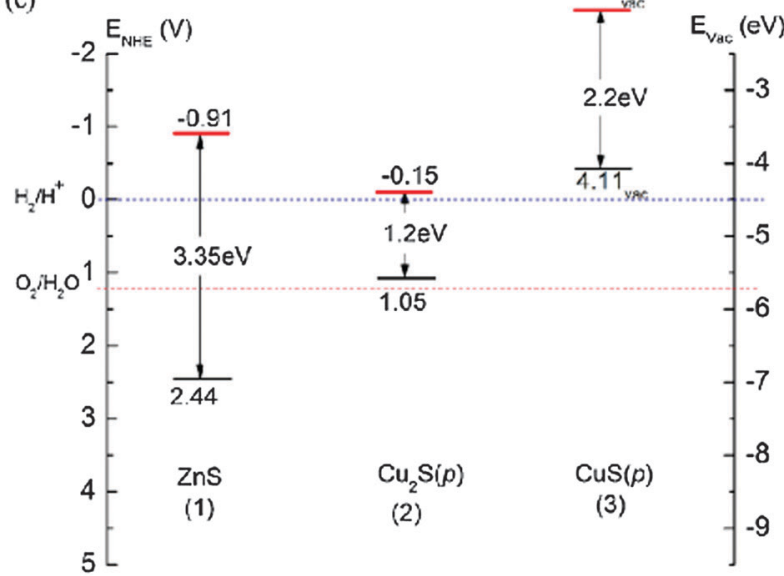

Fig. 31 (a) Comparison of $\mathrm{H}_{2}$ production using CuS/ZnS porous NSs and $\mathrm{ZnS}$ samples under visible light in the presence of $0.35 \mathrm{M} \mathrm{Na}_{2} \mathrm{~S}+0.25 \mathrm{M}$ $\mathrm{Na}_{2} \mathrm{SO}_{3}$. (b) Schematic diagram of interfacial charge transfer from the $\mathrm{VB}$ of $\mathrm{ZnS}$ to the CuS clusters both (a) and (b) are reproduced with copyright permission from ref. 88. CZ0-ZnS, CuS molar concentration denoted as numerals. (c) Energetic values of the $\mathrm{CB}$ and $\mathrm{VB}$ positions of $\mathrm{ZnS}, \mathrm{Cu}_{2} \mathrm{~S}$ and CuS taken from the corresponding references as follows: $\mathrm{ZnS}(1),{ }^{88} \mathrm{Cu}_{2} \mathrm{~S}$ $(2)^{262,263}$ and CuS (p) (3). The figure (c) is redrawn based on the results from ref. $88,261-263$. 
In contrast, after the addition of small amounts of $\mathrm{CuS}$ to $\mathrm{ZnS}$, the generation of $\mathrm{H}_{2}$ is abruptly increased under visible light irradiation. Fig. 31b shows the mechanism for the production of $\mathrm{H}_{2}$ by $\mathrm{CuS}-\mathrm{ZnS}$ porous NSs.

The band-to-band transition of $\mathrm{ZnS}$ cannot take place under visible light irradiation due to the large band gap energy. Pure CuS also shows no visible light activity, although the combination CuS-ZnS provides a platform for visible light activity. Zhang et al. ${ }^{88}$ did not mention the VB of CuS- $\mathrm{Cu}_{2} \mathrm{~S}$, but the band diagram suggests a band gap of $2.94 \mathrm{eV}$ where the VBs of $\mathrm{ZnS}$ and $\mathrm{CuS}-\mathrm{Cu}_{2} \mathrm{~S}$ are at the same energy level. If we consider the published band diagram of $\mathrm{CuS}$ and $\mathrm{Cu}_{2} \mathrm{~S}$, the $\mathrm{VB}$ of $\mathrm{ZnS}$ and $\mathrm{CuS}$ or $\mathrm{Cu}_{2} \mathrm{~S}$ are not energetically in line with each other (Fig. 31c). If interfacial charge transfer has to take place, then the energy difference from the $\mathrm{VB}$ of $\mathrm{ZnS}$ to the $\mathrm{VB}$ of $\mathrm{Cu}_{2} \mathrm{~S}-\mathrm{CuS}$ should be taken into account. In the band gap range 1.2-2.15 eV (CuS- $\mathrm{Cu}_{2} \mathrm{~S}$ combined), illumination at $420 \mathrm{~nm}$ is sufficient to create $\mathrm{e}-\mathrm{h}$ pairs in these semiconductors. In this instance, the transfer of charge takes place from $\mathrm{CuS}-\mathrm{Cu}_{2} \mathrm{~S}$ to $\mathrm{ZnS}$. The interfacial regions are generally defective and we can therefore expect charge carrier traps within the interface. Another combination of heterostructures is NiO-CdS, ${ }^{264}$ where the CdS absorbs visible light and photogenerated electrons are transferred to the NiO. This combination has shown significant $\mathrm{H}_{2}$ production (Fig. 32a). Fig. 32b shows the band alignment and corresponding charge transfer phenomenon under visible light irradiation.

Graphene, apart from having outstanding electrical conductivity, can also inhibit the recombination of the electron-hole pairs by collecting the electrons and enhancing the absorption of visible light. This phenomenon is similar to that of the noble

(a)

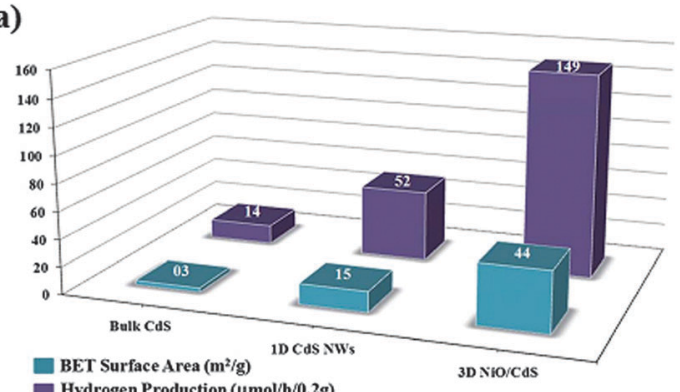

(b)

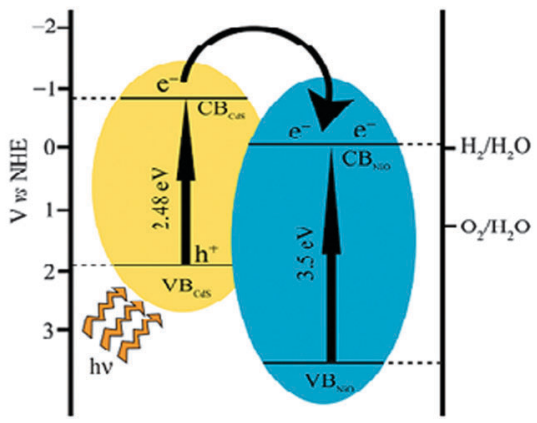

Fig. 32 (a) Surface area and the amount of $\mathrm{H}_{2}$ generated from bulk $\mathrm{CdS}$, 1D CdS NWs and 3D NiO-CdS photocatalysts under visible light irradiation. (b) Schematic diagram of electron transfer and band diagram for $\mathrm{NiO}$ and CdS. Reproduced with copyright permission from ref. 264.
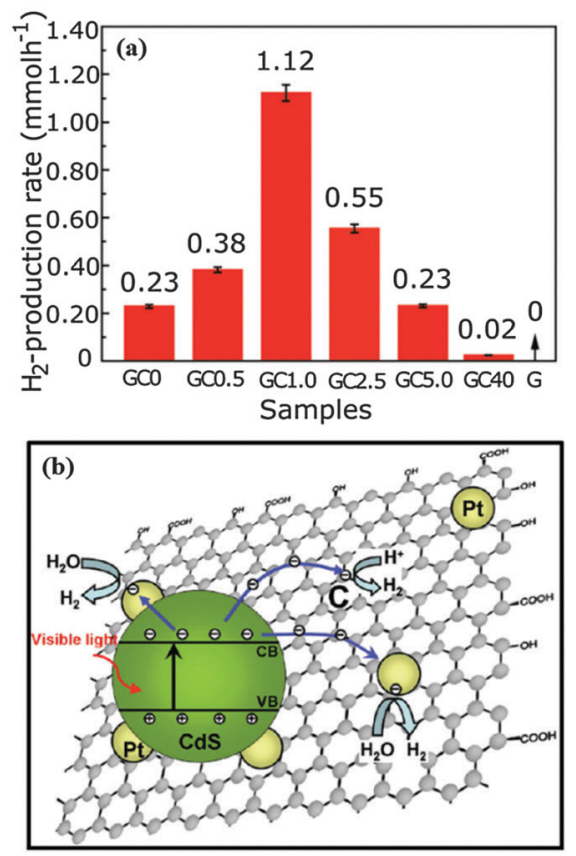

Fig. 33 (a) $\mathrm{H}_{2}$ productivity of graphene oxide-CdS composites in the presence of 10 vol\% aqueous solution of lactic acid and $0.5 \mathrm{wt} \% \mathrm{Pt}$. (b) charge generation and subsequent separation under visible light. Reproduced with copyright permission from ref. 265 . The weight ratios of $\mathrm{GO}$ to $\mathrm{Cd}(\mathrm{Ac})_{2} 2 \mathrm{H}_{2} \mathrm{O}$ were: $0,0.5,1.0,2.5,5.0$ and $40 \%$ and the obtained samples are labelled as GC0, GC0.5, GC1.0, GC2.5, GC5.0 and GC40, respectively.

metal NPs. ${ }^{265}$ Fig. 33 shows the mechanism and influence of graphene oxide with CdS clusters for the high efficiency photocatalytic production of $\mathrm{H}_{2}$ driven by visible light. ${ }^{265}$

5.5.2. Nanolayers. Simulation studies ${ }^{266}$ on $\mathrm{MoS}_{2}$ layered structures suggest that pristine single-layer $\mathrm{MoS}_{2}$ is a good candidate for $\mathrm{H}_{2}$ production. The catalytic activity can be improved by applying a small in-plane compressive strain or an out-of-plane tensile strain. p-type doping (with phosphorus) can also be used to enhance the overall splitting of water. Fig. 34 shows the changes that occur as a result of doping. A layered $\mathrm{Zn}$-In-S photocatalyst in the presence of $\mathrm{NaCl}$ also shows high visible light activity for the evolution of $\mathrm{H}_{2}{ }^{267}$ Morphologically similar structures have been produced with $\mathrm{ZnIn}_{2} \mathrm{~S}_{4}$ and their activity for $\mathrm{H}_{2}$ production tested. ${ }^{268}$

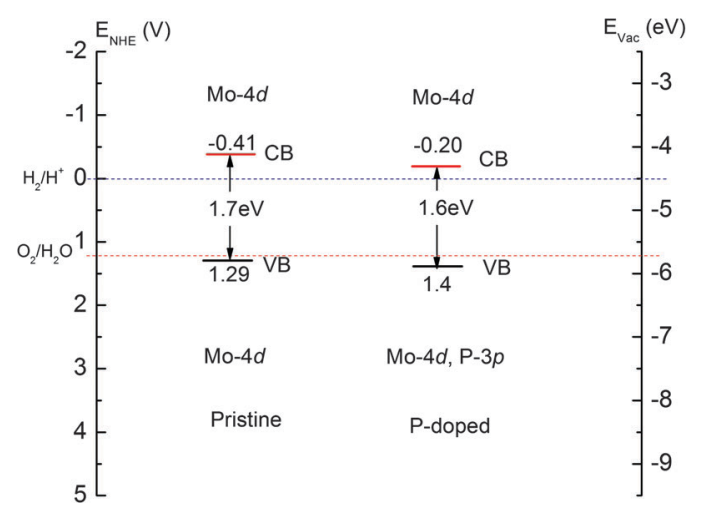

Fig. 34 Band diagram of single-layer $\mathrm{MoS}_{2}$ and its P-doped counterpart. Figure redrawn based on the results from ref. 266. 


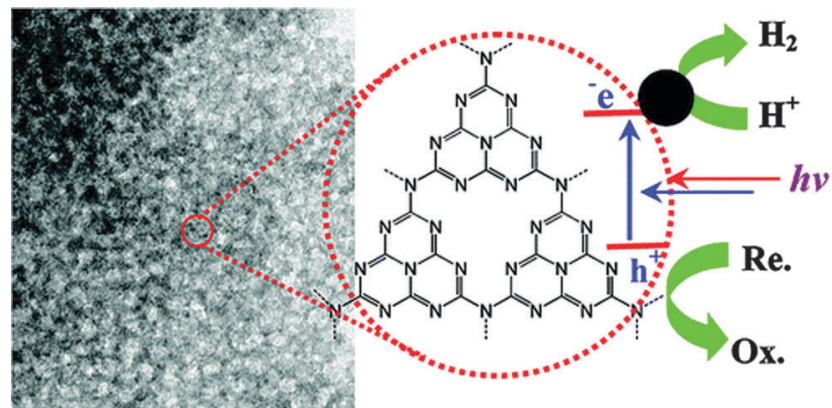

Fig. 35 TEM image of $\mathrm{g}-\mathrm{C}_{3} \mathrm{~N}_{4}$ and $\mathrm{H}_{2}$ evolution under visible light illumination. Figure reproduced with copyright permission from ref. 271.

5.5.3. Nanoribbons. The $\mathrm{MoS}_{2}$ layered structure has been shown to have potential for the evolution of $\mathrm{H}_{2}$. In this instance, the $\mathrm{MoS}_{2}$ layers are exfoliated via ultrasonication and chemically linked to CdSe nanoribbons. The resultant composite has a QY of $9.2 \%$ at $440 \mathrm{~nm}$, whereas bulk CdSe is not active for this reaction. The overall increase is nearly four times, although this depends on the mass percentage of $\mathrm{MoS}_{2}$. The chemical linkage of Pt NPs to the CdSe nanoribbons did not influence the evolution of $\mathrm{H}_{2}{ }^{269}$

5.5.4. Metal-free photocatalysts. Graphitic carbon nitride $\left(\mathrm{g}-\mathrm{C}_{3} \mathrm{~N}_{4}\right)$ has potential for the production of $\mathrm{H}_{2}$ from water under visible light illumination. ${ }^{270}$ Under suitable illumination, the creation of $\mathrm{e}-\mathrm{h}$ pairs is similar to that in metal oxide photocatalysts, where the electrons are excited to the $\mathrm{CB}$ and holes are created in the VB. In this example, the oxidation of $\mathrm{H}_{2} \mathrm{O}$ takes place at the $\mathrm{N}$ atoms, whereas the $\mathrm{C}$ atoms provide reduction sites for $\mathrm{H}_{2}$ (Fig. 35). A similar study has been reported by Wang et al. ${ }^{270}$

The 1D graphitic carbon nitride NRs were synthesized on a template and decorated with Pt NPs. ${ }^{272}$ This hybrid material showed a surprisingly high $\mathrm{H}_{2}$ yield with a low specific SA in the presence of a triethanolamine scavenger. The enhancement is ascribed to the efficient charge separation of the 2D layered structures. Huang et al. ${ }^{273}$ reported bio-inspired carbon nitride mesoporous NSs composed of nanospheres and with the possibility of $\mathrm{H}_{2}$ generation.

\section{Conclusions and future prospects}

Nanomaterials have attracted much attraction and there have been high expectations of innovations in many research areas, including medicine, communications, materials development and energy and environmental technology. At the same time there is growing concern that nanomaterials may be hazardous to both health and the environment. In the energy sector, nanomaterials have great potential as they can be used in energyabsorbing materials, such as batteries, fuel cells and solar cells, for the storage of energy. Although nanomaterials are seen by some workers as the way to meet future requirements, they have some disadvantages. As these particles are very small, problems can arise from their inhalation. Nanotechnology is currently very expensive and further development will be costly; manufacturing difficulties may increase the cost of the products. Realistic market costs of nanomaterials have been reported online. ${ }^{275}$
Environmentally friendly and cost-effective fuels are in great demand and this is why $\mathrm{H}_{2}$ production is of interest. Although it is a promising technology, there are many challenges that require further development before it can be used on an industrial scale. One challenge is the fabrication of a catalyst that harvests $\mathrm{H}_{2}$ from a non-conventional energy resource such as solar energy with significant efficiency. Wide band gap semiconductors cannot use the visible region of the solar spectrum. Some small band gap materials require SRs or are unstable in long-term usage because of the thermodynamic requirement of the positions of the $\mathrm{CB}$ and VB. SRs can inhibit back-reactions by capturing photogenerated holes, ${ }^{93}$ but tend to form $\mathrm{CO}_{2}$ instead of $\mathrm{O}_{2}{ }^{124}$ which has an adverse effect on the environment. Industrial waste (sulfides from aqueous solutions containing $\mathrm{S}^{2-}$ and $\mathrm{SO}_{3}{ }^{2-}$ ) can be used as an SR. These techniques not only clean the environment, but also produce valuable $\mathrm{H}_{2}$ energy. Wide band gap materials can be subjected to band gap engineering to enable activity in the visible light region by doping or creating intrinsic defects. Care should be taken with intrinsic defects as they can act as electron traps, reducing the efficiency of production, whereas hole traps are useful. Defect-mediated catalysis is of prime importance, although these concepts require further investigation.

Delaying the recombination of the photogenerated e-h pairs is the primary objective in enhancing the catalytic activity. The availability of these charge carriers, especially the electrons, on the surface of the catalyst is vital. The transport of electrons to the surface can be improved by creating an internal electric field via heterojunctions. The best studied heterojunctions are based on NWs or NRs, which possess the crucial property of vectorial charge transport. Various methods have been used to fabricate these 1D structures, although electrospinning has the most potential because of its versatility in producing such structures.

It is important to consider a semiconductor combination that drives electrons to the surface of the heterocatalyst, while other combinations separate e-h pairs in the background. Such a combination should increase the harvesting of solar energy. For example, $\mathrm{Zn}_{x} \mathrm{Cd}_{1-x} \mathrm{Te}$ in conjunction with $\mathrm{ZnO}$ in heterostructures helps to extend the absorption of solar energy into the NIR region, which can be as high as $22 \%$ of the solar spectrum. ${ }^{35}$

In the process of fabrication, inorganic nanostructures are generally subjected to thermal treatment(s), note that there are exceptions. Various studies have shown the dependence of $\mathrm{H}_{2}$ production on processing parameters, such as the calcination temperature. However, excessively high temperatures can decrease the output. ${ }^{93}$ The calcination temperature is crucial in determining the quality of the crystal, which, in turn, determines the efficacy of $\mathrm{H}_{2}$ evolution when balanced against the defect density. The density of defects is also process-dependent. The catalytic activity is related to the number density of active sites, which may not be directly related to the SA measured through $\mathrm{N}_{2}$ adsorption and desorption curves. Irregularities on the surface may increase the SA; however, the increased area is not necessarily directly correlated with $\mathrm{H}_{2}$ evolution. For example, $\mathrm{H}_{2}$ evolution increases with synthesis temperature, although the SA decreases. ${ }^{229}$ The characteristic defect density ${ }^{238-241}$ may be obtained from photoluminescence measurements. These can be correlated with the photocatalytic 
activity $^{36,172,173}$ to give a better understanding of the development of promising materials. The photoluminescence may be taken as a standard measurement to quantify the defect density from radiative recombinations. The relation between $\mathrm{SA}$ and $\mathrm{H}_{2}$ evolution has been extensively studied, but a clear correlation has not been obtained because the evolution of $\mathrm{H}_{2}$ depends on a number of variables, such as the catalyst properties, ${ }^{276}$ the particle size, ${ }^{277}$ co-catalysts, the SRs, sensitizers ${ }^{85}$ and, in particular, the kinetics of the chemical reactions that lead to the final formation of $\mathrm{O}_{2}$ and $\mathrm{H}_{2}{ }^{278}$

Finally, the following points need to be considered for the design of efficient and cost-effective photocatalysts: (i) band gap engineering to improve the absorption of photons in the solar spectrum; (ii) an increase in the recombination time of the photogenerated excitons so they can take part in photocatalysis; and (iii) avoidance of back-reactions to form water.

\section{Acknowledgements}

V.J.B. and S.V. thank the Scientific \& Technological Research Council of Turkey (TUBITAK) (TUBITAK-BIDEB 2221, Fellowships for Visiting Scientists and Scientists on Sabbatical) for fellowship. T.U. thanks EU FP7-Marie Curie-IRG (NANOWEB, PIRG06-GA-2009-256428) and The Turkish Academy of SciencesOutstanding Young Scientists Award Program (TUBA-GEBIP) for funding.

\section{Notes and references}

1 Z. Zou, J. Ye, K. Sayama and H. Arakawa, Nature, 2001, 414, 625-627.

2 M. Ashokkumar, Int. J. Hydrogen Energy, 1998, 23, 427-438.

3 H. Balat and E. Kirtay, Int. J. Hydrogen Energy, 2010, 35, 7416-7426.

4 M. Ni, M. K. H. Leung, D. Y. C. Leung and K. Sumathy, Renewable Sustainable Energy Rev., 2007, 11, 401-425.

5 K. Shimura and H. Yoshida, Energy Environ. Sci., 2011, 4, 2467-2481.

6 X. Song and L. Gao, J. Phys. Chem. C, 2008, 112, 15299-15305.

7 F. Lu, W. Cai and Y. Zhang, Adv. Funct. Mater., 2008, 18, 1047-1056.

8 B. B. Kale, J.-O. Baeg, S. M. Lee, H. Chang, S.-J. Moon and C. W. Lee, Adv. Funct. Mater., 2006, 16, 1349-1354.

9 W.-T. Yao, S.-H. Yu, S.-J. Liu, J.-P. Chen, X.-M. Liu and F.-Q. Li, J. Phys. Chem. B, 2006, 110, 11704-11710.

10 J. Zhang, F. Shi, J. Lin, D. Chen, J. Gao, Z. Huang, X. Ding and C. Tang, Chem. Mater., 2008, 20, 2937-2941.

11 J. K. Zhou, L. Lv, J. Yu, H. L. Li, P.-Z. Guo, H. Sun and X. S. Zhao, J. Phys. Chem. C, 2008, 112, 5316-5321.

12 A. Fujishima and K. Honda, Nature, 1972, 238, 37-38.

13 A. J. Bard, J. Photochem., 1979, 10, 59-75.

14 A. J. Bard, Science, 1980, 207, 139-144.

15 A. J. Bard, J. Phys. Chem., 1982, 86, 172-177.

16 A. C. Ford, J. C. Ho, Y.-L. Chueh, Y.-C. Tseng, Z. Fan, J. Guo, J. Bokor and A. Javey, Nano Lett., 2009, 9, 360-365.
17 A. B. F. Martinson, J. E. McGarrah, M. O. K. Parpia and J. T. Hupp, Phys. Chem. Chem. Phys., 2006, 8, 4655-4659.

18 S. Hernandez, V. Cauda, A. Chiodoni, S. Dallorto, A. Sacco, D. Hidalgo, E. Celasco and C. F. Pirri, ACS Appl. Mater. Interfaces, 2014, 6, 12153-12167.

19 T. B. Singh, F. Meghdadi, S. Günes, N. Marjanovic, G. Horowitz, P. Lang, S. Bauer and N. S. Sariciftci, Adv. Mater., 2005, 17, 2315-2320.

20 V. Chakrapani, J. Thangala and M. K. Sunkara, Int. J. Hydrogen Energy, 2009, 34, 9050-9059.

21 K. Aryal, B. N. Pantha, J. Li, J. Y. Lin and H. X. Jiang, Appl. Phys. Lett., 2010, 96, 052110.

22 J. Hensel, G. Wang, Y. Li and J. Z. Zhang, Nano Lett., 2010, 10, 478-483.

23 Z. G. Yu, C. E. Pryor, W. H. Lau, M. A. Berding and D. B. MacQueen, J. Phys. Chem. B, 2005, 109, 22913-22919.

24 A. Kudo and Y. Misekia, Chem. Soc. Rev., 2009, 38, 253-278.

25 S. Yan, L. Wan, Z. Li and Z. Zou, Chem. Commun., 2011, 47, 5632-5634.

26 K. Saito, K. Koga and A. Kudo, Dalton Trans., 2011, 40, 3909-3913.

27 D. Barreca, P. Fornasiero, A. Gasparotto, V. Gombac, C. Maccato, T. Montini and E. Tondello, ChemSusChem, 2009, 2, 230-233.

28 W. Siripala, A. Ivanovskaya, T. F. Jaramillo, S.-H. Baeck and E. W. McFarland, Sol. Energy Mater. Sol. Cells, 2003, 77, 229-237.

29 X. Zhao, P. Wang and B. Li, Chem. Commun., 2010, 46, 6768-6770.

30 R. v. d. Krol, Y. Liang and J. Schoonman, J. Mater. Chem., 2008, 18, 2311-2320.

31 Y. Li and J. Z. Zhang, Laser Photonics Rev., 2010, 4, 517-528.

32 K. Shankar, J. I. Basham, N. K. Allam, O. K. Varghese, G. K. Mor, X. Feng, M. Paulose, J. A. Seabold, K.-S. Choi and C. A. Grimes, J. Phys. Chem. C, 2009, 113, 6327-6359.

33 M. Paulose, K. Shankar, S. Yoriya, H. E. Prakasam, O. K. Varghese, G. K. Mor, T. A. Latempa, A. Fitzgerald and C. A. Grimes, J. Phys. Chem. B, 2006, 110, 16179-16184.

34 Y. Izumi, T. Itoi, S. Peng, K. Oka and Y. Shibata, J. Phys. Chem. C, 2009, 113, 6706-6718.

35 X. Zhan, Q. Wang, F. Wang, Y. Wang, Z. Wang, J. Cao, M. Safdar and J. He, ACS Appl. Mater. Interfaces, 2014, 6, 2878-2883.

36 F. Kayaci, S. Vempati, C. Ozgit, I. Donmez, N. Biyikli and T. Uyar, Nanoscale, 2014, 6, 5735.

37 R. Sathre, C. D. Scown, W. R. MorrowIII, J. C. Stevens, I. D. Sharp, J. W. AgerIII, K. Walczak, F. A. Houleae and J. B. Greenblatt, Energy Environ. Sci., 2014, 7, 3264-3278.

38 T. Hisatomi, J. Kubota and K. Domen, Chem. Soc. Rev., 2014, 43, 7520-7535.

39 M. Zhou, X. W. D. Lou and Y. Xie, Nano Today, 2013, 8, 598-618.

40 G. Wang, Y. Ling, H. Wang, X. Lu and Y. Li, J. Photochem. Photobiol., C, 2014, 19, 35-51.

41 J. Liu, G. Liu, M. Li, W. Shen, Z. Liu, J. Wang, J. Zhao, L. Jiang and Y. Song, Energy Environ. Sci., 2010, 3, 1503-1506. 
42 E. C. Garnett and P. Yang, J. Am. Chem. Soc., 2008, 130, 9224-9225.

43 L. Tsakalakos, J. Balch, J. Fronheiser, B. A. Korevaar, O. Sulima and J. Rand, Appl. Phys. Lett., 2007, 91, 233117.

44 J. B. Veluru, K. K. Manippady, M. Rajendiren, K. M. Mya, P. R. Rayavarapu, S. N. Appukuttan and R. Seeram, Int. J. Hydrogen Energy, 2013, 38, 4324-4333.

45 V. J. Babu, M. K. Kumar, A. S. Nair, T. L. Kheng, S. I. Allakhverdiev and S. Ramakrishna, Int. J. Hydrogen Energy, 2012, 37, 8897-8904.

46 I.-S. Cho, S. Lee, J. H. Noh, D. W. Kim, D. K. Lee, H. S. Jung, D.-W. Kim and K. S. Hong, J. Mater. Chem., 2010, 20, 3979-3983.

47 S. Ikeda, A. Tanaka, K. Shinohara, M. Hara, J. N. Kondo, K.-I. Maruya and K. Domen, Microporous Mater., 1997, 9, 253-258.

48 M. C. Hidalgo, M. Aguilar, M. Maicu, J. A. Navío and G. Colón, Catal. Today, 2007, 129, 50-58.

49 A. Testino, I. R. Bellobono, V. Buscaglia, C. Canevali, M. D'Arienzo, S. Polizzi, R. Scotti and F. Morazzoni, J. Am. Chem. Soc., 2007, 129, 3564-3575.

50 A. Datta, A. Priyam, S. N. Bhattacharyya, K. K. Mukherjea and A. Saha, J. Colloid Interface Sci., 2008, 322, 128-135.

51 S. Y. Chae, M. K. Park, S. K. Lee, T. Y. Kim, S. K. Kim and W. I. Lee, Chem. Mater., 2003, 15, 3326-3331.

52 G. Liu, C. Sun, H. G. Yang, S. C. Smith, L. Wang, G. Q. M. Lu and H.-M. Cheng, Chem. Commun., 2010, 46, 755-757.

53 L. Zhang, J. Li, Z. Chen, Y. Tang and Y. Yu, Appl. Catal., A, 2006, 299, 292-297.

54 J. C. Yu, J. Yu, W. Ho and L. Zhang, Chem. Commun., 2001, 1942-1943.

55 T. Park, S. A. Haque, R. J. Potter, A. B. Holmes and J. R. Durrant, Chem. Commun., 2003, 2878-2879.

56 E. C. Garnett, M. L. Brongersma, Y. Cui and M. D. McGehee, Annu. Rev. Mater. Res., 2011, 41, 269-295.

57 A. I. Hochbaum and P. Yang, Chem. Rev., 2010, 110, 527-546.

58 R. Yan, D. Gargas and P. Yang, Nat. Photonics, 2009, 3, 569-576.

59 Z. Xiong, M. Zheng, S. Liu, L. Ma and W. Shen, Nanotechnology, 2013, 24, 265402.

60 Y.-J. Lee, D. S. Ruby, D. W. Peters, B. B. McKenzie and J. W. P. Hsu, Nano Lett., 2008, 8, 1501-1505.

61 Y. B. Tang, Z. H. Chen, H. S. Song, C. S. Lee, H. T. Cong, H. M. Cheng, W. J. Zhang, I. Bell and S. T. Lee, Nano Lett., 2008, 8, 4191-4195.

62 S. L. Diedenhofen, G. Vecchi, R. E. Algra, A. Hartsuiker, O. L. Muskens, G. Immink, E. P. A. M. Bakkers, W. L. Vos and J. G. m. Rivas, Adv. Mater., 2009, 21, 973-978.

63 O. L. Muskens, J. G. Rivas, R. E. Algra, E. P. A. M. Bakkers and A. Lagendijk, Nano Lett., 2008, 8, 2638-2642.

64 L. Hu and G. Chen, Nano Lett., 2007, 7, 3249-3252.

65 E. Garnett and P. Yang, Nano Lett., 2010, 10, 1082-1087.

66 K. Peng, Y. Xu, Y. Wu, Y. Yan, S.-T. Lee and J. Zhu, Small, 2005, 1, 1062-1067.

67 K. Zhu, N. R. Neale, A. Miedaner and A. J. Frank, Nano Lett., 2007, 7, 69-74.
68 H. W. Jeong and H. Park, Catal. Today, 2014, 230, 15-19.

69 J.-Y. Jung, Z. Guo, S.-W. Jee, H.-D. Um, K.-T. Park and J.-H. Lee, Opt. Express, 2010, 18, A286-A292.

70 Z. Fan, R. Kapadia, P. W. Leu, X. Zhang, Y.-L. Chueh, K. Takei, K. Yu, A. Jamshidi, A. A. Rathore, D. J. Ruebusch, M. Wu and A. Javey, Nano Lett., 2010, 10, 3823-3827.

71 X. Feng, K. Shankar, O. K. Varghese, M. Paulose, T. J. Latempa and C. A. Grimes, Nano Lett., 2008, 8, 3781-3786.

72 M. Law, L. E. Greene, J. C. Johnson, R. Saykally and P. Yang, Nat. Mater., 2005, 4, 455-459.

73 E. Enache-Pommer, J. E. Boercker and E. S. Aydil, Appl. Phys. Lett., 2007, 91, 123116.

74 S. Gubbala, V. Chakrapani, V. Kumar and M. K. Sunkara, Adv. Funct. Mater., 2008, 18, 2411-2418.

75 M. Law, L. E. Greene, A. Radenovic, T. Kuykendall, J. Liphardt and P. Yang, J. Phys. Chem. B, 2006, 110, 22652-22663.

76 J. Liang, Y. Cao, H. Lin, Z. Zhang, C. Huang and a. X. Wang, Inorg. Chem., 2013, 52, 6916-6922.

77 M. Yang, Y. Ji, W. Liu, Y. Wang and X. Liu, RSC Adv., 2014, 4, 15048-15054.

78 Y. Qiu, S.-F. Leung, Q. Zhang, B. Hua, Q. Lin, Z. Wei, K.-H. Tsui, Y. Zhang, S. Yang and Z. Fan, Nano Lett., 2014, 14, 2123-2129.

79 D. W. Hwang, H. G. Kim, J. Kim, K. Y. Cha, Y. G. Kim and J. S. Lee, J. Catal., 2000, 193, 40-48.

80 S. Ikeda, M. Hara, J. N. Kondo and K. Domen, J. Mater. Res., 1998, 13, 852-855.

81 H. Zhou, X. Li, T. Fan, F. E. Osterloh, J. Ding, E. M. Sabio, D. Zhang and Q. Guo, Adv. Mater., 2010, 22, 951-956.

82 Z. Liu, D. D. Sun, P. Guo and J. O. Leckie, Nano Lett., 2007, 7, 1081-1085.

83 G. Yang, W. Yan, Q. Zhang, S. Shen and S. Ding, Nanoscale, 2013, 5, 12432-12439.

84 N. Buhler, K. Meier and J.-F. Reber, J. Phys. Chem., 1984, 88, 3261-3268.

85 S. K. Choi, S. Kim, J. Ryu, S. K. Lim and H. Park, Photochem. Photobiol. Sci., 2012, 11, 1437-1444.

86 I. E. Castelli, J. M. G. Lastra, F. Huser, K. S. Thygesen and K. W. Jacobsen, New J. Phys., 2013, 15, 105026.

87 Y. Xu and M. A. A. Schoonen, Am. Mineral., 2000, 85, 543-556.

88 J. Zhang, J. Yu, Y. Zhang, Q. Li and J. R. Gong, Nano Lett., 2011, 11, 4774-4779.

89 I. Gorczyca, T. Suski, N. E. Christensen and A. Svane, Appl. Phys. Lett., 2010, 96, 101907.

90 S. Burnside, J.-E. Moser, K. Brooks and M. Grätzel, J. Phys. Chem. B, 1999, 103, 9328-9332.

91 S.-C. Chiu and Y.-Y. Li, J. Cryst. Growth, 2009, 311, 1036-1041.

92 T. A. Kandiel, A. Feldhoff, L. Robben, R. Dillert and D. W. Bahnemann, Chem. Mater., 2010, 22, 2050-2060.

93 J. Jitputti, Y. Suzuki and S. Yoshikawa, Catal. Commun., 2008, 9, 1265-1271.

94 L. Kavan, M. Gratzel, S. E. Gilbert, C. Klemenz and H. J. Scheel, J. Am. Chem. Soc., 1996, 118, 6716-6723.

95 B. Ohtani, Y. Ogawa and S.-I. Nishimoto, J. Phys. Chem. B, 1997, 101, 3746-3752. 
96 H. Kominami, Y. Ishii, M. Kohno, S. Konishi, Y. Kera and B. Ohtani, Catal. Lett., 2003, 91, 41-47.

97 L. Yan, J. Zhang, X. Zhou, X. Wu, J. Lan, Y. Wang, G. Liu, J. Yu and L. Zhi, Int. J. Hydrogen Energy, 2013, 38, 3554-3561.

98 S. E. Braslavsky, A. M. Braun, A. E. Cassano, A. V. Emeline, M. I. Litter, L. Palmisano, V. N. Parmon and N. Serpone, Pure Appl. Chem., 2011, 83, 931-1014.

99 X. Chen and S. S. Mao, Chem. Rev., 2007, 107, 2891-2959. 100 Y. Lee, T. Watanabe, T. Takata, M. Hara, M. Yoshimura and K. Domen, Bull. Chem. Soc. Jpn., 2007, 80, 423-428.

101 Z. Zhang, C.-C. Wang, R. Zakaria and J. Y. Ying, J. Phys. Chem. B, 1998, 102, 10871-10878.

102 W. Sun, S. Zhang, Z. Liu, C. Wang and Z. Mao, Int. J. Hydrogen Energy, 2008, 33, 1112-1117.

103 P. V. Kamat, J. Phys. Chem. C, 2007, 111, 2834-2860.

104 N. Bao, L. Shen, T. Takata, D. Lu and K. Domen, Chem. Lett., 2006, 35, 318-319.

105 H. Liu, J. Yang, J. Liang, Y. Huang and C. Tang, J. Am. Ceram. Soc., 2008, 91, 1287-1291.

106 J. S. Jang, S. H. Choi, D. H. Kim, J. W. Jang, K. S. Lee and J. S. Lee, J. Phys. Chem. C, 2009, 113, 8990-8996.

107 J. Jitputti, S. Pavasupree, Y. Suzuki and S. Yoshikawa, Jpn. J. Appl. Phys., 2008, 47, 751-756.

108 Z. Jiang, F. Yang, N. Luo, B. T. T. Chu, D. Sun, H. Shi, T. Xiao and P. P. Edwards, Chem. Commun., 2008, 6372-6374.

109 S. Palmas, A. M. Polcaro, J. R. Ruiz, A. D. Pozzo, M. Mascia and A. Vacca, Int. J. Hydrogen Energy, 2010, 35, 6561-6570.

110 J. Yu, H. Yu, B. Cheng and C. Trapalis, J. Mol. Catal. A: Chem., 2006, 249, 135-142.

111 H. Jia, W.-J. Xiao, L. Zhang, Z. Zheng, H. Zhang and F. Deng, J. Phys. Chem. C, 2008, 112, 11379-11384.

112 Y. Wang, L. Zhang, K. Deng, X. Chen and Z. Zou, J. Phys. Chem. C, 2007, 111, 2709-2714.

113 Y. Li, Y. Hu, S. Peng, G. Lu and S. Li, J. Phys. Chem. C, 2009, 113, 9352-9358.

114 Y. Li, T. Sasaki, Y. Shimizu and N. Koshizaki, J. Am. Chem. Soc., 2008, 130, 14755-14762.

115 F. A. Frame, E. C. Carroll, D. S. Larsen, M. Sarahan, N. D. Browning and F. E. Osterloh, Chem. Commun., 2008, 2206-2208.

116 D. Chen and J. Ye, Chem. Mater., 2009, 21, 2327-2333.

117 S. Chuangchote, J. Jitputti, T. Sagawa and S. Yoshikawa, ACS Appl. Mater. Interfaces, 2009, 1, 1140-1143.

118 Z. Zhang, Z. Wang, S.-W. Cao and C. Xue, J. Phys. Chem. C, 2013, 117, 25939-25947.

119 S. S. Lee, H. Bai, Z. Liu and D. D. Sun, Int. J. Hydrogen Energy, 2012, 37, 10575-10584.

120 L. Macaraig, S. Chuangchote and T. Sagawa, J. Mater. Res., 2014, 29, 123-130.

121 H. Bai, Z. Liu and D. D. Sun, J. Am. Ceram. Soc., 2013, 96, 942-949.

122 X. Yang, A. Wolcott, G. Wang, A. Sobo, R. C. Fitzmorris, F. Qian, J. Z. Zhang and Y. Li, Nano Lett., 2009, 9, 2331-2336.
123 J. Jitputti, S. Pavasupree, Y. Suzuki and S. Yoshikawa, J. Solid State Chem., 2007, 180, 1743-1749.

124 A. Patsoura, D. I. Kondarides and X. E. Verykios, Catal. Today, 2007, 124, 94-102.

125 A. Galińska and J. Walendziewski, Energy Fuels, 2005, 19, 1143-1147.

126 P. Tongying, F. Vietmeyer, D. Aleksiuk, G. J. Ferraudi, G. Krylova and M. Kuno, Nanoscale, 2014, 6, 4117-4124.

127 M.-C. Wu, J. Hiltunen, A. Sapi, A. Avila, W. Larsson, H.-C. Liao, M. Huuhtanen, G. Toth, A. Shchukarev, N. Laufer, A. Kukovecz, Z. Konya, J.-P. Mikkola, R. Keiski, W.-F. Su, Y.-F. Chen, H. Jantunen, P. M. Ajayan, R. Vajtai and K. Kordas, ACS Nano, 2011, 5, 5025-5030.

128 G. K. Mor, H. E. Prakasam, O. K. Varghese, K. Shankar and C. A. Grimes, Nano Lett., 2007, 7, 2356-2364.

129 G. K. Mor, K. Shankar, M. Paulose, O. K. Varghese and C. A. Grimes, Nano Lett., 2005, 5, 191-195.

130 O. K. Varghese, M. Paulose, K. Shankar, G. K. Mor and C. A. Grimes, J. Nanosci. Nanotechnol., 2005, 5, 1158-1165.

131 K. Shankar, G. K. Mor, H. E. Prakasam, S. Yoriya, M. Paulose, O. K. Varghese and C. A. Grimes, Nanotechnology, 2007, 18, 065707.

132 G. K. Mor, O. K. Varghese, R. H. T. Wilke, S. Sharma, K. Shankar, T. J. Latempa, K.-S. Choi and C. A. Grimes, Nano Lett., 2008, 8, 1906-1911.

133 D. Eder, M. Motta and A. H. Windle, Nanotechnology, 2009, 20, 055602.

134 J. H. Park, S. Kim and A. J. Bard, Nano Lett., 2006, 6, 24-28.

135 W. H. Lubberhuizen, D. Vanmaekelbergh and E. V. Faassen, J. Porous Mater., 2000, 7, 147-152.

136 A. F. Feil, P. Migowski, F. R. Scheffer, M. D. Pierozan, R. R. Corsetti, M. Rodrigues, R. P. Pezzi, G. Machado, L. Amaral, S. R. Teixeira, D. E. Weibel and J. Dupont, J. Braz. Chem. Soc., 2010, 21, 1359-1365.

137 Y.-C. Pu, G. Wang, K.-D. Chang, Y. Ling, Y.-K. Lin, B. C. Fitzmorris, C.-M. Liu, X. Lu, Y. Tong, J. Z. Zhang, Y.-J. Hsu and Y. Li, Nano Lett., 2013, 13, 3817-3823.

138 A. Wood, M. Giersig and P. Mulvaney, J. Phys. Chem. B, 2001, 105, 8810-8815.

139 T.-C. Pan, S.-H. Wang, Y.-S. Lai, J.-M. Jehng and S.-J. Huang, Appl. Surf. Sci., 2014, 296, 189-194.

140 M. Ye, J. Gong, Y. Lai, C. Lin and Z. Lin, J. Am. Chem. Soc., 2012, 134, 15720-15723.

141 F.-C. Wang, C.-H. Liu, C.-W. Liu, J.-H. Chao and C.-H. Lin, J. Phys. Chem. C, 2009, 113, 13832-13840.

142 R. P. Antony, T. Mathews, C. Ramesh, N. Murugesan, A. Dasgupta, S. Dhara, S. Dash and A. K. Tyagi, Int. J. Hydrogen Energy, 2012, 37, 8268-8276.

143 X. Wang, G. Liu, Z.-G. Chen, F. Li, G. Q. M. Lu and H.-M. Cheng, Electrochem. Commun., 2009, 1174-1178.

144 M. P. Languer, F. R. Scheffer, A. F. Feil, D. L. Baptista, P. Migowski, G. J. Machado, D. P. d. Moraes, J. Dupont, S. R. Teixeira and D. E. Weibel, Int. J. Hydrogen Energy, 2013, 38, 14440-14450.

145 Y. Li, H. Yu, C. Zhang, W. Song, G. Li, Z. Shao and B. Yi, Electrochim. Acta, 2013, 107, 313-319. 
146 J. Gong, Y. Lai and C. Lin, Electrochim. Acta, 2010, 55, 4776-4782.

147 J. Gong, W. Pu, C. Yang and J. Zhang, Catal. Commun., 2013, 36, 89-93.

148 R. V. Gonçalves, P. Migowski, H. Wender, D. Eberhardt, D. E. Weibel, F. v. C. Sonaglio, M. J. M. Zapata, J. Dupont, A. F. Feil and S. R. Teixeira, J. Phys. Chem. C, 2012, 116, 14022-14030.

149 M. Cargnello, M. Grzelczak, B. Rodriguez-Gonzalez, Z. Syrgiannis, K. Bakhmutsky, V. L. Parola, L. M. Liz-Marzan, R. J. Gorte, M. Prato and P. Fornasiero, J. Am. Chem. Soc., 2012, 134, 11760-11766.

150 X. Chen and A. Selloni, Chem. Rev., 2014, 114, 9281-9282.

151 Y. Lee, T. Watanabe, T. Takata, M. Hara, M. Yoshimura and K. Domen, Bull. Chem. Soc. Jpn., 2007, 80, 423-428.

152 H. Bai, Z. Liu and D. D. Sun, J. Mater. Chem., 2012, 22, 18801-18807.

153 B. M. Kayes, H. A. Atwater and N. S. Lewis, J. Appl. Phys., 2005, 97, 114302.

154 D. Chen and J. Ye, Chem. Mater., 2007, 19, 4585-4591.

155 Y. Sun, W. D. Chemelewski, S. P. Berglund, C. Li, H. He, G. Shi and C. B. Mullins, ACS Appl. Mater. Interfaces, 2014, 6, 5494-5499.

156 B. Sun, T. Shi, Z. Peng, W. Sheng, T. Jiang and G. Liao, Nanoscale Res. Lett., 2013, 8, 462.

157 K. Lin, B. Ma, W. Su and W. Liu, Appl. Surf. Sci., 2013, 286, 61-65.

158 J. Liang, J. Xu, Q. Gu, Y. Zhou, C. Huang, H. Lin and X. Wang, J. Mater. Chem. A, 2013, 1, 7798-7805.

159 X. Yang, J. Xu, T. Wong, Q. Yang and C.-S. Lee, Phys. Chem. Chem. Phys., 2013, 15, 12688-12693.

160 D. Li and Y. Xia, Adv. Mater., 2004, 16, 1151-1170.

161 A. Greiner and J. H. Wendorff, Angew. Chem., Int. Ed., 2007, 46, 5670-5703.

162 D. H. Reneker and A. L. Yarin, Polymer, 2008, 49, 2387-2425.

163 X. Lu and C. W. a. Y. Wei, Small, 2009, 5, 2349-2370.

164 S. J. Limmer, Adv. Mater., 2003, 15, 427-431.

165 Z. Miao, D. Xu, J. Ouyang, G. Guo, X. Zhao and Y. Tang, Nano Lett., 2002, 2, 717-720.

166 M. Adachi, Y. Murata, J. Takao, J. Jiu, M. Sakamoto and F. Wang, J. Am. Chem. Soc., 2004, 126, 14943-14949.

167 Y.-w. Jun, M. F. Casula, J.-H. Sim, S. Y. Kim, J. Cheon and A. P. Alivisatos, J. Am. Chem. Soc., 2003, 125, 15981-15985.

168 J.-M. Wu, H. C. Shih and W.-T. Wu, Nanotechnology, 2006, 17, 105-109.

169 Z. R. Tian, J. A. Voigt, J. Liu, B. Mckenzie and H. Xu, J. Am. Chem. Soc., 2003, 125, 12384-12385.

170 V. S. P. Kumar, V. J. Babu, G. K. Raghuraman, R. Dhamodharan and T. S. Natarajan, J. Appl. Phys., 2007, 101, 114317.

171 V. J. Babu, S. Vempati and S. Ramakrishna, RSC Adv., 2014, 4, 27979-27987.

172 F. Kayaci, S. Vempati, I. Donmez, N. Biyikli and T. Uyar, Nanoscale, 2014, 6, 10224-10234.

173 F. Kayaci, S. Vempati, C. O. Akgun, N. Biyikli and T. Uyar, Appl. Catal., B, 2014, 156-157, 173-183.
174 V. J. Babu, R. S. R. Bhavatharini and S. Ramakrishna, RSC Adv., 2014, 4, 29957-29963.

175 M. M. Khin, S. Nair, J. B. Veluru, M. Rajendiran and S. Ramakrishna, Energy Environ. Sci., 2012, 5, 8075-8109.

176 V. J. Babu, S. Vempati, S. Sundarrajan, M. Sireesha and S. Ramakrishna, Sol. Energy, 2014, 106, 1-22.

177 Y.-Z. Long, M. Yu, B. Sun, C.-Z. Gu and Z. Fan, Chem. Soc. Rev., 2012, 41, 4560-4580.

178 C. J. Luo, S. D. Stoyanov, E. Stride, E. Pelan and M. Edirisinghe, Chem. Soc. Rev., 2012, 41, 4708-4735.

179 A. A. Madhavan, S. Kalluri, D. K. Chacko, T. A. Arun, S. Nagarajan, K. R. V. Subramanian, A. S. Nair, S. V. Nair and A. Balakrishnan, RSC Adv., 2012, 2, 13032-13037.

180 G. Dong, X. Xiao, L. Zhang, Z. Ma, X. Bao, M. Peng, Q. Zhang and J. Qiu, J. Mater. Chem., 2011, 21, 2194-2203.

181 A. Babel, D. Li, Y. Xia and S. A. Jenekhe, Macromolecules, 2005, 38, 4705-4711.

182 M. Tanveer, A. Habib and M. B. Khan, J. Exp. Nanosci., 2014, DOI: 10.1080/17458080.2013.869841.

183 P. Ahmadpoor, A. S. Nateri and V. Motaghitalab, J. Appl. Polym. Sci., 2013, 130, 78-85.

184 L. Gao and C. Li, J. Lumin., 2010, 130, 236-239.

185 M. A. Kanjwal, N. A. M. Barakat, F. A. Sheikh, D. K. Park and H. Y. Kim, J. Mater. Sci., 2010, 45, 3833-3840.

186 J. B. Veluru, K. K. Satheesh, D. C. Trivedi, M. V. Ramakrishna and T. N. Srinivasan, J. Eng. Fibers Fabr., 2007, 2, 25.

187 S. Vempati, J. B. Veluru, R. G. Karunakaran, D. Raghavachari and T. S. Natarajan, J. Appl. Phys., 2011, 110, 113718.

188 M. M. Munir, F. Iskandar, K. M. Yun, K. Okuyama and M. Abdullah, Nanotechnology, 2008, 19, 145603.

189 J.-Y. Chen, C.-C. Kuo, C.-S. Lai, W.-C. Chen and H.-L. Chen, Macromolecules, 2011, 44, 2883-2892.

190 C. Drew, X. Liu, D. Ziegler, X. Wang, F. F. Bruno, J. Whitten, L. A. Samuelson and J. Kumar, Nano Lett., 2003, 3, 143-147.

191 B. Ding, M. Wang, J. Yu and G. Sun, Sensors, 2009, 9, 1609-1624.

192 H. Wu, L. Hu, M. W. Rowell, D. Kong, J. J. Cha, J. R. McDonough, J. Zhu, Y. Yang, M. D. McGehee and Y. Cui, Nano Lett., 2010, 10, 4242-4248.

193 Y. Shmueli, G. E. Shter, O. Assad, H. Haick, P. Sonntag, P. Ricoux and G. S. Grader, J. Mater. Res., 2012, 27, 1672-1679.

194 A. Kumar, R. Jose, K. Fujihara, J. Wang and S. Ramakrishna, Chem. Mater., 2007, 19, 6536-6542.

195 D. Hou, X. Hu, Y. Wen, B. Shan, P. Hu, X. Xiong, Y. Qiao and Y. Huang, Phys. Chem. Chem. Phys., 2013, 15, 20698-20705.

196 V. J. Babu, S. Vempati, G. J. Subha, V. Kumari, T. S. Natarajan, A. S. Nair and S. Ramakrishna, J. Eng. Fibers Fabr., 2011, 6, 57-59.

197 V. J. Babu, V. S. P. Kumar, B. Sundaray, V. R. K. Murthy and T. S. Natarjan, Mater. Sci. Eng., B, 2007, 142, 46-50.

198 H. Bai, J. Juay, Z. Liu, X. Song, S. S. Lee and D. D. Sun, Appl. Catal., B, 2012, 125, 367-374.

199 T. Sun, J. Qiu and C. Liang, J. Phys. Chem. C, 2008, 112, 715-721.

200 W.-W. Wang, Y.-J. Zhu and L.-X. Yang, Adv. Funct. Mater., 2007, 17, 59-64. 
201 S. Xiong, B. Xi, C. Wang, G. Xi and X. L. a. Y. Qian, Chem. - Eur. J., 2007, 13, 7926-7932.

202 T.-G. Xu, C. Zhang, X. Shao, K. Wu and Y.-F. Zhu, Adv. Funct. Mater., 2006, 16, 1599-1607.

203 Y. Matsumoto, S. Ida and T. Inoue, J. Phys. Chem. C, 2008, 112, 11614-11616.

204 E. C. Carroll, O. C. Compton, D. Madsen, F. E. Osterloh and D. S. Larsen, J. Phys. Chem. C, 2008, 112, 2394-2403.

205 C. Ye, Y. Bando, G. Shen and D. Golberg, J. Phys. Chem. B, 2006, 110, 15146-15151.

206 C. Zhang and Y. Zhu, Chem. Mater., 2005, 17, 3537-3545.

207 V. J. Babu, S. R. S. Bhavatharini and S. Ramakrishna, RSC Adv., 2014, 4, 19251-19256.

208 S. H. Kim, S. Park, C. W. Lee, B. S. Han, S. W. Seo, J. S. Kim, I. S. Cho and K. S. Hong, Int. J. Hydrogen Energy, 2012, 37, 16895-16902.

209 K. Parida, M. Satpathy and L. Mohapatra, J. Mater. Chem., 2012, 22, 7350-7357.

210 L. Zhao, J. Ran, Z. Shu, G. Dai, P. Zhai and S. Wang, Int. J. Photoenergy, 2012, 2012, 472958.

211 Z. Li, J. Shen, J.-Q. Wang, D. Wang, Y. Huang and J. Zou, CrystEngComm, 2012, 14, 1874-1880.

212 O. C. Compton and F. E. Osterloh, J. Phys. Chem. C, 2009, 113, 479-485.

213 M. Harada, T. Sasaki, Y. Ebina and M. Watanabe, J. Photochem. Photobiol., A, 2002, 148, 273-276.

214 L. Zhang, D. Chen and X. Jiao, J. Phys. Chem. B, 2006, 110, 2668-2673.

215 X. Zhang, Z. Ai, F. Jia and L. Zhang, J. Phys. Chem. C, 2008, 112, 747-753.

216 M. C. Sarahan, E. C. Carroll, M. Allen, D. S. Larsen, N. D. Browning and F. E. Osterloh, J. Solid State Chem., 2008, 181, 1678-1683.

217 J. Yu, L. Qi and M. Jaroniec, J. Phys. Chem. C, 2010, 114, 13118-13125.

218 G. Xiang, T. Li, J. Zhuang and X. Wang, Chem. Commun., 2010, 46, 6801-6803.

219 J. Jitputti, T. Rattanavoravipa, S. Chuangchote, S. Pavasupree, Y. Suzuki and S. Yoshikawa, Catal. Commun., 2009, 10, 378-382.

220 O. C. Compton, E. C. Carroll, J. Y. Kim, D. S. Larsen and F. E. Osterloh, J. Phys. Chem. C, 2007, 111, 14589-14592.

221 O. C. Compton, C. H. Mullet, S. Chiang and F. E. Osterloh, J. Phys. Chem. C, 2008, 112, 6202-6208.

222 X. Chen, S. Shen, L. Guo and S. S. Mao, Chem. Rev., 2010, 110, 6503-6570.

223 M. Machida, X. W. Ma, H. Taniguchi, J.-I. Yabunaka and T. Kijima, J. Mol. Catal. A: Chem., 2000, 155, 131-142.

224 T. Sasaki, J. Ceram. Soc. Jpn., 2007, 115, 9-16.

225 T. Yamase, Chem. Rev., 1998, 98, 307-326.

226 E. M. Sabio, R. L. Chamousis, N. D. Browning and F. E. Osterloh, J. Phys. Chem. C, 2012, 116, 3161-3170.

227 Y. Zhang, T. Xia, M. Shang, P. Wallenmeyer, D. Katelyn, A. Peterson, J. Murowchick, L. Dong and X. Chen, RSC Adv., 2014, 4, 16146-16152.

228 S. S. Lee, H. Bai, Z. Liu and D. D. Sun, Water Res., 2013, 47, 4059-4073.
229 J. S. Jang, U. A. Joshi and J. S. Lee, J. Phys. Chem. C, 2007, 111, 13280-13287.

230 J. Zhang, Y. Wang, J. Jin, J. Zhang, Z. Lin, F. Huang and J. Yu, ACS Appl. Mater. Interfaces, 2013, 5, 10317-10324.

231 Q. Li and G. Lu, J. Power Sources, 2008, 185, 577-583.

232 M. G. Kibria, S. Zhao, F. A. Chowdhury, Q. Wang, H. P. T. Nguyen, M. L. Trudeau, H. Guo and Z. Mi, Nat. Commun., 2014, 5, 3825 .

233 C. Li, J. Yuan, B. Han, L. Jiang and W. Shangguan, Int. J. Hydrogen Energy, 2010, 35, 7073-7079.

234 C. Liu, J. Tang, H. M. Chen, B. Liu and P. Yang, Nano Lett., 2013, 13, 2989-2992.

235 M. G. Kibria, H. P. T. Nguyen, K. Cui, S. Zhao, D. Liu, H. Guo, M. L. Trudeau, S. Paradis, A.-R. Hakima and Z. Mi, ACS Nano, 2013, 7, 7886-7893.

236 K. Maeda, N. Sakamoto, T. Ikeda, H. Ohtsuka, A. Xiong, D. Lu, M. Kanehara, T. Teranishi and K. Domen, Chem. - Eur. J., 2010, 16, 7750-7759.

237 B. AlOtaibi, H. P. T. Nguyen, S. Zhao, M. G. Kibria, S. Fan and Z. Mi, Nano Lett., 2013, 13, 4356-4361.

238 S. Vempati, S. Chirakkara, J. Mitra, P. Dawson, K. K. Nanda and S. B. Krupanidhi, Appl. Phys. Lett., 2012, 100, 162104.

239 S. Vempati, J. Mitra and P. Dawson, Nanoscale Res. Lett., 2012, 7, 470.

240 S. Vempati, A. Shetty, P. Dawson, K. Nanda and S. B. Krupanidhi, J. Cryst. Growth, 2012, 343, 7-12.

241 S. Vempati, A. Shetty, P. Dawson, K. K. Nanda and S. B. Krupanidhi, Thin Solid Films, 2012, 524, 137-143.

242 Q. Kang, J. Cao, Y. Zhang, L. Liu, H. Xu and J. Ye, J. Mater. Chem. A, 2013, 1, 5766-5774.

243 Y. Liu, H. Zhou, B. Zhou, J. Li, H. Chen, J. Wang, J. Bai, W. Shangguan and W. Cai, Int. J. Hydrogen Energy, 2011, 36, 167-174.

244 Q. Li and G. Lu, J. Mol. Catal. A: Chem., 2007, 266, 75-79.

245 Q. Li, L. Chen and G. Lu, J. Phys. Chem. C, 2007, 111, 11494-11499.

246 G. Khan, S. K. Choi, S. Kim, S. K. Lim, J. S. Jang and H. Park, Appl. Catal., B, 2013, 142-143, 647-653.

247 S. K. Parayil, J. Baltrusaitis, C.-M. Wu and R. T. Koodali, Int. J. Hydrogen Energy, 2013, 38, 2656-2669.

248 P. Khemthong, P. Photai and N. Grisdanurak, Int. J. Hydrogen Energy, 2013, 38, 15992-16001.

249 J. Ran, J. Yu and M. Jaroniec, Green Chem., 2011, 13, 2708-2713.

250 N. S. Chaudhari, S. S. Warule, S. Muduli, B. B. Kale, S. Jouen, B. Lefez, B. Hannoyer and S. B. Ogale, Dalton Trans., 2011, 40, 8003-8011.

251 H. Lv, L. Ma, P. Zeng, D. Ke and T. Peng, J. Mater. Chem., 2010, 20, 3665-3672.

252 S. Mubeen, J. Lee, N. Singh, S. Krämer, G. D. Stucky and M. Moskovits, Nat. Nanotechnol., 2013, 8, 247-251.

253 S. S. Lee, H. Bai, Z. Liu and D. D. Sun, Appl. Catal., B, 2013, 140, 68-81.

254 Z. Zhang, A. Li, S.-W. Cao, M. Bosman, S. Li and C. Xue, Nanoscale, 2014, 6, 5217-5222. 
255 A. Yousef, N. A. M. Barakat, K. A. Khalil, A. R. Unnithan, G. Panthi, B. Pant and H. Y. Kim, Colloids Surf., A, 2012, 410, 59-65.

256 N. Sobti, A. Bensouici, F. Coloma, C. Untiedt and S. Achour, J. Nanopart. Res., 2014, 16, 2577.

257 A. R. Unnithan, N. A. M. Barakat, R. Nirmala, S. S. Al-Deyab and H. Y. Kim, Ceram. Int., 2012, 38, 5175-5180.

258 Q. Li, X. Sun, K. Lozano and Y. Mao, J. Phys. Chem. C, 2014, 118, 13467-13475.

259 N. Bao, L. Shen, T. Takata and K. Domen, Chem. Mater., 2008, 20, 110-117.

260 Z. Lei, W. You, M. Liu, G. Zhou, T. Takata, M. Hara, K. Domen and C. Li, Chem. Commun., 2003, 2142-2143.

261 S. Siol, H. Strater, R. Bruggemann, J. Brotz, G. H. Bauer, A. Klein and W. Jaegermann, J. Phys. D: Appl. Phys., 2013, 46, 495112.

262 X. Li, H. Shen, S. Li, J. Z. Niu, H. Wang and L. S. Li, J. Mater. Chem., 2010, 20, 923-928.

263 S. Panigrahi and D. Basak, RSC Adv., 2012, 2, 11963-11968.

264 Z. Khan, M. Khannam, N. Vinothkumar, M. De and M. Qureshi, J. Mater. Chem., 2012, 22, 12090-12095.

265 Q. Li, B. Guo, J. Yu, J. Ran, B. Zhang, H. Yan and J. R. Gong, J. Am. Chem. Soc., 2011, 133, 10878-10884.

266 Y. Li, Y.-L. Li, C. M. Araujo, W. Luo and R. Ahuja, Catal. Sci. Technol., 2013, 3, 2214-2220.
267 Z. Xu, Y. Li, S. Peng, G. Lu and S. Li, RSC Adv., 2012, 2, 3458-3466.

268 X. Bai and J. Li, Mater. Res. Bull., 2012, 46, 1028-1034.

269 F. A. Frame and F. E. Osterloh, J. Phys. Chem. C, 2010, 114, 10628-10633.

270 X. Wang, K. Maeda, A. Thomas, K. Takanabe, G. Xin, J. M. Carlsson, K. Domen and M. Antonietti, Nat. Mater., 2008, 8, 76-80.

271 X. Wang, K. Maeda, X. Chen, K. Takanabe, K. Domen, Y. Hou, X. Fu and M. Antonietti, J. Am. Chem. Soc., 2009, 131, 1680-1681.

272 J. Liu, J. Huang, H. Zhou and M. Antonietti, ACS Appl. Mater. Interfaces, 2014, 6, 8434-8440.

273 J. Huang, M. Antonietti and J. Liu, J. Mater. Chem. A, 2014, 2, 7686-7693.

274 A. Yousef, N. A. M. Barakat and H. Y. Kim, Appl. Catal., A, 2013, 467, 98-106.

275 http://energy.gov/eere/fuelcells/market-analysis-reports.

276 K. Maeda, H. Hashiguchi, H. Masuda, R. Abe and K. Domen, J. Phys. Chem. C, 2008, 112, 3447-3452.

277 K. Nishijima, T. Kamai, N. Murakami, T. Tsubota and T. Ohno, Int. J. Photoenergy, 2008, 173943.

278 J. Tang, J. R. Durrant and D. R. Klug, J. Am. Chem. Soc., 2008, 130, 13885-13891. 